\title{
Rapid helium isotopic variability in Mauna Kea shield lavas from the Hawaiian Scientific Drilling Project
}

\author{
Mark D. Kurz, Joshua Curtice, and Dempsey E. Lott III \\ Department of Marine Chemistry and Geochemistry, Woods Hole Oceanographic Institution, Woods Hole, \\ Massachusetts 02543, USA (mkurz@whoi.edu) \\ Andy Solow \\ Marine Policy Center, Woods Hole Oceanographic Institution, Woods Hole, Massachusetts 02543, USA
}

[1] This paper presents new magmatic helium isotopic compositions in a suite of lavas from phase II of the Hawaiian Scientific Drilling Project (HSDP2) core, which sampled Mauna Kea volcano to a maximum depth of $3098 \mathrm{~m}$ below sea level. Most of the measurements were performed by in vacuo crushing of olivine phenocrysts, but include submarine pillow glasses from the 2200 to 2500 meter depth interval, and orthopyroxene phenocrysts from an intrusive at $1880 \mathrm{~m}$. The magmatic ${ }^{3} \mathrm{He} /{ }^{4} \mathrm{He}$ ratios range from 6 to 24.7 times atmospheric ( $\mathrm{Ra}$ ), which significantly extends the range of values for Mauna Kea volcano. The ${ }^{3} \mathrm{He} /{ }^{4} \mathrm{He}$ ratios are lowest (i.e., close to MORB values of $\sim 8 \mathrm{Ra}$ ) near the top of the Mauna Kea section and rise slowly, to $10-12 \mathrm{Ra}$, at $1000 \mathrm{~m}$ below sea level, consistent with results from the HSDP1 core. At depths greater than $1000 \mathrm{~m}$ in the core, primarily in the submarine lavas, there are brief periods when the ${ }^{3} \mathrm{He} /{ }^{4} \mathrm{He}$ ratios are higher than $14.5 \mathrm{Ra}$, always returning to a baseline value. Twelve such excursions were identified in the core; all but one are in the submarine section, and most (7) are in the deepest section, at depths of 1950 to $3070 \mathrm{~m}$. The baseline ${ }^{3} \mathrm{He} /{ }^{4} \mathrm{He}$ value rises from $10-12 \mathrm{R}_{\mathrm{a}}$ near $1000 \mathrm{~m}$ depth to $12-$ $14 \mathrm{R}_{\mathrm{a}}$ at $3000 \mathrm{~m}$. The helium spikes are found only in lavas that are older than $380 \mathrm{Ka}$ in age, based on an age model derived from Ar-Ar data (W. D. Sharp et al., manuscript in preparation, 2003). Excluding the excursions defined by single lava flows (3) and intrusive units (3), the average spike duration is approximately $15( \pm 9) \mathrm{Ka}(\mathrm{n}=6)$. The high ${ }^{3} \mathrm{He} /{ }^{4} \mathrm{He}$ spikes are interpreted as pulses of magma from the center of the actively upwelling Hawaiian hot spot. The short duration of the high ${ }^{3} \mathrm{He} /{ }^{4} \mathrm{He}$ excursions suggests that Mauna Kea was never directly over high the ${ }^{3} \mathrm{He} /{ }^{4} \mathrm{He}$ component of the plume (during the HSDP2 eruptive period), presumed to be the plume center. Assuming that the Mauna Kea helium spikes result from melting of heterogeneities within the plume, their short duration implies that the length scales of heterogeneities in the solid upwelling mantle are between $60 \mathrm{~m}$ and $12 \mathrm{~km}$ (for upwelling rates of 2 to $40 \mathrm{~cm} / \mathrm{yr}$ ). The high ${ }^{3} \mathrm{He} /{ }^{4} \mathrm{He}$ are associated with high ${ }^{208} \mathrm{~Pb} /{ }^{204} \mathrm{~Pb}$, and relatively low ${ }^{143} \mathrm{Nd} /{ }^{144} \mathrm{Nd}, \mathrm{Zr} / \mathrm{Nb}$, and $\mathrm{SiO}_{2}$. The correlations with major elements, trace elements and isotopes demonstrate that helium is coupled to the other geochemical variations, and that the Mauna Kea isotopic variability is caused by heterogeneities within the upwelling plume.

Components: 19,307 words, 13 figures, 4 tables.

Keywords: Hawaiian volcanism; helium isotopes; mantle heterogeneity; mantle plume.

Index Terms: 1025 Geochemistry: Composition of the mantle; 1010 Geochemistry: Chemical evolution; 1040 Geochemistry: Isotopic composition/chemistry.

Received 9 September 2002; Revised 30 January 2004; Accepted 4 March 2004; Published 21 April 2004. 
Kurz, M. D., J. Curtice, D. E. Lott III, and A. Solow (2004), Rapid helium isotopic variability in Mauna Kea shield lavas from the Hawaiian Scientific Drilling Project, Geochem. Geophys. Geosyst., 5, Q04G14, doi:10.1029/2002GC000439.

Theme: Hawaii Scientific Drilling Project

Guest Editors: Don DePaolo, Ed Stolper, and Don Thomas

\section{Introduction}

[2] The Wilson-Morgan plume hypothesis, formulated as an explanation for intraplate oceanic volcanoes [Wilson, 1963; Morgan, 1971], has had tremendous impact on models of the Earth's interior. It implies that large time-transgressive volcanic provinces such as the Hawaiian islands (Figure 1) are produced by upwelling hot material, possibly from the lower mantle. Helium isotopes are important tracers of mantle components because the early Earth had very high ${ }^{3} \mathrm{He} /{ }^{4} \mathrm{He}$ ratios (i.e., greater than the present-day sun, or $>100$ times atmospheric, $\mathrm{Ra}$ ) and, by inference, high $\mathrm{He} /(\mathrm{Th}+\mathrm{U})$ ratios. Hawaiian volcanoes have some of the highest oceanic ${ }^{3} \mathrm{He} /{ }^{4} \mathrm{He}$ ratios, and also the largest documented variations within single volcanoes [e.g., Kurz et al., 1983, 1995; Mukhopadhyay et al., 2003]. High ${ }^{3} \mathrm{He} /{ }^{4} \mathrm{He}$ ratios in the present-day Earth would indicate preservation of mantle reservoirs via high time-integrated $\mathrm{He} /(\mathrm{Th}+\mathrm{U})$ ratios in the mantle. Because helium is so volatile, and behaves as an incompatible element, the most common assumption is that degassing near the Earth's surface is the dominant control on $\mathrm{He} /(\mathrm{Th}+\mathrm{U})$ ratios. Therefore the "standard model" for helium is that high ${ }^{3} \mathrm{He} /{ }^{4} \mathrm{He}$ ratios indicate undegassed mantle reservoirs that retain some of their original helium, at least relative to the upper mantle [e.g., Kurz et al., 1982; Allegre et al., 1983; Kurz and Geist, 1999; Farley et al., 1992; Farley and Neroda, 1998]. This is a crucial aspect to geodynamic Earth models, because geochemical and geophysical data have increasingly been interpreted in terms of whole mantle convection and recycling of ocean crust into the deep mantle [e.g., Hofmann, 1997; van der Hilst and Karason, 1999]. Thus helium isotopes provide one argument for storage of undegassed material deep in the Earth.
[3] There are other possible explanations for high ${ }^{3} \mathrm{He} /{ }^{4} \mathrm{He}$ ratios [Anderson, 1998a, 1998b; Albarède, 1998]. If helium is even slightly more compatible during melting than $\mathrm{Th}$ and $\mathrm{U}$, silicate melting could leave behind a residue with high $\mathrm{He} /$ $(\mathrm{Th}+\mathrm{U})$ which could also yield high ${ }^{3} \mathrm{He} /{ }^{4} \mathrm{He}$ ratios, but only if the melting occurred early in Earth history. In this case, high ${ }^{3} \mathrm{He} /{ }^{4} \mathrm{He}$ ratios would indicate ancient depleted mantle, rather than undegassed mantle. Another variation on this idea is that helium could be stored for long periods of time in ancient lithosphere, and then retapped by ocean island volcanism. Kurz and Geist [1999] used correlations between helium, major elements, trace elements, and the isotopes of $\mathrm{Sr}, \mathrm{Nd}$, and $\mathrm{Pb}$ to argue against these possibilities. The HSDP2 core provides an ideal testing ground for these hypotheses, and for relationships between helium and other isotopes, due to its unusual depth and stratigraphic resolution, and the extensive suite of measurements on the same samples.

[4] The highest Hawaiian ${ }^{3} \mathrm{He} /{ }^{4} \mathrm{He}$ ratios are found at Loihi Seamount off the southern coast of Hawaii [Kurz et al., 1983; Valbracht et al., 1996], which is believed to represent the earliest stage of Hawaiian shield building [Claque and Dalrymple, 1989; Moore and Clague, 1992]. This is consistent with the plume model for Hawaiian volcanism, assuming that high ${ }^{3} \mathrm{He} /{ }^{4} \mathrm{He}$ ratios are indicative of plume influence, and that the high ${ }^{3} \mathrm{He} /{ }^{4} \mathrm{He}$ signal diminishes, and approaches the normal mantle value (as indicated by MORB-like ${ }^{3} \mathrm{He} /{ }^{4} \mathrm{He}$ ratios), once the volcanoes are pushed off the hot spot. This hypothesis is supported by stratigraphic studies of Hawaiian volcanoes, where the highest ${ }^{3} \mathrm{He} /{ }^{4} \mathrm{He}$ ratios are always found in the oldest shield building tholeiites. At Haleakala volcano, ${ }^{3} \mathrm{He} /{ }^{4} \mathrm{He}$ ratios are roughly $16-20 \mathrm{Ra}$ in the tholeiites and close to typical MORB value $(8 \mathrm{Ra})$ in the post-shield 


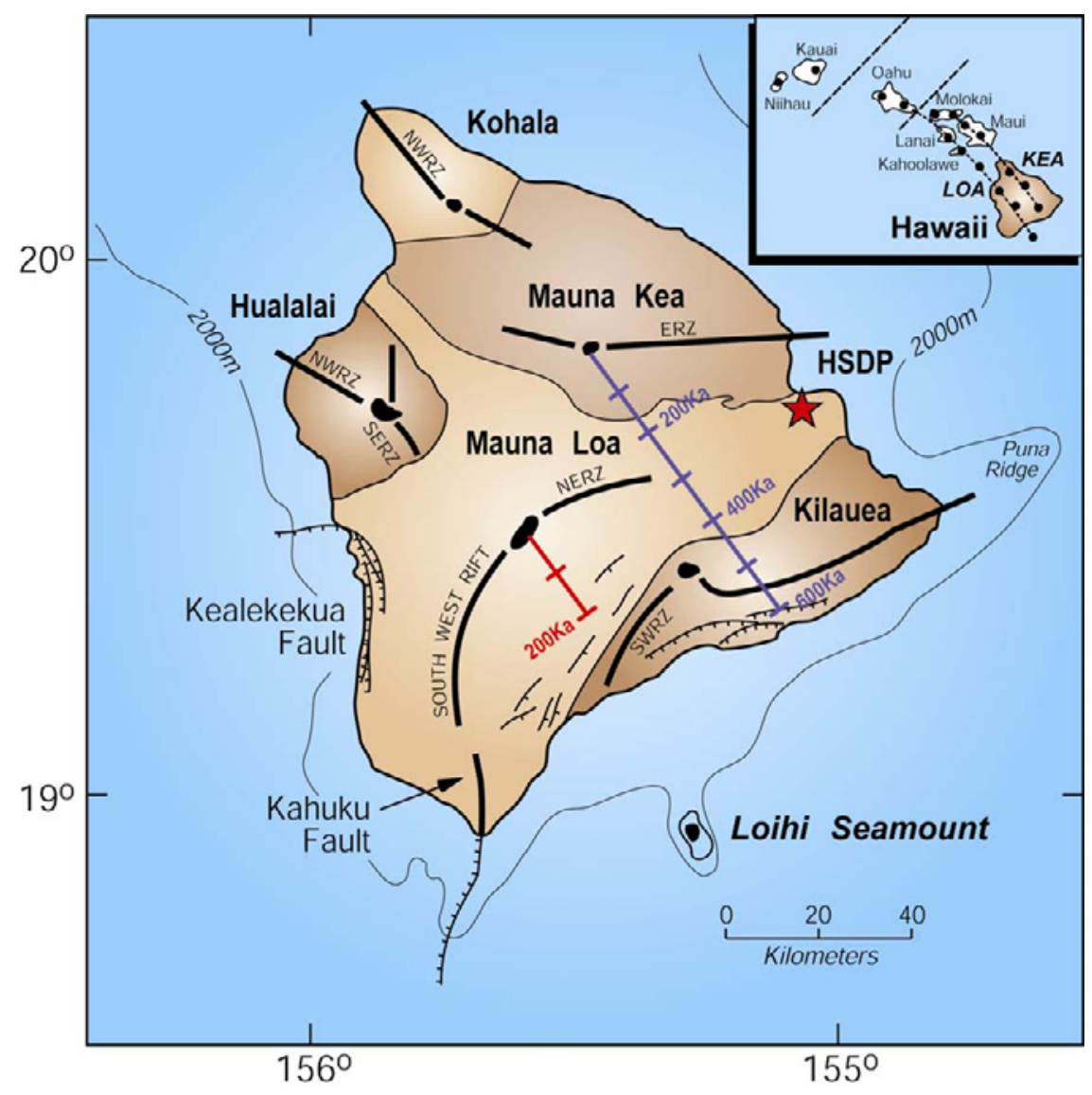

Figure 1. Map of Hawaii showing the location of the HSDP2 drill core on the flank of Mauna Kea; the core has a thin veneer $(240 \mathrm{~m})$ of Mauna Loa lavas near the surface. Also shown are the principal rift zones of the Hawaiian volcanoes and Loihi seamount. The two colored lines extending southeast from the summits of Mauna Loa and Mauna Kea show the approximate plate motion trajectory of the summits for the last few hundred thousand years, assuming a plate velocity of $10 \mathrm{~cm} / \mathrm{yr}$. Mauna Kea was close to the present coastline just southeast of Kilauea at $620 \mathrm{Ka}$ before present (the base of the HSDP2 core). The inset shows the location of Mauna Kea and the two parallel chains of volcanoes, referred to as Loa and Kea trends that make up the Hawaiian island islands. Note that the high ${ }^{3} \mathrm{He} /{ }^{4} \mathrm{He}$ Mauna Kea lavas were erupted between $620 \mathrm{Ka}$ and $375 \mathrm{Ka}$, and stopped when Mauna Kea reached the latitude of present-day Mauna Loa (see text).

alkali basalts [Kurz et al., 1987]. At Mauna Loa volcano, which has erupted tholeiites throughout its known history, ${ }^{3} \mathrm{He} /{ }^{4} \mathrm{He}$ ratios vary from $\sim 14$ $20 \mathrm{Ra}$ in lavas older than $30 \mathrm{Ka}$, to ${ }^{3} \mathrm{He} /{ }^{4} \mathrm{He}$ ratios close to the MORB value $(\sim 8 \mathrm{Ra})$ in the historical lavas. The Mauna Loa temporal evolution is unique in displaying a transition at $\sim 10 \mathrm{Ka}$ ([Kurz and Kammer, 1991; Kurz et al., 1995], with a timescale provided by ${ }^{14} \mathrm{C}$ dated lava flows. Kurz et al. [1995] suggested that the entire Mauna Loa shield older than $10 \mathrm{Ka}$ is characterized by higher ${ }^{3} \mathrm{He} /{ }^{4} \mathrm{He}$ and inferred that this characteristic represented the bulk of the upwelling mantle. DePaolo et al. [2001] argued that the Mauna Loa shield is highly variable isotopically based on samples from the Mauna Loa section of the HSDP1 drill core.

[5] Helium isotopic studies on Mauna Kea lavas from the first phase of the HSDP (referred to here as HSDP1) are generally consistent with results from other Hawaiian volcanoes. ${ }^{3} \mathrm{He} /{ }^{4} \mathrm{He}$ ratios increase from $\sim 6-8 \mathrm{Ra}$ (or close to MORB values) in the top of the Mauna Kea section of the drill core to $\sim 12.4 \mathrm{Ra}$ at $1000 \mathrm{~m}$ below sea level [Kurz et al., 1996]. As with Mauna Loa and Haleakala, the higher ${ }^{3} \mathrm{He} /{ }^{4} \mathrm{He}$ ratios suggest a greater plume contribution to the older shield lavas. However, even the highest ${ }^{3} \mathrm{He} /{ }^{4} \mathrm{He}$ ratio 
of $12.4 \mathrm{Ra}$ in the deepest HSDP1 lavas (at $1000 \mathrm{~m}$ depth) is significantly lower than those found in some other Hawaiian shields. Kurz et al. [1996] suggested that this relates to a concentrically zoned Hawaiian plume, with the present-day plume center near Loihi seamount, in the Loa volcanic chain, and that Kea trend volcanoes (i.e., Mauna Kea, Kilauea) are farther removed from the plume center. (See Figure 1 for a geographic definition of the Loa and Kea volcano chains.) An alternative hypothesis is that the HSDP1 core did not penetrate deeply enough into the volcano. The lava flows recovered from Phase II of the Hawaiian Scientific Drilling Project (referred to here as HSDP2) provide a stratigraphic record of unprecedented resolution and duration. The new data reported here show that higher ${ }^{3} \mathrm{He} /{ }^{4} \mathrm{He}$ ratios, up to $24.7 \mathrm{Ra}$, are found deeper in the Mauna Kea shield lavas, but that the ${ }^{3} \mathrm{He} /{ }^{4} \mathrm{He}$ ratios are highly variable.

\section{Experimental Details}

\subsection{Samples}

[6] Numerous studies have shown that olivine phenocrysts in oceanic basalts retain magmatic helium, which is held within melt inclusions (e.g., Kurz, 1993; Kurz et al., 1996). Crushing and melting experiments from the HSDP1 core showed that more than $80 \%$ of the magmatic helium in olivine is released by crushing [Kurz et al., 1996]. Diffusion rates in olivine are sufficiently slow that helium loss is insignificant after cooling below the closure temperature [Hart, 1984a; Trull and Kurz, 1993]. Because of these considerations, and because olivine is relatively common in the HSDP2 core, most of the measurements reported here were obtained by crushing of olivine phenocrysts in vacuo; Tables 1 and 2 provide a summary of the ${ }^{3} \mathrm{He} /{ }^{4} \mathrm{He}$ ratios as a function of depth. In one lava flow (SR714) orthopyroxene phenocrysts were identified, and it was possible to measure coexisting olivine and orthopyroxene from the same sample (see Table 3), which is relatively rare in oceanic basalts. Most of the samples are from the widely distributed HSDP2 reference suite that was intended to characterize the core, maximizing overlap with other geochemical measurements. Additional samples were collected in key intervals to obtain higher resolution, in an attempt to determine the duration of the prominent ${ }^{3} \mathrm{He} /{ }^{4} \mathrm{He}$ excursions (see Table 1). The data reported here complement the helium and neon data of Althaus et al. [2003] which were obtained from a different suite of HSDP2 samples.

[7] In some intervals of the core, it was not possible to recover olivine or clinopyroxene phenocrysts for the helium isotopic measurements. The depth interval between 2200 and $2500 \mathrm{~m}$ is characterized by undegassed aphyric pillow lavas with consistently low $\mathrm{SiO}_{2}$ contents (E. Stolper, S. Sherman, M. Garcia, M. Baker, and C. Seaman, Glass in the submarine section of the HSDP2 drill core, Hilo, Hawaii, manuscript submitted to Geochemisty, Geophysics, Geosystems, 2004, hereinafter referred to as Stolper et al., submitted manuscript, 2004; C. Seaman, S. Sherman, M. O. Garcia, M. Baker, and E. Stolper, Volatiles in glasses from the HSDP2 drill core, manuscript submitted, Geochemisty, Geophysical, Geosystems, 2003, hereinafter referred to as Seaman et al., submitted manuscript, 2003). For this important depth interval, submarine glasses were analyzed in an attempt to characterize the helium isotopic compositions and also to evaluate the suitability of drilled glasses for noble gas measurements. Undegassed submarine glasses are generally ideal for noble gas measurements because they often have significantly higher concentration than phenocrysts. Volatile measurements in the HSDP2 glasses suggest that the hyaloclastites are extensively degassed (Seaman et al., submitted manuscript, 2003; Stolper et al., submitted manuscript, 2004), potentially at shallow eruption depths; for this reason only glassy pillow lavas were selected for the helium measurements. It is well known that most of the helium in submarine glasses resides within vesicles, and the helium was extracted from the glasses by crushing in vacuo. In order to assess the importance of radiogenic and atmospheric contributions, helium was extracted from the glasses by melting of the powder remaining from crushing. The helium isotopic data from the HSDP pillow glasses are presented in Table 2, and dem- 
Table 1. Helium Concentrations and Isotopic Compositions as a Function of Depth for the HSDP2 Core ${ }^{\mathrm{a}}$

\begin{tabular}{|c|c|c|c|c|c|c|c|c|c|}
\hline Sample & $\begin{array}{l}\text { Top Depth, } \\
\text { mbsl }\end{array}$ & Unit & Model Age & Description & Wt. & $\begin{array}{c}\mathrm{He}, \\
\mathrm{ncc} / \mathrm{g}\end{array}$ & $\begin{array}{c}{ }^{3} \mathrm{He} /{ }^{4} \mathrm{He} \\
\mathrm{R} / \mathrm{Ra}\end{array}$ & \pm & $\begin{array}{c}\text { Grain Size/ } \\
\text { Mineral }\end{array}$ \\
\hline \multicolumn{10}{|c|}{ Mauna Loa } \\
\hline SR0008-2.70 & 9.5 & U02 & & Mauna Loa subaerial & 0.2072 & 7.64 & 8 & 0.1 & $>1 \mathrm{~mm} \mathrm{ol}$ \\
\hline SR0023-2.90 & 34.0 & U06 & & Mauna Loa subaerial & 0.3007 & 7.12 & 10.1 & 0.1 & $>2 \mathrm{~mm} \mathrm{ol}$ \\
\hline SR0031-0.50 & 45.5 & U07 & & Mauna Loa subaerial & 0.172 & 23.45 & 8.8 & 0.1 & $>2 \mathrm{~mm} \mathrm{ol}$ \\
\hline SR0036-1.22 & 53.5 & U08 & & Mauna Loa subaerial & 0.2839 & 1.67 & 8.4 & 0.3 & $>2 \mathrm{~mm} \mathrm{ol}$ \\
\hline SR0040-1.07 & 59.5 & U09 & & Mauna Loa subaerial & 0.2694 & 16.08 & 9 & 0.1 & $>2 \mathrm{~mm} \mathrm{ol}$ \\
\hline SR0066-0.00 & 98.8 & U018 & & Mauna Loa subaerial & 0.2546 & 11.76 & 13.8 & 0.1 & $>2 \mathrm{~mm}$ ol \\
\hline SR0066-0.00 & 98.8 & U018 & & Mauna Loa subaerial & 0.2648 & 25.96 & 13.4 & 0.1 & $1-2 \mathrm{~mm}$ ol \\
\hline SR0080-0.35 & 125.4 & U019 & & Mauna Loa subaerial & 0.1509 & 1.09 & 11.7 & 0.8 & .5 to $1 . \mathrm{mm}$ ol \\
\hline SR0083-7.85 & 137.0 & U020 & & Mauna Loa subaerial & 0.0621 & 0.96 & 10.6 & 1.2 & $.5-1 \mathrm{~mm}$ ol \\
\hline SR0089-1.15 & 149.9 & U022 & & Mauna Loa subaerial & 0.2422 & 0.04 & 11.8 & 10 & .5 to $2 \mathrm{~mm} \mathrm{cpx}$ \\
\hline SR0098-2.00 & 177.8 & U028 & & Mauna Loa subaerial & 0.2857 & 11.47 & 14.8 & 0.1 & $>2 \mathrm{~mm}$ ol \\
\hline SR0104-4.95 & 197.4 & U032 & & Mauna Loa subaerial & 0.2903 & 14.67 & 12.7 & 0.1 & $>2 \mathrm{~mm} \mathrm{ol}$ \\
\hline SR0109-0.65 & 209.1 & U035 & & Mauna Loa subaerial & 0.2207 & 2.82 & 14 & 0.2 & $>1 \mathrm{~mm} \mathrm{ol}$ \\
\hline SR0113-6.20 & 222.5 & U036 & & Mauna Loa subaerial & 0.2733 & 3.33 & 14.6 & 0.2 & $>2 \mathrm{~mm}$ ol \\
\hline SR0117-4.00 & 233.7 & U037 & & Mauna Loa subaerial & 0.303 & 2.24 & 17.6 & 0.2 & $0.5-2 \mathrm{~mm}$ ol \\
\hline SR0120-1.00 & 242.0 & U040 & & Mauna Loa subaerial & 0.2911 & 4.39 & 12.6 & 0.2 & $>2 \mathrm{~mm} \mathrm{ol}$ \\
\hline \multicolumn{10}{|c|}{ Mauna Kea } \\
\hline SR0124-3.90 & 252.9 & U043 & 201.1 & Mauna Kea subaerial & 0.2933 & 10.92 & 7.9 & 0.1 & $>1 \mathrm{~mm} \mathrm{ol}$ \\
\hline SR0129-5.20 & 267.5 & U047 & 214.1 & Mauna Kea subaerial & 0.2852 & 0.93 & 8.5 & 0.4 & $0.5-2 \mathrm{~mm} \mathrm{ol}$ \\
\hline SR0133-8.20 & 281.3 & U049 & 226.4 & Mauna Kea subaerial & 0.2395 & 5.57 & 7.9 & 0.2 & $>2 \mathrm{~mm}$ ol \\
\hline SR0137-5.98 & 293.0 & U053 & 236.8 & Mauna Kea subaerial & 0.2802 & 6.42 & 7.4 & 0.1 & $>1 \mathrm{~mm} \mathrm{ol}$ \\
\hline SR0141-7.90 & 305.8 & U056 & 248.2 & Mauna Kea subaerial & 0.2059 & 1.61 & 8.4 & 0.5 & $>1 \mathrm{~mm} \mathrm{ol}$ \\
\hline SR0148-8.50 & 326.7 & U060 & 266 & Mauna Kea subaerial & 0.2595 & 19.52 & 7.6 & 0.1 & $>2 \mathrm{~mm} \mathrm{ol}$ \\
\hline SR0157-6.25 & 353.0 & U065 & 290.2 & Mauna Kea subaerial & 0.2596 & 0.72 & 6.1 & 0.7 & $>2 \mathrm{~mm} \mathrm{ol}$ \\
\hline SR0167-5.90 & 378.4 & U070 & 312.8 & Mauna Kea subaerial & 0.285 & 0.68 & 7.3 & 0.6 & $.5-2 \mathrm{~mm} \mathrm{ol}$ \\
\hline SR0175-5.25 & 398.1 & U073 & 329.8 & Mauna Kea subaerial & 0.2276 & 3.58 & 8.9 & 0.1 & $>1 \mathrm{~mm} \mathrm{ol}$ \\
\hline SR0175-5.25 & 398.1 & U073 & 329.8 & Mauna Kea subaerial & 0.2868 & 11.03 & 8.6 & 0.1 & $>1 \mathrm{~mm} \mathrm{ol}$ \\
\hline SR0184-2.80 & 421.2 & U076 & 332.3 & Mauna Kea subaerial & 0.1754 & 18.75 & 8.3 & 0.1 & $>2 \mathrm{~mm} \mathrm{ol}$ \\
\hline SR0193-0.00 & 443.6 & U080 & 334.8 & Mauna Kea subaerial & 0.2874 & 9.34 & 9 & 0.1 & $>1 \mathrm{~mm} \mathrm{ol}$ \\
\hline SR0205-1.30 & 467.8 & U083 & 337.5 & Mauna Kea subaerial & 0.255 & 1.37 & 9.3 & 0.2 & $>1 \mathrm{~mm} \mathrm{ol}$ \\
\hline SR0212-8.20 & 490.9 & U088 & 340.0 & Mauna Kea subaerial & 0.2688 & 84.56 & 8.6 & 0.1 & $>2 \mathrm{~mm} \mathrm{ol}$ \\
\hline SR0222-2.00 & 516.2 & U092 & 342.8 & Mauna Kea subaerial & 0.2411 & 7.49 & 10.2 & 0.1 & $>1 \mathrm{~mm} \mathrm{ol}$ \\
\hline SR0232-8.50 & 542.1 & U094 & 345.6 & Mauna Kea subaerial & 0.2387 & 19.46 & 10.27 & 0.05 & $>1 \mathrm{~mm} \mathrm{ol}$ \\
\hline SR0240-3.30 & 563.5 & U098 & 348 & Mauna Kea subaerial & 0.2862 & 24.74 & 9.2 & 0.1 & $1-2 \mathrm{~mm} \mathrm{ol}$ \\
\hline SR0256-0.95 & 589.0 & U0103 & 350.8 & Mauna Kea subaerial & 0.2291 & 12.76 & 9.2 & 0.1 & $1-2 \mathrm{~mm}$ ol \\
\hline SR0267-6.85 & 615.8 & U0107 & 353.7 & Mauna Kea subaerial & 0.192 & 3.77 & 8.2 & 0.3 & $>1 \mathrm{~mm} \mathrm{ol}$ \\
\hline SR0276-7.85 & 636.0 & U0110 & 356.0 & Mauna Kea subaerial & 0.1599 & 5.8 & 10.2 & 0.3 & $>1 \mathrm{~mm} \mathrm{ol}$ \\
\hline SR0284-1.75 & 658.3 & U0114 & 358.4 & Mauna Kea subaerial & 0.1969 & 5.23 & 9.9 & 0.2 & $>1 \mathrm{~mm} \mathrm{ol}$ \\
\hline SR0294-7.65 & 678.6 & U0116 & 360.6 & Mauna Kea subaerial & 0.2222 & 3.36 & 11.1 & 0.1 & $>.5 \mathrm{~mm} \mathrm{ol}$ \\
\hline SR0294-7.3 & & U0116 & 286.0 & Mauna Kea subaerial & 0.1567 & 8.9 & 12.2 & 0.2 & $>.5 \mathrm{~mm} \mathrm{ol}$ \\
\hline SR0311-4.40 & 724.1 & U0124 & 365.7 & Mauna Kea subaerial & 0.1406 & 14.58 & 11.1 & 0.1 & $>1 \mathrm{~mm}$ ol \\
\hline SR0328-3.10 & 759.8 & U0127 & 369.6 & Mauna Kea subaerial & 0.1648 & 7.86 & 11 & 0.1 & $>1 \mathrm{~mm} \mathrm{ol}$ \\
\hline SR0340-1.00 & 793.6 & U0132 & 373.3 & Mauna Kea subaerial & 0.1291 & 4.64 & 12.2 & 0.2 & $>1 \mathrm{~mm} \mathrm{ol}$ \\
\hline SR0346-5.60 & 812.7 & U0136 & 375.4 & Mauna Kea subaerial & 0.1848 & 3.56 & 12.4 & 0.2 & $>0.5 \mathrm{~mm} \mathrm{ol}$ \\
\hline SR0354-7.75 & 833.9 & U0138 & 377.7 & Mauna Kea subaerial & 0.1485 & 3.58 & 16.1 & 0.2 & $>1 \mathrm{~mm} \mathrm{ol}$ \\
\hline SR0354-7.75 & 833.8 & U0138 & 377.7 & Mauna Kea subaerial & 0.1639 & 3.61 & 15.5 & 0.2 & .5 to $1 . \mathrm{mm}$ ol \\
\hline SR0358-3.60 & 845.1 & U0139 & 379.0 & Mauna Kea subaerial & 0.1935 & 9.21 & 13.6 & 0.1 & $>1 \mathrm{~mm} \mathrm{ol}$ \\
\hline SR0360-4.60 & 851.6 & U0140 & 379.7 & Mauna Kea subaerial & 0.2639 & 2.77 & 11.8 & 0.1 & $>1-2 \mathrm{~mm}$ ol \\
\hline SR0360-4.60 & 851.6 & U0140 & 379.7 & Mauna Kea subaerial & 0.1785 & 1.74 & 12 & 0.3 & $>2 \mathrm{~mm} \mathrm{ol}$ \\
\hline SR0363-7.1 ${ }^{\mathrm{b}}$ & 859.7 & U0141 & 380.6 & Mauna Kea subaerial & 0.2188 & 2.03 & 11.1 & 0.3 & $>1 \mathrm{~mm} \mathrm{ol}$ \\
\hline SR0372-2.80 & 871.2 & U0142 & 381.8 & Mauna Kea subaerial & 0.228 & 3.7 & 11.5 & 0.1 & $>0.5 \mathrm{~mm} \mathrm{ol}$ \\
\hline SR0379-3.00 & 888.4 & U0144 & 383.7 & Mauna Kea subaerial & 0.218 & 5.47 & 12.4 & 0.1 & $>0.5 \mathrm{~mm} \mathrm{ol}$ \\
\hline SR0392-4.30 & 921.8 & U0148 & 387.4 & Mauna Kea subaerial & 0.1586 & 5.63 & 10.9 & 0.1 & $>1 \mathrm{~mm} \mathrm{ol}$ \\
\hline SR0401-2.85 & 948.9 & U0151 & 390.4 & Mauna Kea subaerial & 0.1299 & 3.07 & 10.3 & 0.3 & $>1 \mathrm{~mm} \mathrm{ol}$ \\
\hline SR0441-9.10 & 1061.2 & U0166 & 402.7 & Mauna Kea subaerial & 0.1545 & 1.37 & 11.9 & 0.3 & $>0.5 \mathrm{~mm}$ \\
\hline
\end{tabular}


Table 1. (continued)

\begin{tabular}{|c|c|c|c|c|c|c|c|c|c|}
\hline Sample & $\begin{array}{l}\text { Top Depth, } \\
\text { mbsl }\end{array}$ & Unit & Model Age & Description & Wt. & $\begin{array}{l}\mathrm{He}, \\
\mathrm{ncc} / \mathrm{g}\end{array}$ & $\begin{array}{c}{ }^{3} \mathrm{He} /{ }^{4} \mathrm{He} \\
\mathrm{R} / \mathrm{Ra}\end{array}$ & \pm & $\begin{array}{c}\text { Grain Size/ } \\
\text { Mineral }\end{array}$ \\
\hline \multicolumn{10}{|c|}{ Submarine } \\
\hline SR0450-3.55 & 1083.7 & U0171 & 405.2 & Massive (submarine) & 0.2389 & 54.21 & 11.63 & 0.05 & $>1 \mathrm{~mm} \mathrm{ol}$ \\
\hline SR0455-7.40 & 1098.2 & U0179 & 406.8 & Massive & 0.2174 & 82.38 & 12.25 & 0.05 & $>1 \mathrm{~mm} \mathrm{ol}$ \\
\hline SR0490-1.50 & 1229.6 & U0190 & 421.3 & Hyaloclastite & 0.1688 & 11.75 & 11 & 0.1 & $>1 \mathrm{~mm} \mathrm{ol}$ \\
\hline SR502-4.85 & 1265.5 & U0191 & 425.2 & Massive & 0.181 & 15.83 & 12.3 & 0.1 & $>1 \mathrm{~mm} \mathrm{ol}$ \\
\hline SR0518-0.80 & 1311.9 & U0195 & 430.3 & Massive & 0.1901 & 46.69 & 10.5 & 0.1 & $>1 \mathrm{~mm} \mathrm{ol}$ \\
\hline SR0519-5.70 & 1316.2 & U0196 & 430.8 & Hyaloclastite & 0.2159 & 11.71 & 11 & 0.1 & $>1 \mathrm{~mm}$ ol \\
\hline SR0523-7.20 & 1329.2 & U0196 & 432.2 & Hyaloclastite & 0.2101 & 27.16 & 10.77 & 0.04 & $>1 \mathrm{~mm} \mathrm{ol}$ \\
\hline SR0531-4.40 & 1352.3 & U0198 & 434.8 & Hyaloclastite & 0.1844 & 8 & 16.4 & 0.1 & $>1 \mathrm{~mm} \mathrm{ol}$ \\
\hline SR0531-4.40 & 1352.6 & U0198 & 434.8 & Hyaloclastite & 0.1797 & 7.63 & 14.6 & 0.1 & .5 to $1 . \mathrm{mm}$ ol \\
\hline SR0532-2.25 & 1354.8 & U0198 & 435.0 & Hyaloclastite & 0.1814 & 8.81 & 10.6 & 0.1 & $>2 \mathrm{~mm} \mathrm{ol}$ \\
\hline SR0545-8.35 & 1395.0 & U0198 & 439.5 & Hyaloclastite & 0.181 & 9.99 & 16.6 & 0.1 & $>1 \mathrm{~mm} \mathrm{ol}$ \\
\hline SR0545-8.35 & 1395.0 & U0198 & 439.5 & Hyaloclastite & 0.1918 & 6.11 & 16.2 & 0.2 & .5 to $1 . \mathrm{mm}$ ol \\
\hline SR0548-8.00 & 1404.1 & U0199 & 440.5 & Massive & 0.2687 & 66.43 & 10.37 & 0.04 & $>1 \mathrm{~mm} \mathrm{ol}$ \\
\hline SR0552-4.25 & 1409.4 & U0200 & 441.0 & Hyaloclastite & 0.1702 & 43.21 & 10.5 & 0.1 & $1-2 \mathrm{~mm}$ ol \\
\hline SR0552-6.75 & 1410.2 & U0201 & 441.1 & Massive & 0.2637 & 3.51 & 10.8 & 0.1 & $>2 \mathrm{~mm} \mathrm{ol}$ \\
\hline SR0560-7.50 & 1435.4 & U0202 & 443.9 & Hyaloclastite & 0.2362 & 11.14 & 14.7 & 0.1 & $>1 \mathrm{~mm} \mathrm{ol}$ \\
\hline SR0568-0.50 & 1456.0 & U0202 & 446.2 & Hyaloclastite & 0.1773 & 32.58 & 13.3 & 0.1 & $>1 \mathrm{~mm} \mathrm{ol}$ \\
\hline SR0568-0.50 & 1456.0 & U0202 & 446.2 & Hyaloclastite & 0.1671 & 13.32 & 14.1 & 0.1 & $>1 \mathrm{~mm} \mathrm{ol}$ \\
\hline SR0574-1.90 & 1474.7 & U0202 & 448.2 & Hyaloclastite & 0.1349 & 22.62 & 12.2 & 0.1 & $>1 \mathrm{~mm}$ ol \\
\hline SR0582-10.00 & 1497.7 & U0207 & 450.7 & Massive & 0.262 & 38.51 & 12.6 & 0.1 & $>1 \mathrm{~mm} \mathrm{ol}$ \\
\hline SR0594-8.70 & 1521.4 & U0213 & 453.4 & Massive & 0.2576 & 30.34 & 12.4 & 0.1 & $>1 \mathrm{~mm} \mathrm{ol}$ \\
\hline SR0603-8.90 & 1548.2 & U0216 & 456.3 & Hyaloclastite & 0.1831 & 8.05 & 10.9 & 0.1 & $>0.5 \mathrm{~mm} \mathrm{ol}$ \\
\hline SR0604-2.50 & 1549.3 & U0217 & 456.4 & Massive & 0.1515 & 8.29 & 11 & 0.1 & $>0.5 \mathrm{~mm} \mathrm{ol}$ \\
\hline SR0622-7.10 & 1581.2 & U0218 & 459.9 & Hyaloclastite & 0.2271 & 9.93 & 10.2 & 0.1 & $>1 \mathrm{~mm} \mathrm{ol}$ \\
\hline SR0630-6.20 & 1605.0 & U0224 & 462.6 & Massive & 0.2713 & 32.11 & 11.2 & 0.1 & $>1 \mathrm{~mm} \mathrm{ol}$ \\
\hline SR0641-1.00 & 1636.3 & U0226 & 466.0 & Massive & 0.2231 & 20.28 & 10.7 & 0.1 & $>1 \mathrm{~mm} \mathrm{ol}$ \\
\hline SR0655-4.00 & 1678.7 & U0238 & 470.7 & Hyaloclastite & 0.1282 & 2.34 & 9.3 & 0.2 & $.5-2 \mathrm{~mm} \mathrm{ol}$ \\
\hline SR0664-5.10 & 1705.5 & U0238 & 473.6 & Hyaloclastite & 0.1339 & 5.29 & 11.5 & 0.2 & $>.5 \mathrm{~mm} \mathrm{ol}$ \\
\hline SR0668-0.80 & 1715.8 & U0240 & 474.7 & Hyaloclastite & 0.2465 & 6.23 & 11.1 & 0.1 & $>2 \mathrm{~mm} \mathrm{ol}$ \\
\hline SR0670-0.00 & 1721.6 & U0242 & 475.4 & Hyaloclastite & 0.2132 & 3.57 & 11.6 & 0.1 & $>1 \mathrm{~mm} \mathrm{ol}$ \\
\hline SR0672-9.05 & 1730.7 & U0242 & 476.4 & Hyaloclastite & 0.1676 & 5.16 & 11.3 & 0.1 & $>2 \mathrm{~mm}$ ol \\
\hline SR0675-6.90 & 1739.3 & U0243 & 477.3 & Hyaloclastite & 0.2269 & 3.36 & 15.7 & 0.2 & $>.5 \mathrm{~mm} \mathrm{ol}$ \\
\hline SR0675-6.90 & 1739.3 & U0243 & 477.3 & Hyaloclastite & 0.2385 & 0.95 & 16.6 & 0.3 & .5 to $1 . \mathrm{mm}$ ol \\
\hline SR0681-5.6 & 1756.9 & U0244 & 479.3 & Hyaloclastite & 0.1294 & 6.08 & 10 & 0.2 & .5 to $2 \mathrm{~mm} \mathrm{ol}$ \\
\hline SR0683-5.75 & 1763.2 & U0244 & 480.0 & Massive & 0.238 & 6.4 & 10.7 & 0.1 & $>.5 \mathrm{~mm}$ ol \\
\hline SR0694-9.00 & 1794.8 & U0253 & 483.4 & Massive & 0.155 & 3.15 & 10.3 & 0.2 & $>.5 \mathrm{~mm} \mathrm{ol}$ \\
\hline SR0709-13.35 & 1852.0 & U0261 & 489.7 & Hyaloclastite & 0.2163 & 6.85 & 11.4 & 0.1 & $>1 \mathrm{~mm} \mathrm{ol}$ \\
\hline SR0714-11.55 & 1883.6 & U0263 & 493.2 & Intrusive & 0.2977 & 11.17 & 11.8 & 0.1 & $0.5-1 \mathrm{~mm} \mathrm{ol}$ \\
\hline SR0714-11.55 & 1883.6 & U0263 & 493.2 & Intrusive & 0.139 & 1.08 & 8.9 & 0.3 & $.5-1 \mathrm{~mm}$ opx \\
\hline SR0720-18.25 & 1921.6 & U0268 & 497.4 & Intrusive & 0.2815 & 7.26 & 11.1 & 0.1 & $>1 \mathrm{~mm} \mathrm{ol}$ \\
\hline \multicolumn{10}{|c|}{ Pillow Lavas } \\
\hline SR0741-7.90 & 2009.8 & U0278 & 507.1 & Pillow & 0.1768 & 110.92 & 23.5 & 0.1 & $>2 \mathrm{~mm} \mathrm{ol}$ \\
\hline SR0741-10.0 & 2010.4 & U0278 & 507.1 & Pillow & 0.3015 & 23.55 & 21.8 & 0.1 & $>2 \mathrm{~mm} \mathrm{ol}$ \\
\hline SR0750-12.45 & 2062.7 & U0283 & 512.9 & Pillow & 0.2076 & 4.88 & 23.2 & 0.2 & $>1 \mathrm{~mm} \mathrm{ol}$ \\
\hline SR0756-13.25 & 2098.6 & U0284 & 516.8 & Pillow & 0.2107 & 51.78 & 17.4 & 0.1 & $>1 \mathrm{~mm} \mathrm{ol}$ \\
\hline SR0762-4.60 & 2123.7 & U0284 & 519.6 & Pillow & 0.2144 & 6.83 & 19.8 & 0.1 & $>1 \mathrm{~mm} \mathrm{ol}$ \\
\hline SR0768-5.40 & 2144.1 & U0285 & 521.9 & Hyaloclastite & 0.2458 & $\begin{array}{l}0.05 \\
8.42\end{array}$ & $\begin{array}{l}19.0 \\
14.3\end{array}$ & 0.1 & $>1 \mathrm{~mm}$ ol \\
\hline SR0775-16.80 & 2191.2 & U0286 & 527.0 & Hyaloclastite & 0.1073 & 12.13 & 13 & 0.2 & $>.5 \mathrm{~mm}$ ol \\
\hline SR0779-4.50 & 2213.6 & U0287 & 529.5 & Hyaloclastite & 0.11 & 0.36 & 16.3 & 2.2 & $>.5 \mathrm{~mm} \mathrm{ol}$ \\
\hline SR0796-4.30 & 2288.0 & U0290 & 537.7 & Pillow & 0.03876 & 4.14 & 16.9 & 0.7 & glass \\
\hline SR0806-6.05 & 2327.8 & U0292 & 542.1 & Pillow & 0.2021 & 36.69 & 14.9 & 0.1 & glass \\
\hline SR0814-17.60 & 2346.4 & U0292 & 544.1 & Pillow & 0.04343 & 18.88 & 20.1 & 0.2 & glass \\
\hline SR0826-13.80 & 2400.4 & U0293 & 550.0 & Pillow & 0.2065 & 337.43 & 24.8 & 0.1 & glass \\
\hline SR0829-3.40 & 2415.7 & U0293 & 551.7 & Pillow & 0.04383 & 90.49 & 23.1 & 0.1 & glass \\
\hline SR0837-4.20 & 2461.8 & U0296 & 556.8 & Intrusive & 0.2684 & 12.94 & 21.5 & 0.2 & $>2 \mathrm{~mm}$ ol \\
\hline SR0843-1.00 & 2498.0 & U0300 & 560.8 & Massive & 0.2163 & 5.13 & 13.9 & 0.2 & $>.5 \mathrm{~mm} \mathrm{ol}$ \\
\hline SR0843-8.70 & 2500.5 & U0302 & 561.1 & Intrusive & 0.2811 & 15.81 & 20.6 & 0.2 & $>1 \mathrm{~mm}$ ol \\
\hline SR0846-2.80 & 2525.4 & U0303 & 563.8 & Hyaloclastite & 0.1151 & 7.1 & 12.2 & 0.1 & $>.5 \mathrm{~mm} \mathrm{ol}$ \\
\hline
\end{tabular}


Table 1. (continued)

\begin{tabular}{|c|c|c|c|c|c|c|c|c|c|}
\hline Sample & $\begin{array}{c}\text { Top Depth, } \\
\text { mbsl }\end{array}$ & Unit & Model Age & Description & Wt. & $\begin{array}{c}\mathrm{He}, \\
\mathrm{ncc} / \mathrm{g}\end{array}$ & $\begin{array}{c}{ }^{3} \mathrm{He} /{ }^{4} \mathrm{He} \\
\mathrm{R} / \mathrm{Ra}\end{array}$ & \pm & $\begin{array}{c}\text { Grain Size/ } \\
\text { Mineral }\end{array}$ \\
\hline SR0855-0.10 & 2581.8 & U0305 & 570.0 & Hyaloclastite & 0.1647 & 6.51 & 15.6 & 0.1 & $>.5 \mathrm{~mm} \mathrm{ol}$ \\
\hline SR0860-8.10 & 2615.0 & U0310e & 573.7 & Pillow & 0.1596 & 5.68 & 16.5 & 0.2 & $>.5 \mathrm{~mm}$ ol \\
\hline SR0871-13.00 & 2654.1 & U0312 & 578.0 & Pillow & 0.1755 & 17.16 & 13.9 & 0.1 & $1-2 \mathrm{~mm}$ ol \\
\hline SR0891-15.10 & 2730.2 & U0316 & 586.3 & Pillow & 0.1654 & 9.77 & 14 & 0.1 & $>1 \mathrm{~mm} \mathrm{ol}$ \\
\hline SR0896-2.40 & 2759.3 & U0319 & 589.5 & Hyaloclastite & 0.1874 & 13.96 & 12.2 & 0.1 & $>.5 \mathrm{~mm} \mathrm{ol}$ \\
\hline SR0899-2.45 & 2770.9 & U0320 & 590.8 & Pillow & 0.224 & 12.23 & 12.2 & 0.1 & $>1 \mathrm{~mm} \mathrm{ol}$ \\
\hline SR0907-1.65 & 2789.9 & U0321 & 592.9 & Pillow & 0.2265 & 9.21 & 11.7 & 0.1 & $>.5 \mathrm{~mm} \mathrm{ol}$ \\
\hline SR0913-2.40 & 2825.8 & U0327 & 596.8 & Intrusive & 0.2413 & 20.18 & 14.9 & 0.1 & $>.5 \mathrm{~mm} \mathrm{ol}$ \\
\hline SR0916-1.15 & 2837.6 & U0330 & 598.1 & Pillow & 0.1971 & 10.32 & 12.8 & 0.1 & $>1 \mathrm{~mm}$ ol \\
\hline SR0930-15.85 & 2919.5 & U0333 & 607.1 & Pillow & 0.1803 & 17.57 & 12.9 & 0.1 & $>1 \mathrm{~mm} \mathrm{ol}$ \\
\hline SR0939-18.10 & 2961.0 & U0335a & 611.7 & Pillow & 0.2531 & 42.32 & 14.2 & 0.1 & $>1 \mathrm{~mm}$ ol \\
\hline SR0940-18.35 & 2967.8 & U0336c & 612.5 & Intrusive & 0.1501 & 26.34 & 21 & 0.1 & $>.5 \mathrm{~mm}$ ol \\
\hline SR0954-8.00 & 3009.2 & U0339 & 617.0 & Pillow & 0.1627 & 23.92 & 13.9 & 0.1 & $>1 \mathrm{~mm} \mathrm{ol}$ \\
\hline SR0956-18.35 & 3019.0 & U0341b & 618.1 & Intrusive & 0.1301 & 2.7 & 12.8 & 0.2 & .5 to $1 . \mathrm{mm} \mathrm{cpx}$ \\
\hline SR0958-5.20 & 3024.6 & U0340e & 618.7 & Pillow & 0.1449 & 11.04 & 12.3 & 0.1 & $>1 \mathrm{~mm}$ ol \\
\hline SR0963-9.70 & 3052.9 & $\mathrm{U} 0340 \mathrm{e}$ & 621.8 & Pillow & 0.2257 & 14.82 & 12.4 & 0.1 & $>1 \mathrm{~mm}$ ol \\
\hline SR0964-4.30 & 3058.0 & U0340e & 622.4 & Pillow & 0.2889 & 18.31 & 12.3 & 0.1 & $>.5 \mathrm{~mm} \mathrm{ol}$ \\
\hline SR0964-11.90 & 3060.2 & U0342 & 622.6 & Pillow & 0.2292 & 17.23 & 12.4 & 0.1 & $>1 \mathrm{~mm}$ ol \\
\hline SR0967-2.75 & 3068.9 & U0343a & 623.6 & Pillow & 0.1284 & 6.39 & 11.9 & 0.1 & $1-2 \mathrm{~mm}$ ol \\
\hline
\end{tabular}

${ }^{\mathrm{a}}$ All helium measurements by crushing in vacuo. ${ }^{3} \mathrm{He} /{ }^{4} \mathrm{He}$ is reported relative to air $(\mathrm{R} / \mathrm{Ra})$ where $\mathrm{Ra}=\left({ }^{3} \mathrm{He} /{ }^{4} \mathrm{He}\right)$ air $=1.384 \times 10^{-6}$. Errors in ${ }^{3} \mathrm{He} /{ }^{4} \mathrm{He}$ are roughly 1 sigma; analytical errors in ${ }^{4} \mathrm{He}$ concentration are roughly $2-3 \%$. Top depth is the depth of the sample below sea level (m). Submarine subaerial transition is between SR446 and SR450.

${ }^{b}$ Denotes samples not in reference suite. Age model from W. D. Sharp et al. (manuscript in preparation, 2003).

onstrate a wide variability in both helium content and ${ }^{3} \mathrm{He} /{ }^{4} \mathrm{He}$ ratios. The helium concentrations are so low in some of the glasses that they are likely influenced by both radiogenic and atmospheric components, and, as discussed further below, only glass measurements with helium concentrations higher than $10^{-8} \mathrm{ccSTP} / \mathrm{gram}$ are considered to reflect the magmatic helium isotopic compositions.

[8] The phenocrysts and glasses were hand-picked from crushed, sieved, fractions of the lavas, from the 0.5 to $1,1-2$, and greater than 2 millimeter size fractions (see Tables 1 and 3). In order to extract helium from intact vesicles, which are often up to 1 millimeter in size, all the glass samples were greater than $2 \mathrm{~mm}$ in size. In many cases the amount of olivine available was limited and it was necessary to combine several grain sizes to obtain enough material for a reasonably precise helium isotopic measurement (see Table 1). Because the procedure of utilizing different grain sizes for different samples introduces a potential bias, an effort was made to evaluate the grain size dependence on the helium isotopic data; grain size experiments were performed on several samples having high enough phenocryst content. The results of the olivine grain size dependence experiments are presented in Table 3 and discussed in the Appendix A.

\subsection{Mass Spectrometry}

[9] All helium measurements were carried out at Woods Hole Oceanographic Institution using an automated, dual collection, statically operated helium isotope mass spectrometer with a Nier-type ion source. The ${ }^{4} \mathrm{He}$ ion current was measured with a Faraday cup and the ${ }^{3} \mathrm{He}$ ion current was simultaneously measured with an ETP electron multiplier. The concentrations and isotopic compositions are reported relative to air standards, typically close to $1.5 \times 10^{-8}$ cc STP in size $\left(\mathrm{Ra}=1.384 \times 10^{-6}\right)$. The ${ }^{4} \mathrm{He}$ blanks during the course of the study were between 4 and $6.7 \times$ $10^{-11} \mathrm{~cm}^{3}$ (STP) which was small relative to the gas released from the samples. Continuous automated operation allows numerous standards and blanks to be run along with the samples. During the course of a single day, the air standards are typically reproducible to better than $0.5 \%$ on ${ }^{4} \mathrm{He}$ peak height and $1.5 \%$ on the isotopic composition (standard deviation from the mean of $\sim 15$ stand- 
Table 2. Helium Concentrations and Isotopic Compositions of HSDP2 Glasses ${ }^{\mathrm{a}}$

\begin{tabular}{|c|c|c|c|c|c|}
\hline Sample & $\begin{array}{l}\text { Extraction } \\
\text { Method }\end{array}$ & Weight & $\begin{array}{c}{ }^{4} \mathrm{He} \\
\text { n-ccSTP/g }\end{array}$ & $\begin{array}{c}{ }^{3} \mathrm{He} /{ }^{4} \mathrm{He} \\
\mathrm{R} / \mathrm{Ra}\end{array}$ & \pm \\
\hline SR791-12.4 & $\mathrm{C}$ & 0.05103 & 1.03 & 8.3 & 1.1 \\
\hline SR791-12. & M & 0.04219 & 2.39 & 5.6 & 0.7 \\
\hline SR796-4.3- ${ }^{\mathrm{b}}$ & $\mathrm{C}$ & 0.03876 & 4.14 & 16.9 & 0.7 \\
\hline SR796-4.3 & M & 0.03374 & 6.69 & 6.3 & 0.5 \\
\hline SR806-6.05 & $\mathrm{C}$ & 0.2021 & 36.69 & 14.9 & 0.1 \\
\hline SR806-6.05 & M & 0.1906 & 9.17 & 6.6 & 0.1 \\
\hline SR814-17.6 & $\mathrm{C}$ & 0.04343 & 18.88 & 20.1 & 0.2 \\
\hline SR814-17 & M & 0.04168 & 8.99 & 10.4 & 0.3 \\
\hline SR826-13.8 & $\mathrm{C}$ & 0.2065 & 337.4 & 24.8 & 0.1 \\
\hline SR826-13. & M & 0.1956 & 7.68 & 12.9 & 0.2 \\
\hline SR829-3.4A ${ }^{b}$ & $\mathrm{C}$ & 0.04383 & 90.49 & 23.1 & 0.1 \\
\hline SR829-3.4 & M & 0.03879 & 7.21 & 9.2 & 0.5 \\
\hline SR829-3.4B ${ }^{b}$ & $\mathrm{C}$ & 0.02441 & 48.67 & 23.9 & 0.2 \\
\hline SR829-3.4 & M & 0.02123 & 8.37 & 13.5 & 0.5 \\
\hline SR975-8.8 & $\mathrm{C}$ & 0.1769 & 11.37 & 3.6 & 0.0 \\
\hline SR975-8.8 & M & 0.1629 & 7.42 & 3.9 & 0.1 \\
\hline SR970-0.55 & $\mathrm{C}$ & 0.1395 & 39.81 & 3.8 & 0.0 \\
\hline SR970-0.5 & M & 0.1313 & 5.48 & 3.7 & 0.1 \\
\hline SR943-0.9 & $\mathrm{C}$ & 0.2256 & 23.51 & 4.7 & 0.1 \\
\hline SR943-0.9 & M & 0.2161 & 10.34 & 6.7 & 0.1 \\
\hline SR947-5.6 & $\mathrm{C}$ & 0.1676 & 5.32 & 7.8 & 0.2 \\
\hline SR947-5.6 & M & 0.152 & 5.59 & 5.0 & 0.1 \\
\hline SR0956-18.35 & $\mathrm{C}$ & 0.1534 & 0.08 & 9.2 & 3.6 \\
\hline SR0956-18.35 & M & 0.1069 & 9.08 & 0.5 & 0.0 \\
\hline SR0956-18.35 & $\mathrm{C}$ & 0.2441 & 0.10 & 14.1 & 5.9 \\
\hline SR0956-18.35 & M & 0.2278 & 9.63 & 0.4 & 0.1 \\
\hline
\end{tabular}

${ }^{\mathrm{a}} \mathrm{C}$, crushing in vacuo of $2 \mathrm{~mm}$ glass chips; $\mathrm{M}$, melting of powder in vacuum.

${ }^{\mathrm{b}}$ Isotopic composition used as magmatic value. Concentrations are in nano $\mathrm{cm}^{3} / \mathrm{gram}$.

ards). Curve fitting to daily trends can result in significantly lower uncertainties (typically $1-2$ per mil on ${ }^{4} \mathrm{He}$ and $2-4$ per mil on ${ }^{3} \mathrm{He} /{ }^{4} \mathrm{He}$ ), so variations in standard determinations are not significant sources of uncertainty. The blank is typically reproducible to $4 \%$ or better $\left( \pm 1 \times 10^{-11} \mathrm{cc}\right.$ STP ${ }^{4} \mathrm{He}$ ) and contributes uncertainty only for low concentration samples. The helium contents in the mineral and glass samples varied widely, between $3 \times 10^{-11}$ to $3 \times 10^{-7}$ cc STP ${ }^{4} \mathrm{He} /$ gram; the blank corrections are variable in size, but are always less than $10 \%$ for the crushing measurements. Measurement uncertainties are not individually tabulated for the helium concentration measurements, but are typically within 1-2\% for the higher concentrations, and always less than $10 \%$.

[10] The duplicates and grain size experiments in Table 3 show that the reproducibility of both helium concentration and ${ }^{3} \mathrm{He} /{ }^{4} \mathrm{He}$ ratios is generally beyond the estimated uncertainties on individual determinations. As discussed below, this is believed to reflect natural variability within the populations of Mauna Kea phenocrysts. Note that the variability within single samples, or between different grain sizes of a single sample, is small compared to the overall isotopic variability in the entire data set. Repeated measurements of an internal WHOI standard, MORB glass Alv8921 , provides an estimate of reproducibility and overall system performance, and demonstrates that the variability in the samples is not related to instrument performance. Aliquots of the MORB standard, run routinely with the samples, yielded good agreement with previous determinations, with a standard deviation of $3 \%$ in ${ }^{4} \mathrm{He}$ concentration and $1 \%$ in ${ }^{3} \mathrm{He} /{ }^{4} \mathrm{He}$ ratios (over the course of the one year period when most of these measurements were made, $\mathrm{n}=36$ ). Concentrations were pre-measured using a quadrupole mass spectrometer to control the quantity of gas inlet to the mass spectrometer which minimizes memory effects within the mass spectrometer. Memory effects within the extraction line and mass spectrometer are known to be negligible due to the reproducibility of the samples, standards, and blanks.

\section{Magmatic Helium Measurements in the HSDP2 Core}

\subsection{Overview}

[11] Figure 2 shows the HSDP $2{ }^{3} \mathrm{He} /{ }^{4} \mathrm{He}$ ratios as a function of depth, with the major lithologic boundaries also indicated [DePaolo et al., 1999; Stolper et al., submitted manuscript, 2004]. This diagram includes olivine and selected pillow glass measurements that are believed to reflect magmatic ${ }^{3} \mathrm{He} /{ }^{4} \mathrm{He}$ ratios. Results from the HSDP 1 core showed that small amounts of radiogenic and cosmogenic helium can be present in these lavas, but that crushing of olivines is a robust way of determining magmatic helium isotopic compositions [Kurz et al., 1996]. The transition between Mauna Loa and Mauna Kea lavas is obvious in the helium-depth plot, at roughly $250 \mathrm{~m}$ below sea level, because Mauna Loa shield lavas older than 
Table 3. Compilation of Duplicates (of the Same Sample and Same Grain Size Population) and Grain Size Experiments (Same Sample With Different Grain Sizes) and Olivine/Orthopyroxene Pairs ${ }^{\mathrm{a}}$

\begin{tabular}{|c|c|c|c|c|c|}
\hline Sample & Weight & ${ }^{4} \mathrm{He}$, ncc/gram & ${ }^{3} \mathrm{He} /{ }^{4} \mathrm{He}, \mathrm{R} / \mathrm{Ra}$ & \pm & Grain Size \\
\hline \multicolumn{6}{|c|}{ Duplicates } \\
\hline SR0175-5.25 & 0.2276 & 3.58 & 8.9 & 0.1 & $>1 \mathrm{~mm} \mathrm{ol}$ \\
\hline SR0175-5.25 & 0.2868 & 11.04 & 8.6 & 0.1 & $>1 \mathrm{~mm} \mathrm{ol}$ \\
\hline SR0212-8.20 & 0.2922 & 1.30 & 7.7 & 0.2 & $.5-1 \mathrm{~mm}$ olivine \\
\hline SR0212-8.20 & 0.3287 & 9.35 & 8.8 & 0.1 & $.5-1 \mathrm{~mm}$ ol \\
\hline SR0240-3.30 & 0.2862 & 24.74 & 9.2 & 0.1 & $1-2 \mathrm{~mm}$ ol \\
\hline SR0240-3.30 & 0.262 & 9.03 & 10.4 & 0.1 & $1-2 \mathrm{~mm} \mathrm{ol}$ \\
\hline SR0294-7.65 & 0.2222 & 3.36 & 11.1 & 0.1 & $>.5 \mathrm{~mm}$ \\
\hline SR0294-7.3 & 0.1567 & 8.90 & 12.2 & 0.2 & $>.5 \mathrm{~mm}$ \\
\hline SR0720-18.25 & 0.2609 & 8.56 & 10.7 & 0.1 & $.5-1 \mathrm{~mm} \mathrm{ol}$ \\
\hline SR0720-18.25 & 0.2989 & 9.36 & 10.8 & 0.1 & $.5-1 \mathrm{~mm}$ \\
\hline SR0720-18.25 & 0.2815 & 7.26 & 11.1 & 0.1 & $>1 \mathrm{~mm}$ ol \\
\hline SR0720-18.25 & 0.3009 & 20.40 & 10.5 & 0.1 & $>1 \mathrm{~mm} \mathrm{ol}$ \\
\hline SR0568-0.50 & 0.1773 & 32.58 & 13.3 & 0.1 & $>1 \mathrm{~mm}$ ol from clast \\
\hline SR0568-0.50 & 0.1671 & 13.32 & 14.1 & 0.1 & $>1 \mathrm{~mm}$ ol from breccia \\
\hline \multicolumn{6}{|c|}{ Different Grain Sizes } \\
\hline SR0212-8.20 & 0.2688 & 84.56 & 8.6 & 0.1 & $>2 \mathrm{~mm} \mathrm{ol}$ \\
\hline SR0212-8.20 & 0.1879 & 1.77 & 8.2 & 0.2 & $1-2 \mathrm{~mm} \mathrm{ol}$ \\
\hline SR0212-8.20 & 0.2922 & 1.30 & 7.7 & 0.2 & $.5-1 \mathrm{~mm}$ olivine \\
\hline SR0360-4.60 & 0.1785 & 1.74 & 12.0 & 0.3 & $>2 \mathrm{~mm} \mathrm{ol}$ \\
\hline SR0360-4.60 & 0.2639 & 2.77 & 11.8 & 0.1 & $>1-2 \mathrm{~mm}$ ol \\
\hline SR066-0.00 & 0.2546 & 11.76 & 13.8 & 0.1 & $>2 \mathrm{~mm} \mathrm{ol}$ \\
\hline SR066-0.00 & 0.2648 & 25.97 & 13.4 & 0.1 & $1-2 \mathrm{~mm}$ ol \\
\hline SR0354-7.75 & 0.1485 & 3.58 & 16.1 & 0.2 & $>1 \mathrm{~mm}$ \\
\hline SR0354-7.75 & 0.1639 & 3.61 & 15.5 & 0.2 & .5 to $1 . \mathrm{mm}$ \\
\hline SR0531-4.40 & 0.1844 & 8.00 & 16.4 & 0.1 & $>1 \mathrm{~mm}$ \\
\hline SR0531-4.40 & 0.1797 & 7.63 & 14.6 & 0.1 & .5 to $1 . \mathrm{Mm}$ \\
\hline SR0545-8.35 & 0.181 & 9.99 & 16.6 & 0.1 & $>1 \mathrm{~mm}$ \\
\hline SR0545-8.35 & 0.1918 & 6.11 & 16.2 & 0.2 & .5 to $1 . \mathrm{mm}$ \\
\hline SR0552-6.75 & 0.2637 & 3.51 & 10.8 & 0.1 & $>2 \mathrm{~mm}$ \\
\hline SR0552-4.25 & 0.1702 & 43.21 & 10.5 & 0.1 & $1-2 \mathrm{~mm}$ \\
\hline SR0668-0.80 & 0.2465 & 6.23 & 11.1 & 0.1 & $>2 \mathrm{~mm}$ \\
\hline SR0668-0.80 & 0.1948 & 3.58 & 10.5 & 0.2 & $1-2 \mathrm{~mm}$ \\
\hline SR0668-0.80 & 0.2413 & 3.47 & 11.3 & 0.2 & $.5-1 \mathrm{~mm}$ \\
\hline SR0675-6.90 & 0.2269 & 3.36 & 15.7 & 0.2 & $>.5 \mathrm{~mm}$ \\
\hline SR0675-6.90 & 0.2385 & 0.95 & 16.6 & 0.3 & .5 to $1 . \mathrm{mm}$ \\
\hline SR0720-18.25 & 0.2815 & 7.26 & 11.1 & 0.1 & $>1 \mathrm{~mm} \mathrm{ol}$ \\
\hline SR0720-18.25 & 0.3009 & 20.40 & 10.5 & 0.1 & $>1 \mathrm{~mm}$ ol \\
\hline SR0720-18.25 & 0.2989 & 9.36 & 10.8 & 0.1 & $.5-1 \mathrm{~mm}$ \\
\hline SR0741-7.90 & 0.1768 & 110.92 & 23.5 & 0.1 & $>2 \mathrm{~mm} \mathrm{ol}$ \\
\hline SR0741-7.90 & 0.1229 & 4.20 & 22.1 & 0.3 & $1-2 \mathrm{~mm} \mathrm{ol}$ \\
\hline SR0741-7.90 & 0.1095 & 3.89 & 21.1 & 0.3 & $.5-1 \mathrm{~mm} \mathrm{ol}$ \\
\hline SR0741-10.0 & 0.3015 & 23.56 & 21.9 & 0.1 & $>2 \mathrm{~mm} \mathrm{ol}$ \\
\hline SR0741-10.0 & 0.1653 & 2.93 & 19.7 & 0.3 & $1-2 \mathrm{~mm}$ ol \\
\hline \multicolumn{6}{|c|}{ Olivine/Orthopyroxene Pair } \\
\hline SR0714-11.55 & 0.2977 & 11.17 & 11.8 & 0.1 & $.5-1 \mathrm{~mm}$ green ol \\
\hline melt powder & 0.2836 & 17.78 & 11.1 & 0.1 & ol \\
\hline SR0714-11.55 & 0.139 & 1.08 & 8.9 & 0.3 & $.5-1 \mathrm{~mm}$ opx \\
\hline melt powder & 0.1203 & 1.71 & 1.8 & 0.3 & opx \\
\hline
\end{tabular}

\footnotetext{
${ }^{\mathrm{a}}$ All measurements, except those denoted for SR0714, were carried out by crushing in vacuo. Concentrations are in nano $\mathrm{cm}^{3}$
} (STP)/gram.

$10 \mathrm{Ka}$ have significantly higher ${ }^{3} \mathrm{He} /{ }^{4} \mathrm{He}$ than subaerial Mauna Kea [e.g., Kurz and Kammer, 1991; Kurz et al., 1995]. The transition is seen in major and trace elements [Rhodes and Vollinger,
2004; Huang and Frey, 2003] and isotopes [Blichert-Toft et al., 2003; Eisele et al., 2003]. The temporal trend defined by the new Mauna Loa HSDP2 data is entirely consistent with data 


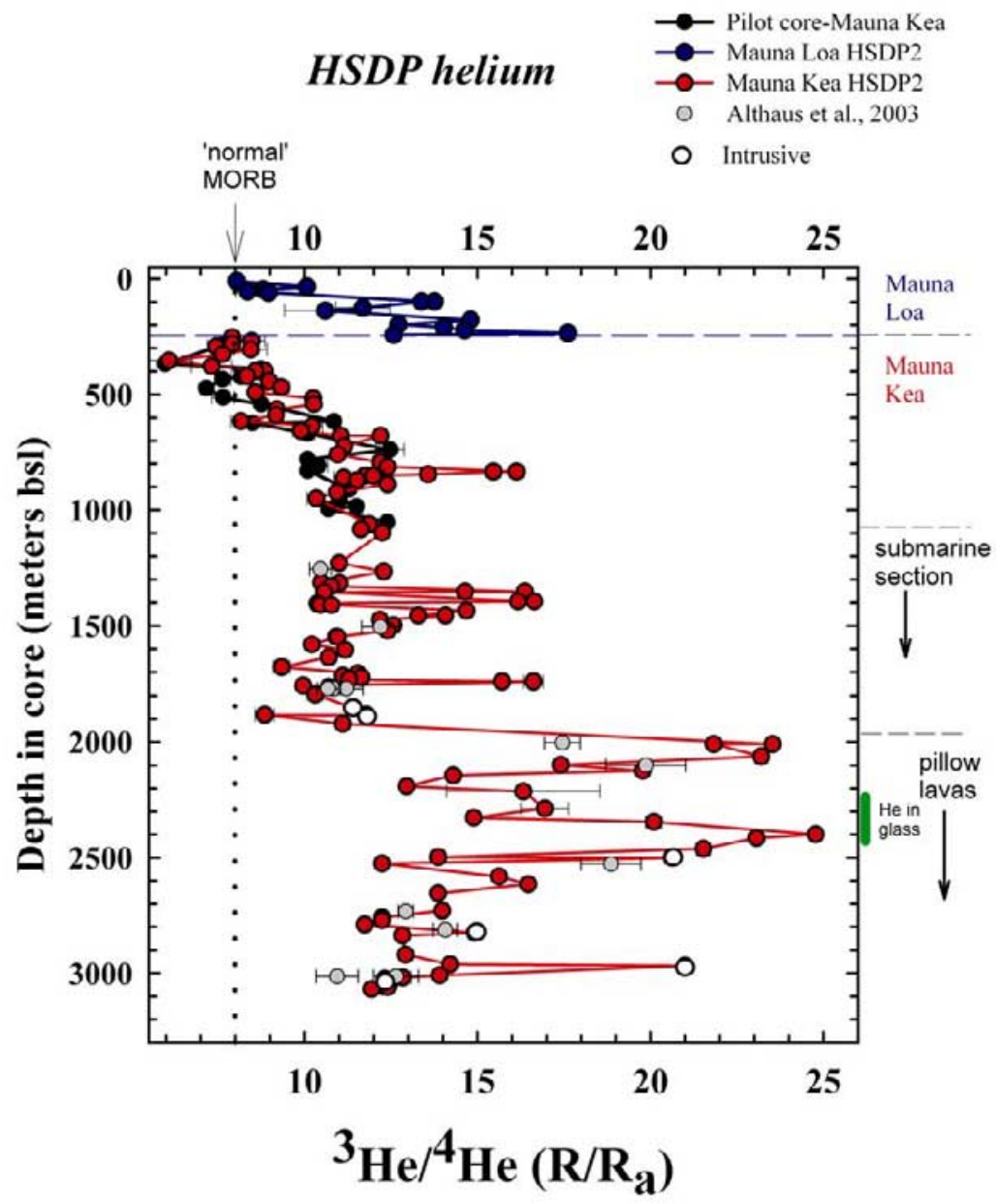

Figure 2. $3 \mathrm{He} /{ }^{4} \mathrm{He}$ as a function of depth (meters below sea level) in the HSDP core, see Table 1 . The helium isotopic results from the pilot core (which reached a depth of $1050 \mathrm{~m}$; data from Kurz et al. [1996]) are shown as solid black symbols, and the Mauna Loa lavas are shown as blue symbols. Note that the ${ }^{3} \mathrm{He} /{ }^{4} \mathrm{He}$ ratios increase with depth, and that there are excursions to significantly higher ${ }^{3} \mathrm{He} /{ }^{4} \mathrm{He}$ ratios deep in the core. Open circles denote intrusive units. Error bars are smaller than the symbols if they are not shown. Data of Althaus et al. [2003] are shown for comparison (for clarity, submarine Mauna Kea data only).

from the exposed subaerial flanks of Mauna Loa, and Mauna Loa HSDP1 data. It is well documented that Mauna Loa ${ }^{3} \mathrm{He} /{ }^{4} \mathrm{He}$ decreases from $13-17 \mathrm{Ra}$ in the older lavas to $\sim 8-10 \mathrm{Ra}$ in the youngest lavas [Kurz and Kammer, 1991; Kurz et al., 1996; DePaolo et al., 2001].

[12] The Mauna Kea data from the HSDP1 pilot core (black dots in Figure 2) are in reasonable agreement with the new HSDP2 data. In the top $1000 \mathrm{~m}$ of the Mauna Kea section, ${ }^{3} \mathrm{He} /{ }^{4} \mathrm{He}$ ratios gradually increase with depth, with the highest values of $\sim 12 \mathrm{Ra}$ near $1000 \mathrm{~m}$. This was previ- ously interpreted as an increasing contribution from the hot spot as a function of depth and age [Kurz et al., 1996]. A notable disagreement between the two data sets is the excursion to high ${ }^{3} \mathrm{He} /{ }^{4} \mathrm{He}$ ratios, up to $16.1 \mathrm{Ra}$, at $834 \mathrm{~m}$ (SR03547.75), in the HSDP2 data. (Huang and Frey [2003] noted that sample SR0354-7.75, with high ${ }^{3} \mathrm{He} /{ }^{4} \mathrm{He}$ at $834 \mathrm{~m}$, is also characterized by low $\mathrm{SiO} 2$, and is important because it is the youngest lava with this distinctive feature.) This may be explained by the improved resolution of the HSDP2 data, or that different lavas were sampled by the two different drill cores, which are 
approximately $2 \mathrm{~km}$ apart. Although individual flows have been correlated between the two cores (R177 and SR131 [Huang and Frey, 2003]), Blichert-Toft et al. [2003] also found isotopic differences between the two drill cores, suggesting that slightly different lava sequences were sampled.

[13] Below $1060 \mathrm{~m}$, where the lavas were erupted in a submarine environment, and hyaloclastite and pillows coexist, the HSDP2 core is characterized by a number of excursions or "spikes" in ${ }^{3} \mathrm{He} /{ }^{4} \mathrm{He}$. The highest value, of $24.8 \mathrm{Ra}$, is found in one of these excursions near $2400 \mathrm{~m}$ depth, and is the highest value yet reported for Mauna Kea. Eleven of the twelve helium "spikes" occur in the submarine section of the core, the exception being the excursion at $830 \mathrm{~m}$. The ${ }^{3} \mathrm{He} /{ }^{4} \mathrm{He}$ ratios always return to a significantly lower "baseline" value after an excursion; this baseline appears to be slightly higher between 2000 and $3000 \mathrm{~m}$, i.e., 12 to $14 \mathrm{Ra}$, as opposed to 10 to $12 \mathrm{Ra}$ at $1000 \mathrm{~m}$. The helium "spikes" at various intervals deep in the core have not previously been observed and are a unique feature of the HSDP2 core. Note that the transition from high to low ${ }^{3} \mathrm{He} /{ }^{4} \mathrm{He}$ occurs within a single unit in at least one case (SR532, unit 198).

[14] Although most of the material sampled by the HSDP2 core are extrusive subaerial lava flows, submarine pillow lavas, and hyaloclastites, some of the units deep in the core may be intrusive. They are found only in the submarine section, at depths greater than $1880 \mathrm{~m}$ (see Table 1 and the lithologic summary [DePaolo et al., 1999; Stolper et al., submitted manuscript, 2004]), and have been identified by sharp lithology contrasts and glassy contacts on both sides. Some of the helium data reported in Table 1, including the two deepest high ${ }^{3} \mathrm{He} /{ }^{4} \mathrm{He}$ spikes, were obtained from units classified as intrusive units. This is potentially important to the interpretation because, if they are intrusive, they are not in stratigraphic order.

[15] The helium concentrations, obtained by crushing the olivines in vacuo, range between $10^{-9}$ and $10^{-7} \mathrm{cc} \mathrm{STP/gram} \mathrm{which} \mathrm{is} \mathrm{typical} \mathrm{for}$ olivine phenocrysts. There does not appear to be any systematic relationship between helium concentration in the olivines and depth or isotopic composition. Because of the variable olivine content of the core, and the limited amount of material available from each depth, the helium measurements were sometimes performed on different olivine size fractions $(0.5-1 \mathrm{~mm}, 1-2$ $\mathrm{mm}$, and $>2 \mathrm{~mm}$ ). In order to evaluate the influence of variable grain size on the isotopic data, a set of duplicate measurements were performed on different grain size olivines from selected samples. The results of these experiments, shown in Table 3 and discussed in the appendix, demonstrate that large olivine phenocrysts tend to have higher ${ }^{3} \mathrm{He} /{ }^{4} \mathrm{He}$ than the smaller coexisting olivines. This grain size effect on ${ }^{3} \mathrm{He} /{ }^{4} \mathrm{He}$ appears to be larger for the high ${ }^{3} \mathrm{He} /{ }^{4} \mathrm{He}$ lavas. They have differences of 1.5 to $2.5 \mathrm{R}_{\mathrm{a}}$ between grain sizes, while the lower ${ }^{3} \mathrm{He} /{ }^{4} \mathrm{He}$ ratio samples have a range of 0.2 to $0.9 R_{a}$ between grain sizes. The helium concentrations in the olivine phenocrysts do not have any simple grain size dependence. It is not presently possible to distinguish between diffusive olivine reequilibration and trapping of different melt inclusion populations as the explanation for the helium isotopic variability with grain size. Either scenario would imply that the Mauna Kea magmatic system was changing rapidly, which is consistent with the rapid ${ }^{3} \mathrm{He} /{ }^{4} \mathrm{He}$ variability found in the down-core record. See appendix for further discussion.

\subsection{Helium in HSDP2 Pillow Glasses}

[16] Because of the relative rarity of olivine phenocrysts in the important 2200 to 2500 meter depth interval, helium measurements were performed on submarine pillow glasses for these samples. Basaltic glass has a significantly higher helium diffusivity than olivine [e.g., Kurz and Jenkins, 1981; Trull and Kurz, 1993] and significantly higher Th and $U$ contents, so glasses can be susceptible to degassing and contamination from atmospheric or radiogenic helium. Even though submarine glasses can also have higher helium concentrations than phenocrysts, pre-eruptive and syn-eruptive degassing can lead to huge variations 
Table 4 (Representative Sample). Electron Microprobe Data for Selected Olivine Grains From the Helium Grain Size Experiments and Orthopyroxene From SR714 (The full Table 4 is available in the HTML version of this article at http://www.g-cubed.org)

\begin{tabular}{|c|c|c|c|c|c|c|c|c|c|c|c|c|}
\hline Sample/Grain Size & Label & $\mathrm{SiO}_{2}$ & $\mathrm{TiO}_{2}$ & $\mathrm{Al}_{2} \mathrm{O}_{3}$ & $\mathrm{Cr}_{2} \mathrm{O}_{3}$ & $\mathrm{FeO}$ & $\mathrm{MnO}$ & $\mathrm{MgO}$ & $\mathrm{CaO}$ & $\mathrm{NiO}$ & Total & Fo \# \\
\hline SR354 & \multirow[t]{3}{*}{ Grain 1} & 39.86 & 0.0256 & 0.0513 & 0.0749 & 11.84 & 0.1605 & 47.37 & 0.2342 & 0.3914 & 100 & 0.877 \\
\hline \multirow[t]{14}{*}{$>2 \mathrm{~mm}$} & & 40.17 & 0.0082 & 0.0639 & 0.0447 & 11.67 & 0.1826 & 47.48 & 0.25 & 0.3806 & 100.25 & 0.879 \\
\hline & & 40.07 & 0.0127 & 0.0621 & 0.0671 & 11.63 & 0.1321 & 47.69 & 0.245 & 0.3839 & 100.3 & 0.880 \\
\hline & \multirow[t]{3}{*}{ Grain 2} & 39.84 & 0.0025 & 0.0501 & 0.0692 & 12.88 & 0.2029 & 46.36 & 0.2441 & 0.3804 & 100.03 & 0.865 \\
\hline & & 39.94 & 0.0052 & 0.0482 & 0.0585 & 13.12 & 0.2109 & 46.5 & 0.2463 & 0.333 & 100.46 & 0.863 \\
\hline & & 38.85 & 0.0266 & 0.0481 & 0.0745 & 16.48 & 0.2479 & 43.64 & 0.2219 & 0.3256 & 99.92 & 0.825 \\
\hline & \multirow[t]{3}{*}{ Grain 3} & 40.19 & 0.0077 & 0.0503 & 0.0403 & 11.54 & 0.1611 & 48.01 & 0.2409 & 0.3745 & 100.61 & 0.881 \\
\hline & & 40.24 & 0.0054 & 0.0497 & 0.0532 & 11.66 & 0.1862 & 47.97 & 0.223 & 0.3839 & 100.77 & 0.880 \\
\hline & & 40.37 & 0.0136 & 0.0596 & 0.0707 & 11.4 & 0.1768 & 48.03 & 0.2315 & 0.405 & 100.75 & 0.883 \\
\hline & \multirow[t]{3}{*}{ Grain 4} & 40.2 & 0.017 & 0.0506 & 0.0634 & 11.3 & 0.1672 & 48.19 & 0.2276 & 0.445 & 100.66 & 0.884 \\
\hline & & 40.14 & 0.0157 & 0.0569 & 0.0679 & 11.55 & 0.1875 & 48.21 & 0.2307 & 0.4604 & 100.92 & 0.881 \\
\hline & & 37.98 & 0.0286 & 0.0593 & 0.0591 & 21.31 & 0.3508 & 39.83 & 0.2033 & 0.3237 & 100.14 & 0.769 \\
\hline & \multirow[t]{3}{*}{ Grain 5} & 40.25 & 0.0206 & 0.0591 & 0.0655 & 12.03 & 0.1935 & 47.57 & 0.2331 & 0.4117 & 100.83 & 0.876 \\
\hline & & 40.06 & 0.013 & 0.0514 & 0.0705 & 11.94 & 0.1762 & 47.49 & 0.2167 & 0.3458 & 100.37 & 0.876 \\
\hline & & 39.02 & 0.0237 & 0.0433 & 0.0763 & 15.46 & 0.2416 & 44.1 & 0.2076 & 0.3113 & 99.49 & 0.836 \\
\hline \multirow[t]{15}{*}{$0.5-1.0 \mathrm{~mm}$} & \multirow[t]{3}{*}{ Grain 6} & 40.31 & 0.0078 & 0.0447 & 0.0585 & 10.95 & 0.1623 & 47.86 & 0.2199 & 0.3747 & 99.99 & 0.886 \\
\hline & & 40.36 & 0.0032 & 0.0459 & 0.0837 & 11.31 & 0.178 & 47.9 & 0.217 & 0.4168 & 100.52 & 0.883 \\
\hline & & 39.36 & 0.0224 & 0.0721 & 0.0636 & 14.82 & 0.2167 & 44.29 & 0.2063 & 0.3231 & 99.37 & 0.842 \\
\hline & \multirow[t]{3}{*}{ Grain 7} & 39.92 & 0.0162 & 0.0322 & 0.0554 & 12.94 & 0.2156 & 46.4 & 0.2534 & 0.3813 & 100.22 & 0.865 \\
\hline & & 39.9 & 0.0238 & 0.0309 & 0.0501 & 12.59 & 0.2221 & 46.57 & 0.2725 & 0.3855 & 100.04 & 0.868 \\
\hline & & 39.49 & 0.0162 & 0.0493 & 0.0536 & 13.18 & 0.2141 & 46.27 & 0.276 & 0.3181 & 99.86 & 0.862 \\
\hline & \multirow[t]{3}{*}{ Grain 8} & 40.01 & 0.011 & 0.0464 & 0.0509 & 13.31 & 0.1748 & 46.62 & 0.2623 & 0.3154 & 100.8 & 0.862 \\
\hline & & 39.79 & 0.0335 & 0.0537 & 0.0721 & 13.42 & 0.1857 & 46.53 & 0.2496 & 0.2915 & 100.62 & 0.861 \\
\hline & & 38.19 & 0.0363 & 0.0377 & 0.0484 & 19.3 & 0.3378 & 41.56 & 0.1795 & 0.3067 & 100 & 0.793 \\
\hline & \multirow[t]{3}{*}{ Grain 9} & 39.68 & 0.0128 & 0.0386 & 0.0678 & 12.66 & 0.189 & 46.98 & 0.2241 & 0.3902 & 100.24 & 0.869 \\
\hline & & 39.75 & 0.0338 & 0.0379 & 0.0701 & 12.8 & 0.189 & 46.81 & 0.2361 & 0.344 & 100.27 & 0.867 \\
\hline & & 37.98 & 0.0449 & 0.0456 & 0.0928 & 21.21 & 0.3122 & 39.2 & 0.1756 & 0.3314 & 99.4 & 0.767 \\
\hline & \multirow[t]{3}{*}{ Grain 10} & 39.7 & 0.0174 & 0.0428 & 0.0292 & 12.62 & 0.2096 & 46.73 & 0.2247 & 0.2917 & 99.86 & 0.868 \\
\hline & & 39.88 & 0.0264 & 0.0466 & 0.0487 & 13.06 & 0.186 & 46.76 & 0.228 & 0.2156 & 100.45 & 0.865 \\
\hline & & 37.68 & 0.032 & 0.0486 & 0.0674 & 20.57 & 0.2751 & 40.57 & 0.1898 & 0.2477 & 99.68 & 0.779 \\
\hline SR531 & \multirow[t]{3}{*}{ Grain 1} & 40.52 & 0.0132 & 0.05 & 0.101 & 10.31 & 0.1865 & 48.85 & 0.2057 & 0.4319 & 100.66 & 0.894 \\
\hline \multirow{14}{*}{$>2 \mathrm{~mm}$} & & 40.28 & 0.0001 & 0.0568 & 0.0934 & 10.47 & 0.1564 & 48.88 & 0.224 & 0.4276 & 100.59 & 0.893 \\
\hline & & 40.42 & 0.0035 & 0.0601 & 0.1036 & 10.45 & 0.1517 & 49 & 0.2022 & 0.3861 & 100.77 & 0.893 \\
\hline & \multirow[t]{3}{*}{ Grain 2} & 40.05 & 0.02 & 0.0626 & 0.1 & 10.92 & 0.1374 & 47.93 & 0.2155 & 0.437 & 99.86 & 0.887 \\
\hline & & 40.08 & 0.0047 & 0.056 & 0.0824 & 10.92 & 0.191 & 48.25 & 0.2313 & 0.4268 & 100.25 & 0.887 \\
\hline & & 40.12 & 0.0021 & 0.0558 & 0.0692 & 10.95 & 0.1421 & 48.5 & 0.2355 & 0.4724 & 100.54 & 0.888 \\
\hline & Grain 3 & 39.29 & 0.0124 & 0.0646 & 0.0502 & 12.44 & 0.1986 & 46.37 & 0.2277 & 0.3951 & 99.05 & 0.869 \\
\hline & & 39.2 & 0.0136 & 0.0521 & 0.0517 & 12.29 & 0.1498 & 46.47 & 0.2418 & 0.336 & 98.8 & 0.871 \\
\hline & & 38.66 & 0.0174 & 0.0433 & 0.0488 & 14.02 & 0.2077 & 45.28 & 0.2609 & 0.3302 & 98.87 & 0.852 \\
\hline & Grain 4 & 40.11 & 0.0016 & 0.0513 & 0.0704 & 11.28 & 0.1609 & 47.61 & 0.2074 & 0.4512 & 99.94 & 0.883 \\
\hline & & 39.89 & 0.0158 & 0.0579 & 0.0801 & 11.75 & 0.1687 & 47.7 & 0.2193 & 0.4449 & 100.32 & 0.879 \\
\hline & & 39.56 & 0.0233 & 0.0575 & 0.06 & 12.28 & 0.1528 & 47.45 & 0.2505 & 0.3808 & 100.22 & 0.873 \\
\hline & Grain 5 & 40.25 & 0.0082 & 0.0362 & 0.0693 & 11.63 & 0.153 & 47.76 & 0.2109 & 0.4102 & 100.52 & 0.880 \\
\hline & & 40.18 & 0 & 0.0466 & 0.096 & 11.53 & 0.2049 & 47.89 & 0.2237 & 0.4265 & 100.6 & 0.881 \\
\hline & & 40.03 & 0.0102 & 0.0465 & 0.0861 & 11.9 & 0.2064 & 47.81 & 0.21 & 0.4386 & 100.73 & 0.877 \\
\hline $0.5-1.0 \mathrm{~mm}$ & Grain 6 & 39.77 & 0.0203 & 0.0627 & 0.0863 & 12.12 & 0.1418 & 47.26 & 0.2106 & 0.3916 & 100.06 & 0.874 \\
\hline & & 39.96 & 0.0187 & 0.0515 & 0.0743 & 12.49 & 0.1685 & 47.17 & 0.2292 & 0.4092 & 100.57 & 0.871 \\
\hline & & 39.94 & 0.0344 & 0.0625 & 0.0422 & 13.52 & 0.1746 & 45.63 & 0.2855 & 0.3553 & 100.03 & 0.858 \\
\hline & Grain 7 & 39.11 & 0.0242 & 0.0559 & 0.0691 & 15.36 & 0.2339 & 44.61 & 0.2221 & 0.3535 & 100.04 & 0.838 \\
\hline & & 39.4 & 0.0313 & 0.0566 & 0.0695 & 15.43 & 0.2527 & 44.46 & 0.2332 & 0.3481 & 100.28 & 0.837 \\
\hline & & 39.02 & 0.0277 & 0.0447 & 0.0711 & 15.02 & 0.2466 & 44.66 & 0.2279 & 0.3197 & 99.64 & 0.841 \\
\hline & Grain 8 & 39.96 & 0.0223 & 0.0427 & 0.1065 & 11.22 & 0.0995 & 48.22 & 0.2025 & 0.4212 & 100.3 & 0.884 \\
\hline & & 39.82 & 0.0075 & 0.0548 & 0.0833 & 10.98 & 0.1435 & 47.81 & 0.2141 & 0.4205 & 99.53 & 0.886 \\
\hline & & 39.4 & 0.0002 & 0.0448 & 0.0918 & 11.17 & 0.1578 & 48.66 & 0.2193 & 0.3668 & 100.12 & 0.886 \\
\hline
\end{tabular}

\footnotetext{
${ }^{\text {a }}$ All oxide data are presented in weight percent. Fo \# is fraction forsterite $[\mathrm{Mg} /(\mathrm{Mg}+\mathrm{Fe})]$. Each grain has three spots: middle of the grain, midway to edge, and edge (respectively) to examine zoning. With the exception of SR0714, the first 5 grains are large grain size and the second 5 grains are small. The orthopyroxene grains (SR0714) did not include the grain edge, so the three spots do not necessary test for zoning. All data from MIT (N. Chatterjee, analyst).
} 
in gas contents. Several of the HSDP2 glasses have relatively high concentrations $\left(9 \times 10^{-8} \mathrm{cc} /\right.$ gram and $3.4 \times 10^{-7} \mathrm{cc}$ gram for SR829 and SR826), and the measured ${ }^{3} \mathrm{He} /{ }^{4} \mathrm{He}$ ratios in these samples probably represent the magmatic isotopic compositions. Pillow glass sample SR826 from $2400 \mathrm{~m}$ has the highest ${ }^{3} \mathrm{He} /{ }^{4} \mathrm{He}$ ratio, of $24.8 \mathrm{Ra}$, in the entire core. Even these glass samples, with the most helium, have concentrations more than ten times lower than MORB glasses. Volatile studies show that the HSDP2 pillow glasses have been variably outgassed (Stolper et al., submitted manuscript, 2004; Seaman et al., submitted manuscript, 2003). The glasses in Table 2 were selected for proximity in the core to "undegassed" pillow glass, based on the data and classification scheme of Seaman et al. (submitted manuscript, 2003). Unfortunately, we do not have volatile measurements on the same samples, but the low concentrations suggest extensive helium loss even in relatively undegassed sections of the HSDP2 core.

[17] The helium concentrations in most of the glass samples are sufficiently low (i.e., less than $10^{-7} \mathrm{cc} /$ gram) that the glass ${ }^{3} \mathrm{He} /{ }^{4} \mathrm{He}$ ratios must be viewed as lower limits, due to the possible contributions from atmospheric and radiogenic helium, both of which would lower ${ }^{3} \mathrm{He} /{ }^{4} \mathrm{He}$ ratios. The presence of atmospheric or radiogenic helium in the glasses is confirmed by the melting measurements (Table 2), which always have ${ }^{3} \mathrm{He} /{ }^{4} \mathrm{He}$ ratios lower than the crushing measurements. One sample (SR0956) has ${ }^{3} \mathrm{He} /{ }^{4} \mathrm{He}$ ratios lower than atmospheric (on melting only) which conclusively demonstrates the presence of radiogenic helium. Given the age of the HSDP2 lavas, it is likely that radiogenic helium is partly responsible for the low ${ }^{3} \mathrm{He} /{ }^{4} \mathrm{He}$ ratios in the glasses. The age of the core at 2200 to $2500 \mathrm{~m}$ is approximately $550 \mathrm{Ka}$ (W. D. Sharp et al., manuscript in preparation, 2003); during that time, decay of Th and U would produce approximately $3 \times 10^{-8} \mathrm{cc}{ }^{4} \mathrm{He} /$ gram (assuming $\mathrm{Th}=1.1$ and $\mathrm{U}=0.3 \mathrm{ppm}$ ). Crushing in vacuo selectively releases gases from vesicles, and only a small fraction of this radiogenic helium would be released, since it will primarily reside within the glass itself. However, helium isotopic data from samples with $\mathrm{He}$ concentrations lower than $10^{-8} \mathrm{ccSTP} / \mathrm{gram}$ (by crushing) must be viewed as lower limits, because release of even $1 \%$ of the radiogenic helium from the matrix would lower the ${ }^{3} \mathrm{He} /{ }^{4} \mathrm{He}$ ratio by more than $30 \%$. Many of the glasses have ${ }^{3} \mathrm{He} /{ }^{4} \mathrm{He}$ ratios that are lower than the coexisting olivines, and lower than 6 to $8 \mathrm{Ra}$, the probable lower limit for Mauna Kea, which suggests that many of the glass isotopic compositions are influenced by radiogenic and/ or atmospheric contamination. Samples with higher helium concentrations (greater than $10^{-8}$ ccSTP/gram) are less likely to be influenced by such contamination processes, and only five of the glass ${ }^{3} \mathrm{He} /{ }^{4} \mathrm{He}$ ratios are included in the magmatic depth profile (see Tables 1 and 2).

\subsection{Helium in Orthopyroxene Phenocrysts}

[18] Orthopyroxene phenocrysts were found in one of the reference suite intrusives (SR714-11.55). Because orthopyroxene is not a common phenocryst phase in oceanic basalts, helium was measured (by crushing and melting) in both olivine and orthopyroxene phenocrysts from this sample, in order to evaluate the olivine/orthopyroxene partitioning (Table 3). The magmatic (crushing) helium concentrations and isotopic composition of SR714 orthopyroxene are both significantly lower than the coexisting olivine $\left(1.08 \times 10^{-9} \mathrm{cc} \mathrm{STP} / \mathrm{gram}\right.$ and $8.85 \mathrm{Ra}$, compared to $1.12 \times 10^{-8} \mathrm{cc} \mathrm{STP} /$ gram and $11.8 \mathrm{Ra}$, respectively). The difference in isotopic composition may reflect crystallization of the olivine and orthopyroxene from different magmas, or radiogenic contributions. The electron microprobe data (Table 4) suggests that that the olivines and orthopyroxenes are out of equilibrium, because the $\mathrm{Fe} / \mathrm{Mg} \mathrm{K} \mathrm{d}_{\mathrm{d}}(\mathrm{Ol} / \mathrm{Opx})$ is significantly lower than expected (i.e., $\sim 0.6$, as opposed to $>1.0$ [Kinzler and Grove, 1992]). The orthopyroxene contains radiogenic ${ }^{4} \mathrm{He}$, as is shown by the low ${ }^{3} \mathrm{He} /{ }^{4} \mathrm{He}$ ratio obtained by melting (1.7 $\mathrm{Ra}$ compared to 11.1 Ra for olivine), which may also contribute to the lower crushed value. Using the magmatic (crushed) ${ }^{3} \mathrm{He} /{ }^{4} \mathrm{He}$ ratio to correct for radiogenic helium in the melted powder yields a magmatic ${ }^{4} \mathrm{He}$ content in the orthopyroxene of $3.4 \times 10^{-9}$, which is roughly 50 times lower than the olivine powder ${ }^{4} \mathrm{He}$ content. Taken at face value, this 
would imply that the crystal/melt helium partition coefficient is 50 times lower for orthopyroxene than for olivine. This calculation assumes that the orthopyroxene and olivine equilibrated with similar melts, ignores the possible influence of melt inclusions for determining phenocryst helium abundances, and must be viewed as preliminary.

[19] The orthopyroxene helium measurement is also noteworthy because the lower ${ }^{3} \mathrm{He} /{ }^{4} \mathrm{He}$ ratios, obtained by melting, imply that orthopyroxene might be used to determine emplacement ages. Unfortunately, the Th and U content of the orthopyroxenes are not well known. On the basis of the W. D. Sharp et al. (manuscript in preparation, 2003) age model, this section of the core is approximately $490 \mathrm{Ka}$ in age. Using this age, and the helium isotopic disequilibrium to calculate radiogenic helium, the thorium and uranium contents of the orthopyroxene would be approximately $0.02 \mathrm{ppm}$. This is significantly higher than would be predicted from the measured $\mathrm{Th}$ and $\mathrm{U}$ contents of SR714 (0.96 and 0.29 ppm, respectively [Huang and Frey, 2003]) and the highest literature values (i.e., maximum values) for the orthopyroxene/melt Th and $U$ partition coefficients $\left(\sim 3 \times 10^{-3}\right.$ and $8 \times$ $10^{-3}$ respectively [Blundy and Wood, 2003]); this could be explained by a small amount of groundmass $T h$ and $U$ adhering to the phenocrysts. Nevertheless, the measurements suggest that orthopyroxene could be used for independent age determinations.

\section{Discussion}

\subsection{Upper Mauna Kea Lavas}

[20] Relatively low ${ }^{3} \mathrm{He} /{ }^{4} \mathrm{He}$ ratios were observed at the top of the Mauna Kea section in the HSDP1 core [Kurz et al., 1996]. The new HSDP2 data show a similar trend and agree reasonably well with the pilot core, with ${ }^{3} \mathrm{He} /{ }^{4} \mathrm{He}$ ratios as low as 6 times atmospheric near the Mauna Kea-Mauna Loa transition. As illustrated by Figure 3, the upper Mauna Kea HSDP2 core lavas have the lowest ${ }^{3} \mathrm{He} /{ }^{4} \mathrm{He}$, ranging between 6 and $8.5 \mathrm{Ra}$, and the highest ${ }^{143} \mathrm{Nd} /{ }^{144} \mathrm{Nd}$ ratios (J. G. Bryce and D. J. DePaolo, manuscript in preparation, 2003), which was also found for the HSDP1 core [Kurz et al.,
1996; Lassiter et al., 1996]. The lavas near the top of the Mauna Kea section are also characterized by relatively low ${ }^{18} \mathrm{O} /{ }^{16} \mathrm{O}, \mathrm{SiO}_{2}$, and $\mathrm{Zr} / \mathrm{Nb}$, and high $\mathrm{Sm} / \mathrm{Yb}$ [Wang et al., 2003; Huang and Frey, 2003; Feigenson et al., 2003; Rhodes and Vollinger, 2004]. Huang and Frey [2003] distinguished the subaerial Mauna Kea lavas having low $\mathrm{SiO}_{2}$ from those deeper in the core. This distinction is well documented in Figures 8-9, which show that in the top $1000 \mathrm{~m}$, low $\mathrm{SiO}_{2}$ values (and also low $\mathrm{Zr}$ / $\mathrm{Nb})$ are associated with low ${ }^{3} \mathrm{He} /{ }^{4} \mathrm{He}$. In contrast, deeper in the core low $\mathrm{SiO}_{2}$ (and low $\mathrm{Zr} / \mathrm{Nb}$ ) contents are associated with higher ${ }^{3} \mathrm{He} /{ }^{4} \mathrm{He}$ ratios. The high $\mathrm{Sm} / \mathrm{Yb}$ has been interpreted as resulting from low degrees of melting in the presence of residual garnet [Huang and Frey, 2003; Feigenson et al., 2003]. The low $\mathrm{SiO}_{2}$ content in the subaerial Mauna Kea "post shield" lavas may be a melting effect and those from the submarine lavas may be related to source heterogeneities [Huang and Frey, 2003]. The low ${ }^{3} \mathrm{He} /{ }^{4} \mathrm{He}$ ratios overlap with MORB values, which most likely reflects ambient mantle contributions (as opposed to the plume), when plume influence was waning.

[21] Low $\delta^{18} \mathrm{O}$ values are unique to the subaerial Mauna Kea ( $\sim 4.8$ per mil, compared to 5.1 for submarine), and are roughly correlated with low ${ }^{3} \mathrm{He} /{ }^{4} \mathrm{He}$ ratios, which may relate to interaction with seawater altered crust or lithosphere [Wang et al., 2003]. However, helium is among the least sensitive indicators of crust and seawater interactions because there is so little helium in the hydrosphere, and because it is difficult to inject seawater helium into a magma. It is unlikely that the relatively low ${ }^{3} \mathrm{He} /{ }^{4} \mathrm{He}$ ratios found near the top of the HSDP2 core reflect the direct influence of atmospheric helium, because they are so consistently close to MORB values. Values lower than MORB would be expected if this were an important process for helium (see for example low values obtained by melting of glass powders in Table 2). If the low $\mathrm{Sm} / \mathrm{Yb}$ indicates greater depth of melting [Huang and Frey, 2003; Feigenson et al., 2003], it is possible that MORBlike ${ }^{3} \mathrm{He} /{ }^{4} \mathrm{He}$ ratios indicate melting of previously melted plume components. Helium may have been efficiently extracted by earlier melting in the upwelling plume [e.g., Kurz and Geist, 1999] leaving 
HSDP2 Mauna Kea only

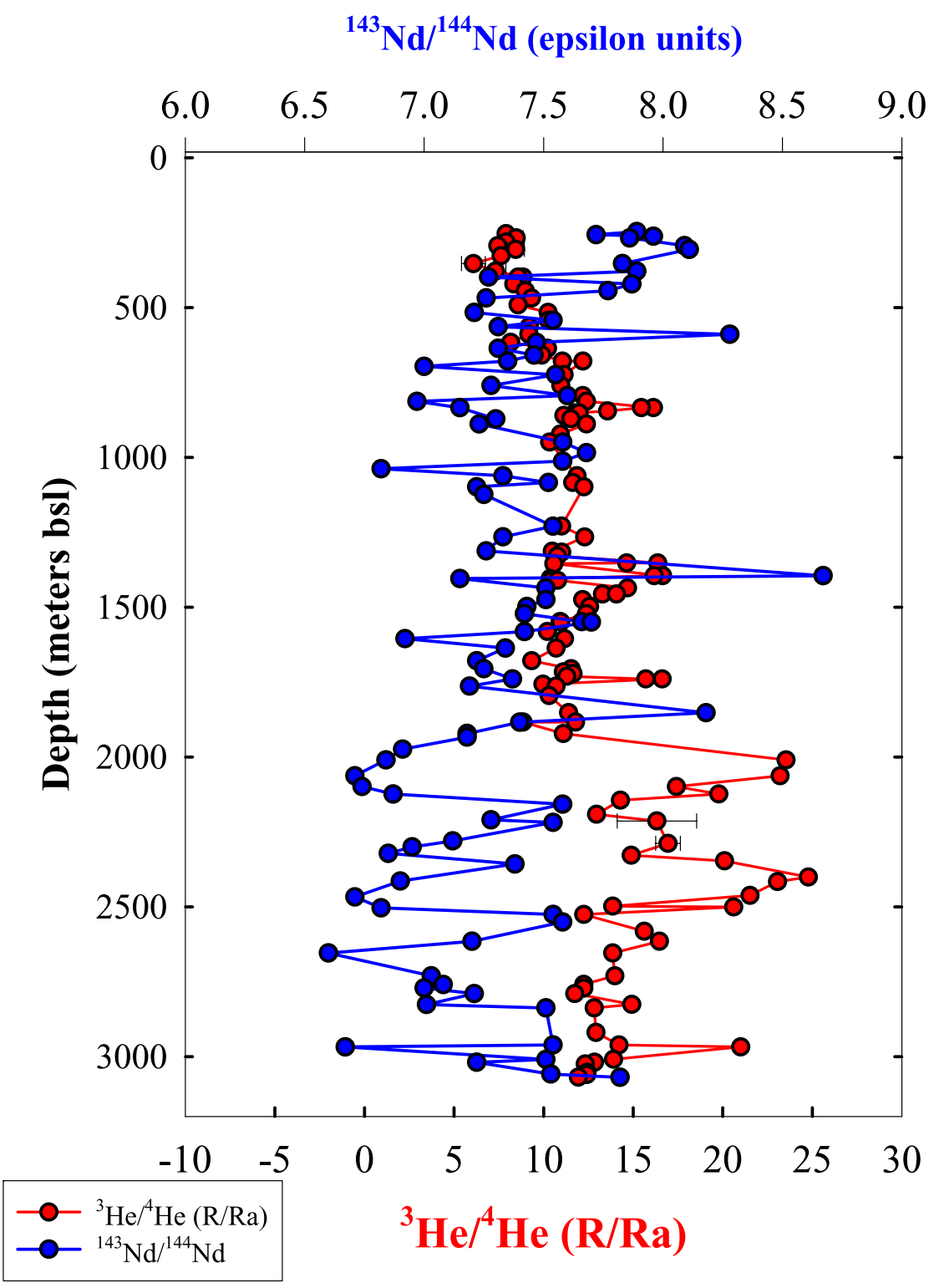

Figure 3. Helium and neodymium isotopic variations as a function of depth in the core (Nd isotopic data from J. G. Bryce and D. J. DePaolo (manuscript in preparation, 2003)). The two data sets are plotted together to allow direct comparison. Note that the high helium excursions deep in the core are accompanied by low Nd values. See also Figure 5 for a Nd-He plot.

the late stage Mauna Kea melts susceptible to domination by ambient mantle helium.

\subsection{Relationships Between Helium Isotopes and Other Geochemical Parameters in Mauna Kea}

[22] Most of the helium isotopic variability is found in the submarine Mauna Kea lavas, which dominate the correlations between helium isotopes and the other isotope systems. The largest neodymium isotopic variations are observed deeper in the core and low ${ }^{143} \mathrm{Nd} /{ }^{144} \mathrm{Nd}$ values are associated with the highest ${ }^{3} \mathrm{He} /{ }^{4} \mathrm{He}$ ratios (see Figure 3). The negative correlation between helium and neodymium isotopic variations suggest that there are changes in mantle sources, and that there is mixing between melts. 


\section{HSDP2 Mauna Kea only $87 \mathrm{Sr} / 86 \mathrm{Sr}$}

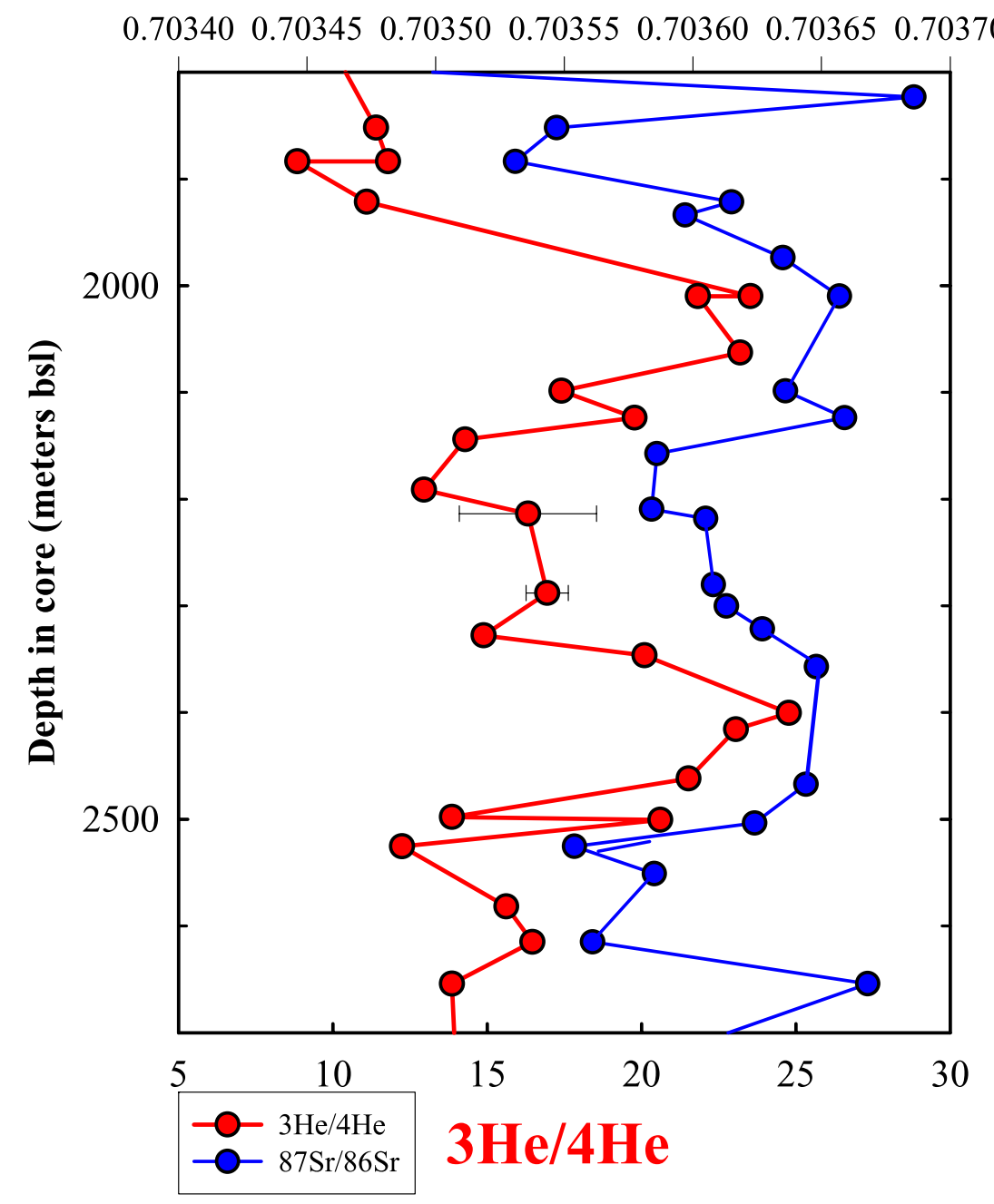

Figure 4. The ${ }^{87} \mathrm{Sr} /{ }^{86} \mathrm{Sr}$ and ${ }^{3} \mathrm{He} /{ }^{4} \mathrm{He}$ as a function of depth in the core for the interval 1800 to $2700 \mathrm{~m}$. These two parameters are not well correlated for the rest of the core, but show some coherence over this particular depth interval, which includes some of the highest ${ }^{3} \mathrm{He} /{ }^{4} \mathrm{He}$ ratios. As discussed in the text, it is significant that high ${ }^{3} \mathrm{He} /{ }^{4} \mathrm{He}$ ratios are associated with high ${ }^{87} \mathrm{Sr} /{ }^{86} \mathrm{Sr}$ ratios (see also Figure 5). Sr data from J. G. Bryce and D. J. DePaolo (manuscript in preparation, 2003).

[23] ${ }^{87} \mathrm{Sr} /{ }^{86} \mathrm{Sr}$ in the HSDP2 core shows a very small range, from0.7035 to 0.70369 (J. G. Bryce and D. J. DePaolo, manuscript in preparation, 2003). For the purposes of interpreting the helium data, it is noteworthy that these values are significantly higher than normal MORB values ( $\sim 0.7022$ to 0.7028$)$, and that the variations are not as well correlated with helium as $\mathrm{Nd}$ isotopes. However, between depths of 1800 and $2500 \mathrm{~m}$ in the core the $\mathrm{Sr}$ and $\mathrm{He}$ isotopic variations appear to correlate, with high ${ }^{3} \mathrm{He} /{ }^{4} \mathrm{He}$ ratios associated with elevated ${ }^{87} \mathrm{Sr} /{ }^{86} \mathrm{Sr}$ (see Figure 4). Figure 5 shows the $\mathrm{Sr}-\mathrm{Nd}-\mathrm{He}$ isotopic data from the HSDP2 core with respect to the other volcanoes on the island of Hawaii. The relatively small range in $\mathrm{Sr}$ and $\mathrm{Nd}$ isotopic data is apparent, but there is overlap with values from Loihi seamount. The highest ${ }^{3} \mathrm{He} /{ }^{4} \mathrm{He}$ samples from Mauna Kea, having slightly higher ${ }^{87} \mathrm{Sr} /{ }^{86} \mathrm{Sr}$, and generally lower ${ }^{143} \mathrm{Nd} /{ }^{144} \mathrm{Nd}$, are found deep in the HSDP2 core overlap with the 

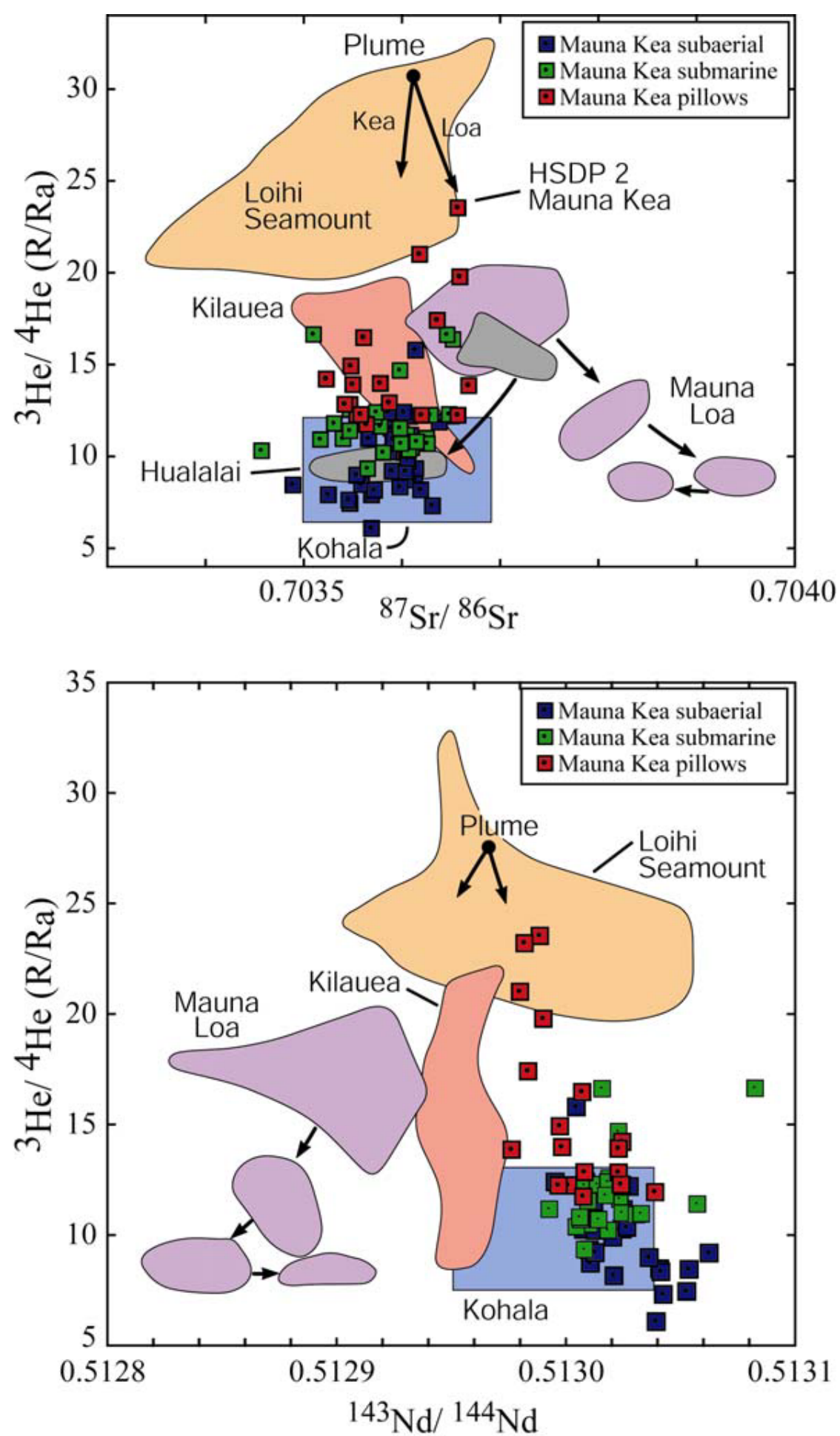

Figure 5. Helium isotopic variations for Hawaiian volcanoes, compared to strontium and neodymium isotopic variations (island of Hawaii only). Data sources are as follows: Mauna Loa [Kurz and Kammer, 1991; Kurz et al., 1995], Loihi Seamount [Kurz et al., 1982, 1983; Staudigel et al., 1984]; Hualalai [Kurz, 1993, and Kurz, unpublished data, 2002); Kilauea, unpublished data this laboratory, and Kohala [Graham et al., 1990]. The arrows associated with the Mauna Loa show time evolution from old $(\sim 200 \mathrm{Ka})$ to young (historical) lavas. Note that the oldest Mauna Kea and Mauna Loa lavas have isotopic compositions that are closest to Loihi seamount. HSDP2 Sr and Nd data are from J. G. Bryce and D. J. DePaolo (manuscript in preparation, 2003)]. 

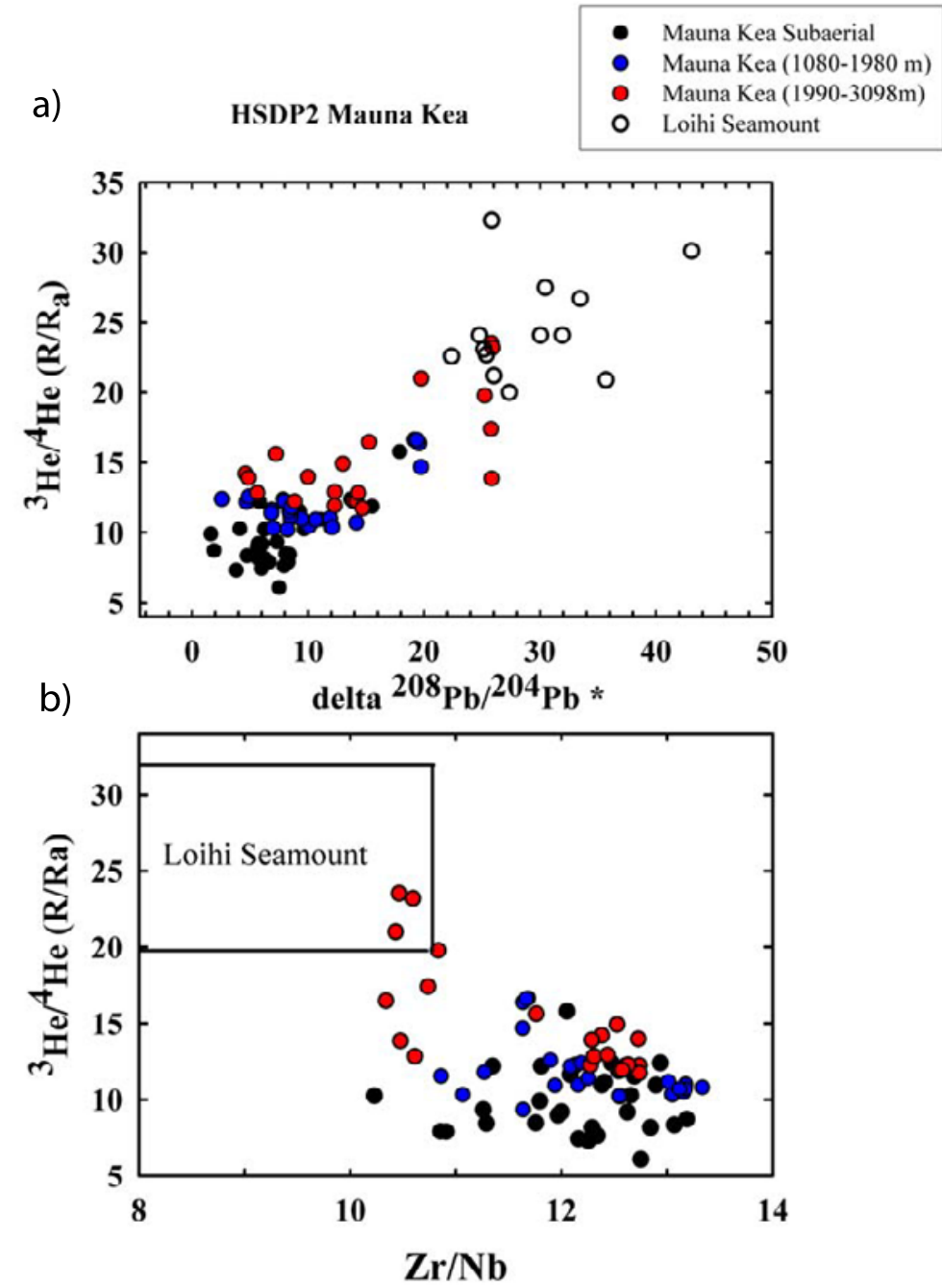

Figure 6. (a) Delta ${ }^{208} \mathrm{~Pb} /{ }^{204} \mathrm{~Pb}$ plotted against ${ }^{3} \mathrm{He} /{ }^{4} \mathrm{He}$ for the Mauna Kea HSDP 2 data. Pb data are from BlichertToft et al. [2003] and Eisele et al. [2003]. Delta ${ }^{208} \mathrm{~Pb} /{ }^{204} \mathrm{~Pb}$ is deviation from a northern hemisphere reference line as defined by Hart [1984b] (Delta ${ }^{208} \mathrm{~Pb} /{ }^{204} \mathrm{~Pb}=100\left[{ }^{208} \mathrm{~Pb} /{ }^{204} \mathrm{Pbmeas}-\left(1.209 *{ }^{206} \mathrm{~Pb} /{ }^{204} \mathrm{Pbmeas}+15.627\right)\right]$ ). High values of delta ${ }^{208} \mathrm{~Pb} /{ }^{204} \mathrm{~Pb}$ indicate ${ }^{208} \mathrm{~Pb} /{ }^{204} \mathrm{~Pb}$ values that are relatively high (for a particular ${ }^{206} \mathrm{~Pb} /{ }^{204} \mathrm{~Pb}$ on a Pb-Pb diagram) suggesting elevated values of $\mathrm{Th} / \mathrm{U}$. Delta ${ }^{208} \mathrm{~Pb} /{ }^{204} \mathrm{~Pb}$ is similar to ${ }^{208} \mathrm{~Pb}^{*} /{ }^{206} \mathrm{~Pb} *$ in indicating high ${ }^{208} \mathrm{~Pb} /{ }^{204} \mathrm{~Pb}$ values. (b) $\mathrm{Zr} / \mathrm{Nb}$ plotted against $3 \mathrm{He} / 4 \mathrm{He}$ for the Mauna Kea HSDP data. $\mathrm{Zr} / \mathrm{Nb}$ data from Rhodes and Vollinger [2004].

isotopic values found for Loihi seamount (see also Figure 5). Loihi seamount has the highest Hawaiian ${ }^{3} \mathrm{He} /{ }^{4} \mathrm{He}$ ratios, which has been used to argue that it best represents the center of the plume [e.g., Kurz et al., 1983, 1995, 1996]. The $\mathrm{Sr}$ and $\mathrm{Nd}$ isotopic data are consistent with this hypothesis because they define a trend that could result from mixing with a plume "end-member" having Loihi characteristics. It is noteworthy that the Mauna Kea data display a slightly larger helium isotopic variability than Mauna Loa, but a significantly smaller $\mathrm{Sr}$ and $\mathrm{Nd}$ isotopic variability. This comparison is hampered by the variable timescales for the different Hawaiian volcanoe data sets. For example, most of the Mauna Loa isotopic variability is observed in samples that are less than $20 \mathrm{Ka}$ in age, based on ${ }^{14} \mathrm{C}$ chronology. 


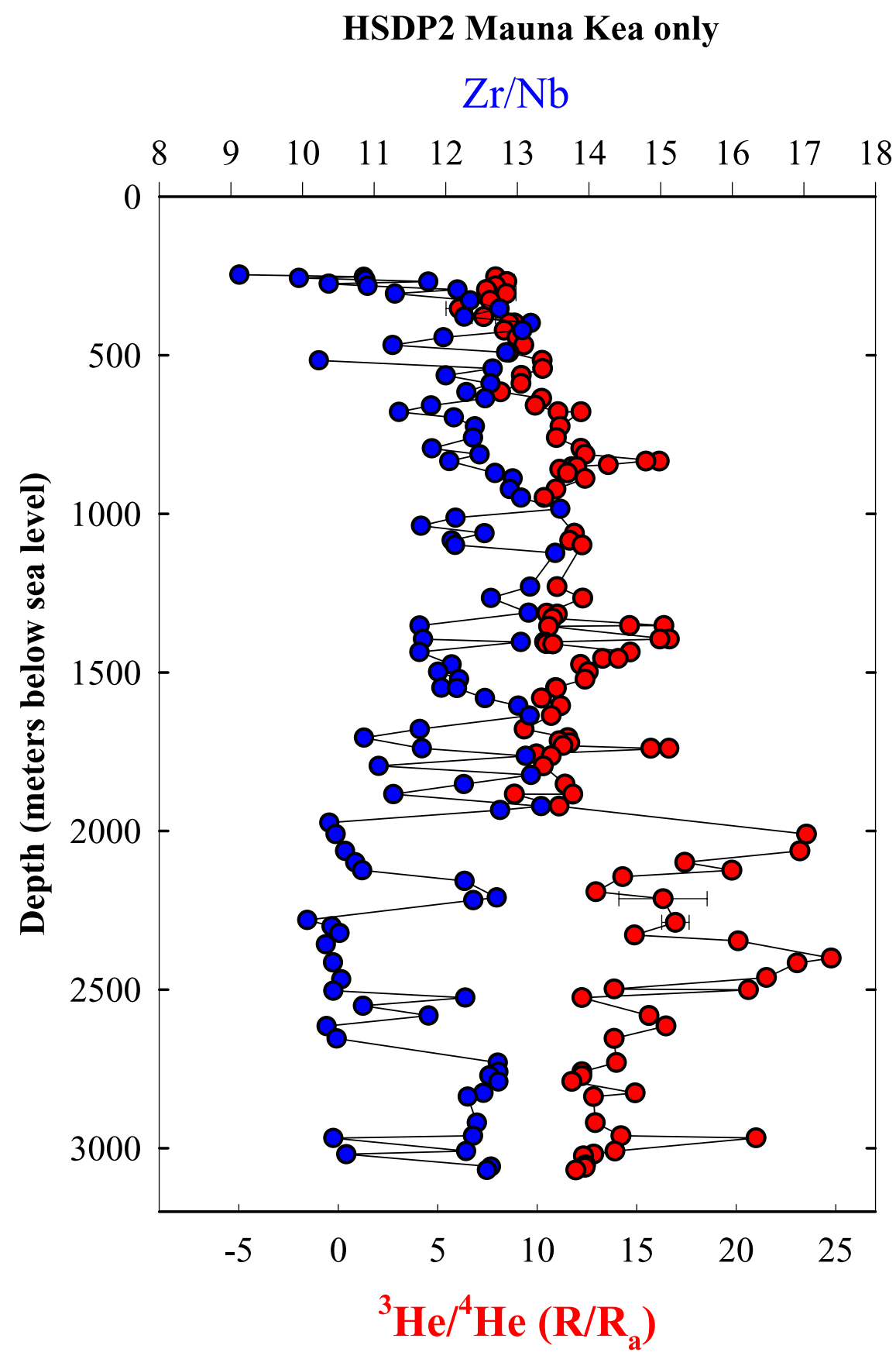

Figure 7. The helium isotopic variations (red symbols, axis on bottom) compared to $\mathrm{Zr} / \mathrm{Nb}$ variations (blue symbols, axis on top) with depth. $\mathrm{Zr} / \mathrm{Nb}$ ratios are from Rhodes and Vollinger [2004].

[24] There is a striking positive correlation between helium and lead isotopes. As also discussed by Blichert-Toft et al. [2003] and Eisele et al. [2003], the highest ${ }^{3} \mathrm{He} /{ }^{4} \mathrm{He}$ ratios are found in lavas with the highest delta ${ }^{208} \mathrm{~Pb} /{ }^{204} \mathrm{~Pb}$ ratios. This is illustrated in Figure 6 which shows the delta ${ }^{208} \mathrm{~Pb} /{ }^{204} \mathrm{~Pb}$ ratios plotted against ${ }^{3} \mathrm{He} /{ }^{4} \mathrm{He}$. The parameter delta ${ }^{208} \mathrm{~Pb} /{ }^{204} \mathrm{~Pb}$ is calculated relative to the northern hemisphere reference line [Hart, 1984b], which also passes through the Hawaiian data. High values of delta ${ }^{208} \mathrm{~Pb} /{ }^{204} \mathrm{~Pb}$ indicate a long term elevation of $\mathrm{Th} / \mathrm{U}$. This implies that the high ${ }^{3} \mathrm{He} /{ }^{4} \mathrm{He}$ ratios are associated with relatively high time-integrated $\mathrm{Th} / \mathrm{U}$ ratios. Eiler et al. [1998] previously noted a correlation between ${ }^{208} \mathrm{~Pb} /{ }^{204} \mathrm{~Pb}$ and ${ }^{3} \mathrm{He} /{ }^{4} \mathrm{He}$ in Hawaiian lavas; the new HSDP 
data support this and also define a linear trend with Loihi seamount as possible mixing end-member (see Figures 5 and 6).

[25] The high ${ }^{3} \mathrm{He} /{ }^{4} \mathrm{He}$ ratio excursions in the core are also seen in major and trace elements, as illustrated here for silica and $\mathrm{Zr} / \mathrm{Nb}$ (Figures 7 and 8), and discussed elsewhere [Huang and Frey, 2003; Rhodes and Vollinger, 2004]. As with the $\mathrm{Pb}$ isotopes, we use a delta $\mathrm{SiO}_{2}$ parameter. Delta $\mathrm{SiO}_{2}$ is defined by deviation from a linear regression through a plot of $\mathrm{MgO}$ versus $\mathrm{SiO}_{2}$, with subaerial Mauna Kea as a reference. Delta $\mathrm{SiO}_{2}$ values of zero are on the subaerial reference line, negative values have lower $\mathrm{SiO}_{2}$ for a particular $\mathrm{MgO}$ and positive values have higher $\mathrm{SiO}_{2}$ for a particular $\mathrm{MgO}$ (see Rhodes and Vollinger [2004] for a $\mathrm{MgO}$ versus $\mathrm{SiO}_{2}$ plot). As discussed above (and in Huang and Frey [2003] and Rhodes and Vollinger [2004]), there are two distinct low $\mathrm{SiO}_{2}$ trends in the core. Near the top of the Mauna Kea section low $\mathrm{SiO}_{2}$ contents are associated with relatively low ${ }^{3} \mathrm{He} /{ }^{4} \mathrm{He}$ ratios (i.e., close to the MORB values). In the submarine section of the HSDP2 core, low $\mathrm{SiO}_{2}$ are associated with high ${ }^{3} \mathrm{He} /{ }^{4} \mathrm{He}$ ratios. The relationship between helium and $\mathrm{Zr} / \mathrm{Nb}$ also varies with depth. In the submarine lavas, high ${ }^{3} \mathrm{He} /{ }^{4} \mathrm{He}$ ratios are associated with low $\mathrm{Zr} / \mathrm{Nb}$, whereas in the top of the HSDP2 core the lowest ${ }^{3} \mathrm{He} /{ }^{4} \mathrm{He}$ are associated with low $\mathrm{Zr} / \mathrm{Nb}$. Huang and Frey [2003] attribute the low $\mathrm{Zr} / \mathrm{Nb}$ in the top of the core to low degree of partial melting.

[26] The "spikes" in helium isotopic composition are reflected in the isotopic, major element, and trace element composition of the HSDP2 lava flows [Huang and Frey, 2003; Rhodes and Vollinger, 2004]. As illustrated in Figures 3-8, the high ${ }^{3} \mathrm{He} /{ }^{4} \mathrm{He}$ excursions are generally associated with low ${ }^{143} \mathrm{Nd} /{ }^{144} \mathrm{Nd}$, high ${ }^{208} \mathrm{~Pb} /{ }^{204} \mathrm{~Pb}$, low $\mathrm{SiO} 2$, and low $\mathrm{Zr} / \mathrm{Nb}$ in the HSDP2 whole rocks. There are additional correlations with other geochemical parameters as discussed further below, but Figures 3-8 show that helium is strongly coupled to other trace element and isotopic parameters. Although it is quite likely that the grain size dependence of the helium isotopic variations (discussed in the Appendix A) are caused by hetero- geneous populations of melt inclusions, or diffusive helium re-equilibration, this strong coherence shows that such effects are minor. The correlations between helium and the other geochemical parameters imply that the spikes are caused by changes in the magma source.

\section{Mauna Kea Temporal Evolution}

\subsection{Age Model and Comparison to Mauna Loa}

[27] The "standard model" for helium isotopes would explain the high ${ }^{3} \mathrm{He} /{ }^{4} \mathrm{He}$ ratios as an indication of less degassed mantle, and the spikes would therefore reflect an influx of magma from the center of the Hawaiian plume. The excellent resolution of the HSDP2 core allows estimation of the spike duration, which can be used to constrain magmatic volumes [e.g., Albarède, 1993; Pietruszka and Garcia, 1999a]. Ar-Ar determinations (W. D. Sharp et al., manuscript in preparation, 2003) provide several ages as a function of depth in the HSDP2 core. It is important to note that the age depth model derived from these Ar-Ar dates is speculative in several respects. There are a number of Ar-Ar dates in the top of the core, where higher K contents make the measurements more robust, but the age-depth model rests heavily on a few age determinations near the base of the core (W. D. Sharp et al., manuscript in preparation, 2003). The age depth model also explicitly assumes steady state, non-episodic, eruption rates, which is unlikely over such a long timescale. The occurrence of intrusive units is an obvious problem for the age model. These considerations make the shortest timescales the most uncertain.

[28] Figure 9 shows the HSDP2 Mauna Kea helium data plotted as a function of model age (compare to Figure 2, which has depth as the y axis). Despite the uncertainties in the age model, a number of important and robust generalizations emerge. First, it is obvious that all of the high ${ }^{3} \mathrm{He} /{ }^{4} \mathrm{He}$ spikes occur in Mauna Kea lavas that are older than $380 \mathrm{Ka}$. The youngest lavas in the Mauna Kea section are $\sim 200 \mathrm{Ka}$ (before present) in age, so the final $100 \mathrm{Ka}$ of Mauna Kea eruptions (i.e., 200-300 Ka before present; see Figure 9) had 


\section{HSDP2 Mauna Kea}

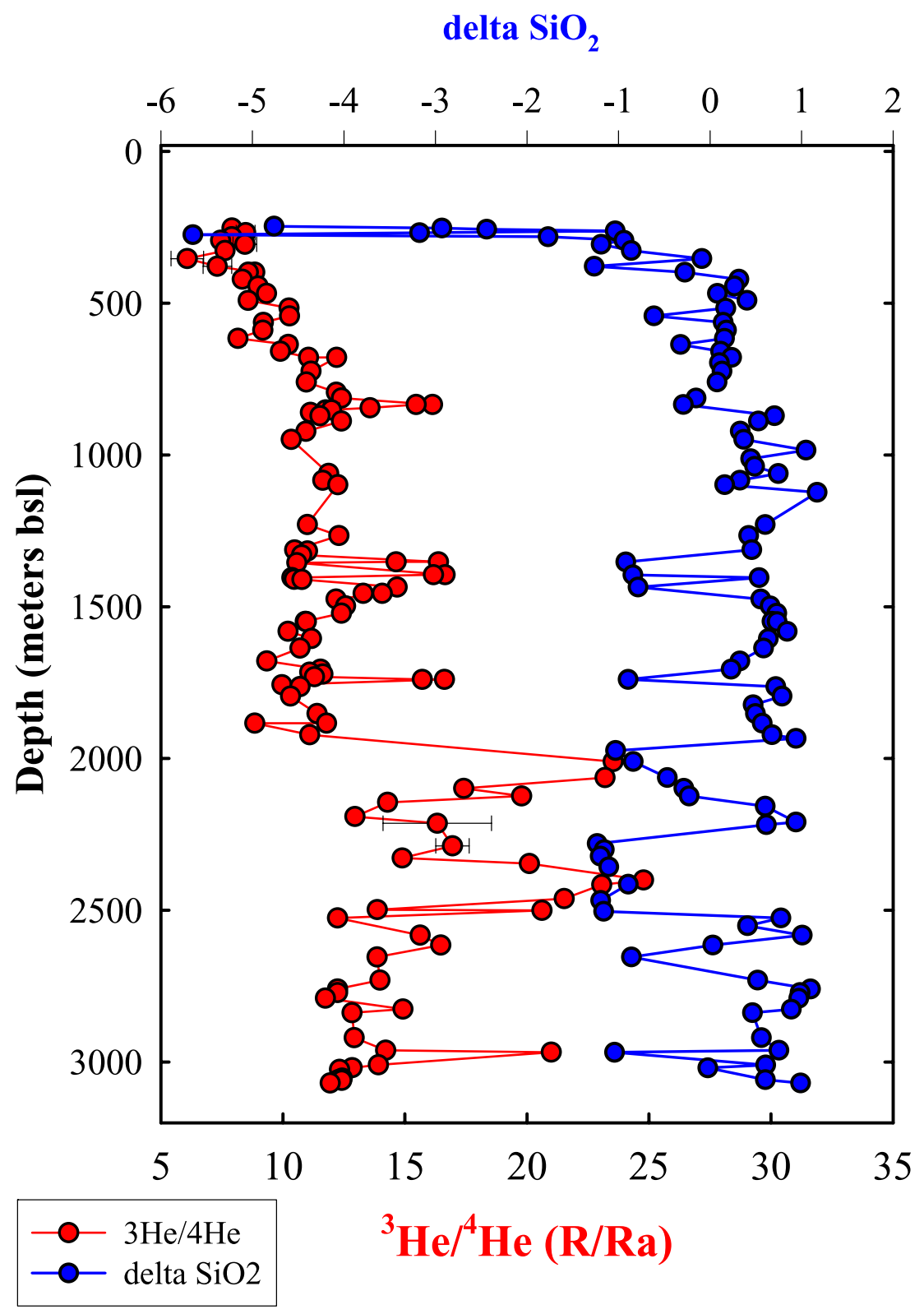

Figure 8. Depth variations of ${ }^{3} \mathrm{He} /{ }^{4} \mathrm{He}$ ratio (red symbols, axis at bottom) compared to delta $\mathrm{SiO}_{2}$ (blue symbols, axis on top). Delta $\mathrm{SiO}_{2}$ is calculated as deviation from the subaerial Mauna Kea trend on a $\mathrm{MgO}-\mathrm{SiO}_{2}$ diagram, so negative values imply lower amounts of $\mathrm{SiO}_{2}$ for a given $\mathrm{MgO} . \mathrm{SiO}_{2}$ data are from Rhodes and Vollinger [2004]. 

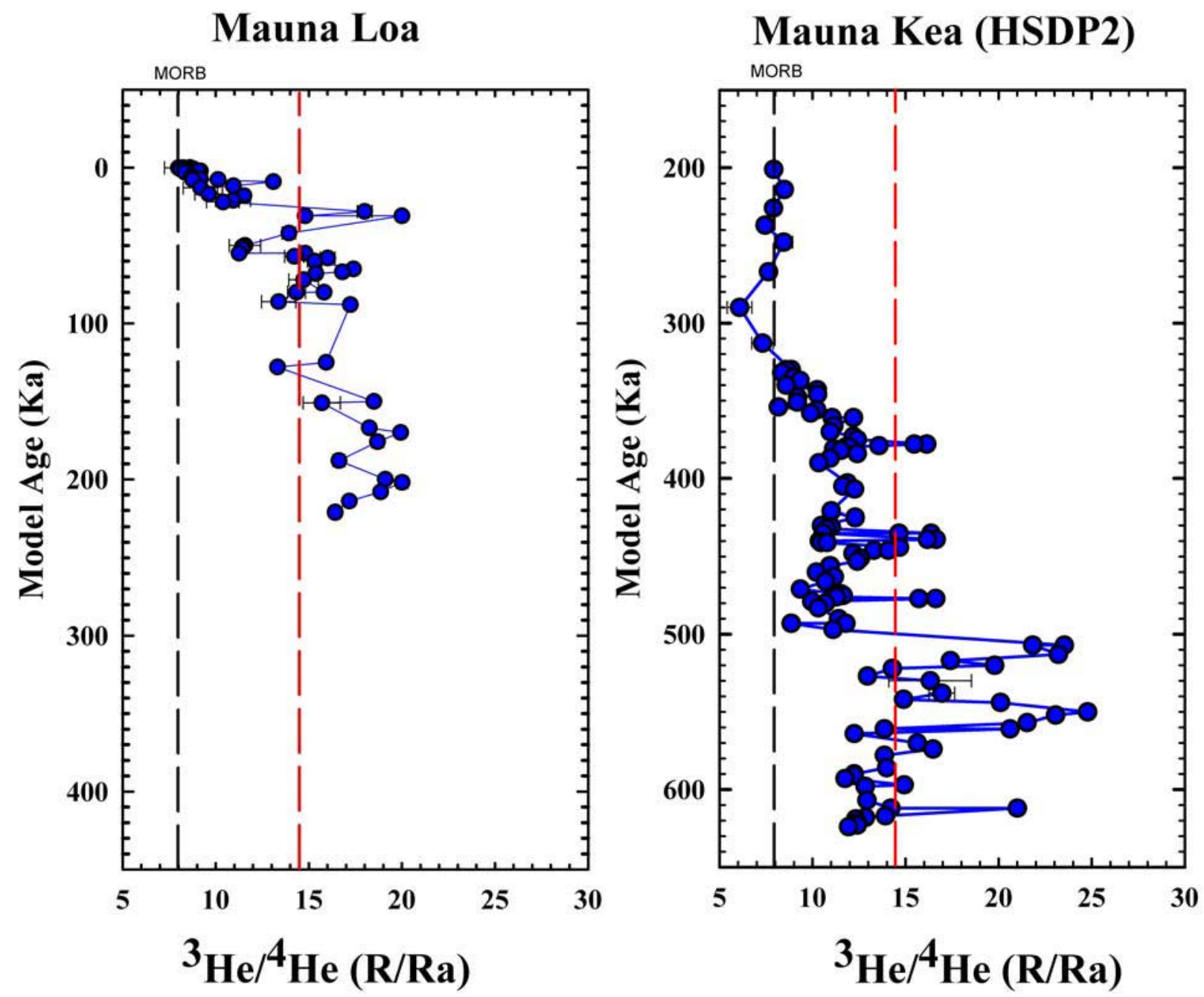

Figure 9. Helium isotopic variations with age in the Mauna Kea HSDP2 core (right, this paper) compared to those of Mauna Loa (left, from Kurz et al. [1996]). In both panels the red dashed lines shows the ${ }^{3} \mathrm{He} /{ }^{4} \mathrm{He}$ value (14.5 Ra) used to define the "spikes" in the HSDP2 lavas and the dark dashed line shows typical MORB values ( 8 Ra). The age model is that of DePaolo and Stolper [1996] and DePaolo et al. [2001] for Mauna Loa, and W. D. Sharp et al. (manuscript in preparation, 2003) for Mauna Kea. Note that all the spikes in ${ }^{3} \mathrm{He} /{ }^{4} \mathrm{He}$ ratios occur in HSDP2 Mauna Kea lavas that are older than $3800 \mathrm{Ka}$, and that the variations in the last $200 \mathrm{Ka}$ are much smaller. Age model of W. D. Sharp et al. (manuscript in preparation, 2003): Age $(\mathrm{Ka})=-24+\operatorname{Depth}(\mathrm{m}) * .89(<382 \mathrm{~m} \mathrm{depth})$ and Age $=286+$ Depth $(\mathrm{m}) * 0.11$ (>382 $\mathrm{m}$ depth).

relatively low ${ }^{3} \mathrm{He} /{ }^{4} \mathrm{He}$ ratios, close to the MORB value. For the $100 \mathrm{Ka}$ prior to that $(300-400 \mathrm{Ka}$ before present) the ${ }^{3} \mathrm{He} /{ }^{4} \mathrm{He}$ ratios are slightly higher for the oldest flows, up to roughly 10$11 \mathrm{Ra}$ at $400 \mathrm{Ka}$, which is consistent with the HSDP1 data [Kurz et al., 1996]. However, the prominent ${ }^{3} \mathrm{He} /{ }^{4} \mathrm{He}$ spikes are only found in HSDP2 lavas older than $400 \mathrm{Ka}$ in age.

[29] Figure 9 also shows previously published helium data for Mauna Loa [Kurz and Kammer,
1991; Kurz et al., 1995; DePaolo et al., 2001] on a timescale similar to the Mauna Kea HSDP2 data. The Mauna Loa samples younger than $30 \mathrm{Ka}$ are radiocarbon dated [Kurz and Kammer, 1991], and ages for the older samples are assigned absolute ages using the age model of Stolper and DePaolo [1996; see DePaolo et al., 2001]. At Mauna Loa, the transition from high to low ${ }^{3} \mathrm{He} /{ }^{4} \mathrm{He}$ ratios took place fairly recently, in a single step roughly $10 \mathrm{Ka}$ before present [Kurz and Kammer, 1991]. As illustrated in Figure 9, prior to that time the 


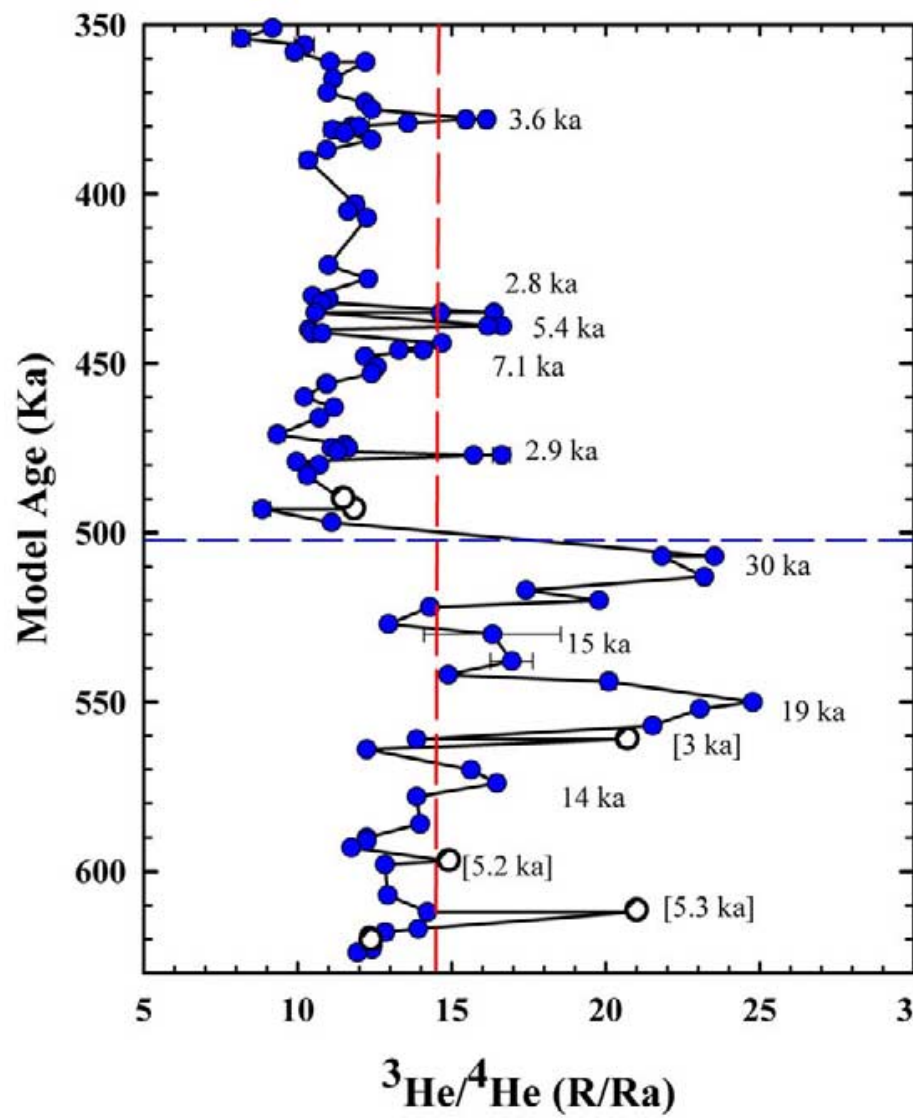

submarine/ hyaloclastites

Figure 10. Helium isotopic variations with age in the lower part of the HSDP2 Mauna Kea core, based on the age model of W. D. Sharp et al. (manuscript in preparation, 2003). The red dashed line shows the value (14.5 Ra) used to define spikes in ${ }^{3} \mathrm{He} /{ }^{4} \mathrm{He}$. The numbers at right denote the calculated duration of each spike. Open symbols (durations in parenthesis) are intrusive units which do not conform to the age model.

${ }^{3} \mathrm{He} /{ }^{4} \mathrm{He}$ ratios were uniformly higher than $14.5 \mathrm{Ra}$, with few excursions, for roughly $200 \mathrm{Ka}$. There are significant uncertainties in the age assignments for the older Mauna Loa lavas from different parts of the volcano (i.e., those older than the radiocarbon dating).

[30] The Mauna Loa stratigraphic section is based on a combination of surficial, submarine, and HSDP1 flows, and is not as long, or well resolved, as the Mauna Kea HSDP2 section. However, the Mauna Loa temporal record differs markedly from Mauna Kea in having constant and relatively high ${ }^{3} \mathrm{He} /{ }^{4} \mathrm{He}$ ratios for most of its history. There are no other detailed stratigraphic/geochemical records with which to compare, but this fundamental difference between Mauna Loa and Mauna Kea may reflect proximity to the plume center, and the geometry of the Loa and Kea volcanic chains, as discussed further below.

\subsection{Duration of the Helium Spikes}

[31] If we define an excursion, or "spike", as any lava flow, or series of flows, in the HSDP2 core with ${ }^{3} \mathrm{He} /{ }^{4} \mathrm{He}$ ratios that are higher than $14.5 \mathrm{Ra}$, there are 12 such excursions in the Mauna Kea section. One is in the subaerial section and eleven are in the submarine section of the core; 4 are in the shallow submarine section (1060 to $1950 \mathrm{~m}$ depth, where hyaloclastites appear) and 7 in the deeper submarine section (1950 to $3030 \mathrm{~m}$ depth, where pillow lavas appear). We define the spike duration as the minimum age difference between the closest bracketing lavas with baseline ${ }^{3} \mathrm{He} /{ }^{4} \mathrm{He}$ ratios; the 

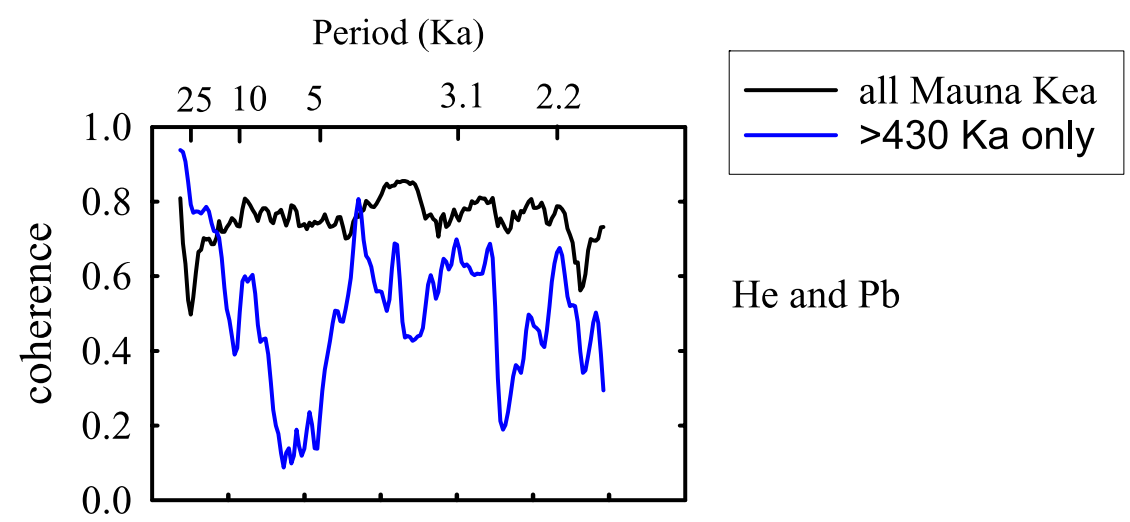

$\mathrm{He}$ and $\mathrm{Pb}$

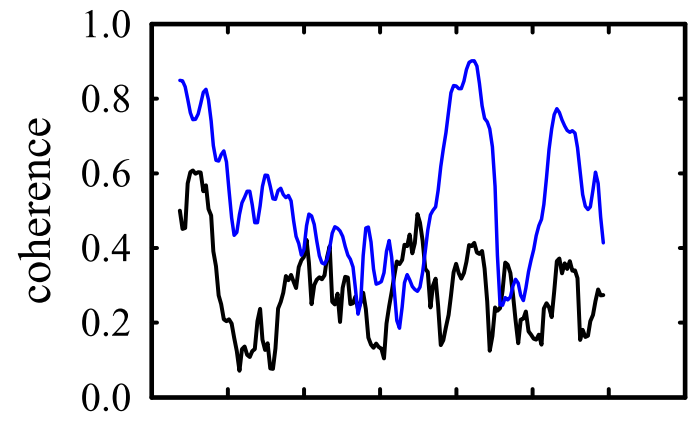

$\mathrm{He}$ and $\mathrm{Zr} / \mathrm{Nb}$

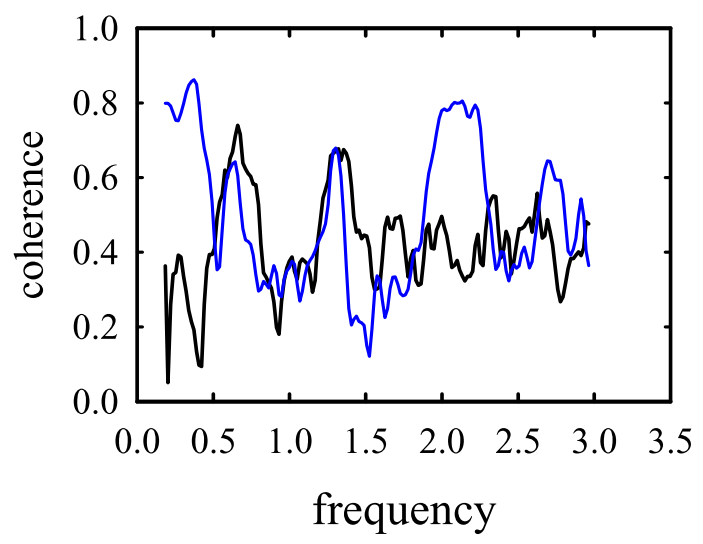

$\mathrm{He}$ and $\mathrm{SiO} 2$

Figure 11. Coherence for ${ }^{3} \mathrm{He} /{ }^{4} \mathrm{He}$ and delta ${ }^{208} \mathrm{~Pb} /{ }^{204} \mathrm{~Pb}, \mathrm{Zr} / \mathrm{Nb}$, and $\mathrm{SiO}_{2}$ as a function of frequency for all Mauna Kea HSDP2 data (black line) and for submarine HSDP2 only (blue line). Period is shown at top (period $=2 \pi / f$ ).

"baseline" ${ }^{3} \mathrm{He} /{ }^{4} \mathrm{He}$ ratios increase with depth. As illustrated by Figure 10, the spike duration varies between 2.8 and $30 \mathrm{Ka}$. Three of the spikes are found in putatively intrusive units, and three are defined by single lava flows, which makes the spike duration a questionable concept in these cases. Excluding the intrusive units and single lava flows, the average spike duration is $15( \pm 9) \mathrm{Ka}$. We emphasize the uncertainties in the age model particularly for such short duration events.

[32] Despite the uncertainties in the age model, the durations of these geochemical changes can place constraints on magma reservoir sizes and magma chamber residence times. A large and long-lived magma chamber would homogenize the geochemical variations observed here, and the HSDP2 data are therefore inconsistent with large, long-lived, magma chambers beneath Mauna Kea prior to $380 \mathrm{Ka}$. Note that most of the geochemical variations are observed in the HSDP2 submarine sections, so it is possible that the magma chamber size changed as Mauna Kea evolved, with smaller more ephemeral chambers beneath early Mauna Kea. Geochemical variations between historical lavas at Kilauea also suggest a small magma 
chamber [Pietruszka and Garcia, 1999a, 1999b]. The duration of the HSDP2 Mauna Kea variations is also very short, although the time-scale resolution is not adequate to directly compare with Kilauea the neighboring volcano.

\subsection{Time Series}

[33] The relatively dense geochemical sampling of lava flows from Mauna Kea and the availability of an age model make it possible to use time series methods to quantitatively evaluate temporal variability. To investigate the relationships between helium isotopes and other geochemical variations, we estimated the coherence between the reconstructed time series. Coherence is a standard measure of dependence between time series [Priestley, 1981]. It is based on the representation of a time series as a weighted integral of sinusoids of different frequency. For a fixed frequency $\omega$, the coherence can be interpreted as the correlation coefficient between the random weights in this integral representation of the two time series at this frequency. Because coherence does not account for phase differences that can give rise to negative cross-correlations between the original time series, it is constrained to lie between 0 and 1 .

[34] The estimation of coherence from regularly spaced time series is discussed in many time series texts [e.g., Priestley, 1981]. In the case of the HSDP2 core, the reconstructed time series are not regularly spaced and an alternative approach to estimation is needed. Here, we adapt the approach of Chan et al. [1998] for the estimation of the spectral density of a single time series from irregularly spaced observations. Consider an irregularly spaced time series $X_{t_{1}}$, $X_{t_{2}}, \ldots, X_{t_{\mathrm{n}}}$ where $X_{t_{k}}$ is the value of the time series at time $t_{k}$ and define the quantities:

$$
\begin{aligned}
& A_{X}(\omega)=\sum_{k=2}^{n} X_{t_{k}} \cos \left(\omega t_{k}\right)\left(t_{k}-t_{k-1}\right) \\
& B_{X}(\omega)=\sum_{k=2}^{n} X_{t_{k}} \sin \left(\omega t_{k}\right)\left(t_{k}-t_{k-1}\right)
\end{aligned}
$$

A slightly modified version of the periodogram proposed by Chan et al. [1998] can be written as:

$$
I_{X}(\omega)=\left(A_{X}^{2}(\omega)+B_{X}^{2}(\omega)\right) / T
$$

where $T$ is the total length of the observation period. This is essentially a discrete approximation to the periodogram of a continuous parameter stationary process. Suppose this periodogram is evaluated at frequencies $\omega_{1}, \omega_{2}, \ldots, \omega_{p}$. As with a regularly spaced time series, the spectral density function can be estimated by smoothing the periodogram in (3):

$$
\hat{f}_{X}(\omega)=\sum_{j=1}^{p} w\left(\left|\omega-\omega_{j}\right|\right) I_{X}\left(\omega_{j}\right) / \sum_{j=1}^{p} w\left(\left|\omega-\omega_{j}\right|\right)
$$

where $w\left(\left|\omega-\omega_{j}\right|\right)=1$ if $\left|\omega-\omega_{j}\right|$ is less than a bandwidth $h$ and 0 otherwise, so that $\hat{f}_{X}(\omega)$ is a simple moving average of the periodogram ordinates.

[35] Consider a second irregularly spaced time series $Y_{s_{1}}, Y_{s_{2}}, \ldots, Y_{s_{\mathrm{n}}}$, where the observation times need not coincide with, nor be equal in number, to those for the first time series. This approach can be extended to estimate the coherence between the two time series. The estimate is given by:

$$
\hat{C} \operatorname{ch}_{X Y}(\omega)=\sqrt{\frac{\hat{c}_{X Y}^{2}(\omega) \hat{q}_{X Y}^{2}(\omega)}{\hat{f}_{X}(\omega) \hat{f}_{Y}(\omega)}}
$$

where $\hat{c}_{X Y}(\omega)$ and $\hat{q}_{X Y}(\omega)$ are estimates of the cospectrum and quadrature spectrum, respectively, found by simple moving averages of:

$$
\tilde{c}_{X Y}(\omega)=\left(A_{X}(\omega) A_{Y}(\omega)+B_{X}(\omega) B_{Y}(\omega)\right) / T
$$

and:

$$
\tilde{q}_{X Y}(\omega)=\left(B_{X}(\omega) A_{Y}(\omega)+A_{X}(\omega) B_{Y}(\omega)\right) / T
$$

respectively, where the expressions for $A_{Y}(\omega)$ and $B_{Y}(\omega)$ are analogous to (1) and (2).

[36] The coherence between the time series of ${ }^{3} \mathrm{He} /{ }^{4} \mathrm{He}$, delta ${ }^{208} \mathrm{~Pb} /{ }^{204} \mathrm{~Pb}, \mathrm{Zr} / \mathrm{Nb}$, and $\mathrm{SiO} 2$, are shown in Figure 11. The coherence was calculated for the entire core and separately for the submarine section of the core, because so much of the variability is found deep in the submarine lavas. A simple "rule-of-thumb" is that two time series are related, having similar periodicity, if coherence is greater than or equal to $\sim 0.6$. As shown in Figure 11, the time series for helium is strongly related to the other time series. As already implied by the linear corre- 
lation in Figure 6, $\mathrm{Pb}$ and He have coherence $>0.6$ over a wide range of frequencies, which suggests a common trend over the whole timescale, possibly dominated by the low frequencies. In contrast, there is only coherence at low frequency between $\mathrm{He}$ and $\mathrm{Zr} / \mathrm{Nb}$ for the whole core, probably reflecting the shallow trend; the peak at 0.25 corresponds to a wavelength of $25 \mathrm{Ka}($ period $=2 \pi / \mathrm{f})$. However, when the submarine section is isolated there is strong coherence at frequencies 2 and 2.8 for helium, $\mathrm{Pb}, \mathrm{Zr} / \mathrm{Nb}$, and $\mathrm{SiO}_{2}$, which translates to periods of 3.1 and $2.2 \mathrm{Ka}$. Figure 11 therefore shows there is both long and short wavelength coherence between helium and the other elements.

[37] Because of the uncertainties in the timescale, and the sparse data, this is only a preliminary examination of the data using time series methods. This treatment differs from the univariate spectral analysis of Blichert-Toft et al. [2003] and Eisele et al. [2003] in examining the coherence between the time series. We do not present the univariate periodograms here because they are similar to those reported by Blichert-Toft et al. [2003] and Eisele et al. [2003] with slight differences due to scaling. However, the time series analysis suggests that helium and the other elements are influenced by common underlying physical processes over some frequency ranges. Even though the resolution of the timescale is not adequate at the shortest timescale (i.e., at the $2-3 \mathrm{Ka}$ resolution), there is clearly coherence that reflects the rapid geochemical variability in the submarine HSDP2 Mauna Kea lavas, and demonstrates that helium is strongly coupled to the other elements.

\section{Geodynamic Implications}

\subsection{Origin of the High Hawaiian ${ }^{3} \mathrm{He} /{ }^{4} \mathrm{He}$ Ratios}

[38] The HSDP2 Mauna Kea data have important implications for the origin of high ${ }^{3} \mathrm{He} /{ }^{4} \mathrm{He}$ ratios found in Hawaiian and other oceanic volcanism. Of particular interest is the hypothesis that helium might be slightly more compatible than Th and $\mathrm{U}$ during melting in the mantle, which would imply that high ${ }^{3} \mathrm{He} /{ }^{4} \mathrm{He}$ ratios result from ancient depletions rather than undegassed mantle [e.g.,
Anderson, 1998a, 1998b]. The correlations between helium and the other elements provide an argument against the ancient melting explanation for high ${ }^{3} \mathrm{He} /{ }^{4} \mathrm{He}$ ratios. The highest ${ }^{3} \mathrm{He} /{ }^{4} \mathrm{He}$ ratios are associated with high ${ }^{208} \mathrm{~Pb}$, low ${ }^{143} \mathrm{Nd} /{ }^{144} \mathrm{Nd}$, and slightly higher ${ }^{87} \mathrm{Sr} /{ }^{86} \mathrm{Sr}$ (in the 2000 to 2500 meter depth interval). If high ${ }^{3} \mathrm{He} /{ }^{4} \mathrm{He}$ ratios were derived from ancient depleted mantle, it would be expected to have lower ${ }^{87} \mathrm{Sr} /{ }^{86} \mathrm{Sr}$ and higher ${ }^{143} \mathrm{Nd} /{ }^{144} \mathrm{Nd}$ than ambient mantle. As shown in Figures 4-6, this is the opposite of the HSDP2 trends. All Mauna Kea lavas are on the enriched side of MORB Sr and $\mathrm{Nd}$ values, so even the most depleted melts in the HSDP2 core are enriched relative to MORB. An ancient melting event should lead to depletion relative to ambient mantle (i.e., MORB).

[39] The association between high ${ }^{3} \mathrm{He} /{ }^{4} \mathrm{He}$ and elevated ${ }^{208} \mathrm{~Pb} /{ }^{204} \mathrm{~Pb}$ (and elevated time-integrated $\mathrm{Th} / \mathrm{U}$ ratios) is harder to interpret because $\mathrm{Th}$ and $\mathrm{U}$ are fractionated differently as a function of pressure and residual phase (i.e., melting in the presence of garnet or spinel). Because garnet preferentially retains $U$, an ancient depletion resulting from melting in the garnet stability field would result in lower $\mathrm{Th} / \mathrm{U}$ ratio, and should not lead to an association between high ${ }^{3} \mathrm{He} /{ }^{4} \mathrm{He}$ and ${ }^{208} \mathrm{~Pb} /{ }^{204} \mathrm{~Pb}$. An ancient spinel melting event could lead to such an association. Because it is unclear if the major and trace element variations are caused by mantle heterogeneities or melting processes, the association between high ${ }^{3} \mathrm{He} /{ }^{4} \mathrm{He}$ and low $\mathrm{Zr} / \mathrm{Nb}$ and $\mathrm{SiO}_{2}$ is also difficult to interpret. Variations in $\mathrm{SiO}_{2}$ can be produced by different depths of melt segregations, with lower $\mathrm{SiO}_{2}$ related to greater depth of melt extraction [Walter, 1998] and also melt-silicate interactions (Stolper et al., submitted manuscript, 2004). However, $\mathrm{Nb}$ is an extremely incompatible element and it would be difficult to explain the association between high ${ }^{3} \mathrm{He} /{ }^{4} \mathrm{He}$ and low $\mathrm{Zr} / \mathrm{Nb}$ by an ancient melting event.

[40] The temporal evolution of Mauna Loa and Mauna Kea also provide constraints on the origin of high ${ }^{3} \mathrm{He} /{ }^{4} \mathrm{He}$ ratios in the mantle. The relatively uniform and high ${ }^{3} \mathrm{He} /{ }^{4} \mathrm{He}$ ratios in the older Mauna Loa shield lavas ( $>20 \mathrm{Ka}$ in age; see Figure 9) suggest that a significant volume of the Mauna Loa 
(plume) source has high ${ }^{3} \mathrm{He} /{ }^{4} \mathrm{He}$ ratios. This would argue against lithospheric or ancient lithospheric sources, or ancient depleted mantle, because such sources should not be fertile enough to produce the huge volume of Mauna Loa. The new HSDP2 data show that the Mauna Kea shield is not characterized by ${ }^{3} \mathrm{He} /{ }^{4} \mathrm{He}$ ratios as high as the Mauna Loa shield, except in brief magmatic pulses. This difference is interpreted to result from proximity of Mauna Loa to the upwelling plume center.

[41] These arguments do not prove that higher ${ }^{3} \mathrm{He} /{ }^{4} \mathrm{He}$ ratios are derived from undegassed mantle sources. However, they do argue against an ancient melting event, or selective storage of helium in ancient lithosphere. The correlations between helium and the other isotopes argue against decoupling of helium from the other highly incompatible elements. The He-Sr-Nd relations within HSDP2 Mauna Kea are not consistent with helium being more compatible than $\mathrm{Th}$ and $\mathrm{U}$ during silicate melting. Models of Th-U-He evolution of the lithosphere, based on observed abundances, suggest that lithospheric ${ }^{3} \mathrm{He} /{ }^{4} \mathrm{He}$ ratios should decrease relatively rapidly [Moreira and Kurz, 2001] which also argues against lithospheric storage models.

[42] In summary, the relationships between helium and the other isotopes are not consistent with ancient depletion as a mechanism for producing high ${ }^{3} \mathrm{He} /{ }^{4} \mathrm{He}$ ratios. Better understanding of noble gas mineral/melt partitioning behavior is required, but the available evidence suggests that near surface degassing is the main mechanism for altering $(\mathrm{Th}+\mathrm{U}) / \mathrm{He}$ ratios and producing the helium isotopic variations. Therefore the best explanation for high ${ }^{3} \mathrm{He} /{ }^{4} \mathrm{He}$ ratios remains preservation of relatively undegassed material in the deep mantle.

\subsection{Where is the Center of the Hawaiian Hot Spot?}

[43] If high ${ }^{3} \mathrm{He} /{ }^{4} \mathrm{He}$ ratios reflect undegassed mantle, and the Hawaiian plume is derived from the lower-most mantle, then high ${ }^{3} \mathrm{He} /{ }^{4} \mathrm{He}$ ratios should be diagnostic of the plume center. This simple reasoning, coupled with the high ${ }^{3} \mathrm{He} /{ }^{4} \mathrm{He}$ ratios found at Loihi seamount, supports the hypothesis that Loihi seamount represents the early shield building stage of Hawaiian volcanoes, and most directly overlies the actively upwelling zone. The intermediate Mauna $\mathrm{Kea}{ }^{3} \mathrm{He} /{ }^{4} \mathrm{He}$ ratios found in the HSDP1 core led to the suggestion that Mauna Kea was at the edge of a concentrically zoned plume [Kurz et al., 1996]. However, the HSDP1 core only penetrated to 1 kilometer below sea level and it was unclear if higher ratios would be found at greater depths. The HSDP2 core now partially answers this question. The helium spikes, shown in Figures 2 and 9, are found only in lavas older than $380 \mathrm{Ka}$ and most commonly in lavas older than $430 \mathrm{Ka}$. Using the simplified plate trajectory in Figure 1, and assuming a fixed Hawaiian hot spot, the earliest helium spikes correspond roughly to a time when the Mauna Kea summit was $20 \mathrm{~km}$ southeast of the present-day latitude of Kilauea, near the present-day coastline. The most recent ${ }^{3} \mathrm{He} /{ }^{4} \mathrm{He}$ spike was erupted when the Mauna Kea summit was roughly $10 \mathrm{~km}$ northeast of the Kilauea summit ( $\sim 370 \mathrm{ka})$. The spikes are of limited duration, which implies that Mauna Kea has not been directly over the high ${ }^{3} \mathrm{He} /{ }^{4} \mathrm{He}$ component of the plume for the last $600 \mathrm{Ka}$, even when it was southeast of Kilauea. Assuming that Loihi represents the plume center, this places an upper limit on the plume size, in the northeast direction, of roughly $50 \mathrm{~km}$ (i.e., the distance between Loihi and the point where the earliest HSDP2 lava was erupted, $600 \mathrm{Ka}$ ).

[44] In contrast to Mauna Kea, Mauna Loa continuously erupted lavas with high ${ }^{3} \mathrm{He} /{ }^{4} \mathrm{He}$ ratios for the period 220 to $20 \mathrm{Ka}$ before present. Using the same plate trajectory and velocity, the earliest Mauna Loa lavas in Figure 9 were erupted when the Mauna Loa summit was roughly $65 \mathrm{~km}$ northwest of Loihi seamount, close to the present-day latitude of Kilauea. When Mauna Kea was at a similar latitude, farther to the east (at $600 \mathrm{Ka}$ ), it was alternating between high and low ${ }^{3} \mathrm{He} /{ }^{4} \mathrm{He}$ lavas. (Note that the trajectory of Mauna Kea during the eruption of the spikes (600 to $380 \mathrm{ka}$ ) was over a similar latitude as the $200 \mathrm{ka}$ of Mauna Loa (see Figure 1)). This shows that high ${ }^{3} \mathrm{He} /{ }^{4} \mathrm{He}$ ratio source material was volumetrically more important for the Mauna Loa shield (prior to $10 \mathrm{Ka}$ ), but was only present as a trace constituent 
in early Mauna Kea. Again assuming an association between high ${ }^{3} \mathrm{He} /{ }^{4} \mathrm{He}$ and the plume center, this contrast suggests that the plume center extends at least $70 \mathrm{~km}$ to the northwest, from Loihi seamount to just south of the present Mauna Loa summit, but is narrower than $40 \mathrm{~km}$ to the northeast.

[45] The summit of Kilauea volcano presently lies north of the point where Mauna Kea stopped erupting high ${ }^{3} \mathrm{He} /{ }^{4} \mathrm{He}$ lavas. However, in contrast to Mauna Kea, Kilauea is presently erupting lavas with high ${ }^{3} \mathrm{He} /{ }^{4} \mathrm{He}$ ratios of $\sim 14$ to $17 \mathrm{Ra}$ (1960 to 1974 eruptions) and has erupted lavas with similar ${ }^{3} \mathrm{He} /{ }^{4} \mathrm{He}$ ratios for at least the last 10,000 years [Kurz, 1993]. Assuming that high ${ }^{3} \mathrm{He} /{ }^{4} \mathrm{He}$ ratios are indicative of the plume center, then Kilauea is presently closer to the plume center than Mauna Kea has been for the last $600 \mathrm{Ka}$. The position of the Kilauea summit is roughly $25 \mathrm{~km}$ from the Mauna Loa-Loihi line, and is south of the putative Mauna Kea trajectory (see Figure 1); the high Kilauea ${ }^{3} \mathrm{He} /{ }^{4} \mathrm{He}$ ratios are also consistent with a plume radius less than $40 \mathrm{~km}$.

[46] In summary, the new HSDP2 Mauna Kea helium data show that only Mauna Kea lavas older than $400 \mathrm{Ka}$ had high ${ }^{3} \mathrm{He} /{ }^{4} \mathrm{He}$ ratios. In contrast to Mauna Loa, these high values were transitory, for eruptive periods of 3 to $30 \mathrm{Ka}$. If we associate high ${ }^{3} \mathrm{He} /{ }^{4} \mathrm{He}$ ratios with the plume center, then this suggests that Mauna Kea was never over the center of the plume. Assuming that Loihi is the present center of the plume, then the Mauna Kea helium data implies that the plume edge-to-center distance is less than $40 \mathrm{~km}$ to the northeast, and approximately $70 \mathrm{~km}$ to the northwest, in the direction of plate motion, extending roughly the distance from Loihi to just south of Mauna Loa.

[47] The proposed explanation for the difference between the Mauna Kea and Mauna Loa helium isotopic evolution (see Figure 9) is that Mauna Kea has never been directly over the high ${ }^{3} \mathrm{He} /{ }^{4} \mathrm{He}$ plume center. This rests on the assumption that high ${ }^{3} \mathrm{He} /{ }^{4} \mathrm{He}$ ratios are indicative of proximity to the plume center. At present, this assumption is supported by the voluminous volcanism in the
Hawaiian hot spot province [e.g., Sleep, 1990] and that Hawaii has some of the highest ${ }^{3} \mathrm{He} /{ }^{4} \mathrm{He}$ ratios found in the ocean basins [e.g., Kurz et al., 1995; Farley and Neroda, 1998]. Other large active hot spot provinces such as Galapagos and Iceland also have very high ${ }^{3} \mathrm{He} /{ }^{4} \mathrm{He}$ ratios [e.g., Hilton et al., 1999; Kurz and Geist, 1999], and there is a possible link between the most active volcanism, the plume center, and the highest local ${ }^{3} \mathrm{He} /{ }^{4} \mathrm{He}$ ratios [Kurz et al., 1995; Breddam et al., 2000; Kurz and Geist, 1999]. Other authors have postulated that the high ${ }^{3} \mathrm{He} /{ }^{4} \mathrm{He}$ ratios are associated with the plume edge rather than the plume center [e.g., Lassiter et al., 1996]. If, as suggested here, Mauna Kea was never over the plume center, how could it have grown to become such a large volcano? One possible answer is that lithospheric flexure can control volcano location via crack propagation [ten Brink, 1991; Hieronymus and Bercovici, 2000]. In this scenario, the primary mantle upwelling and melting would produce the Loa trend volcanoes, and the Kea trend volcanoes would be more influenced by flexure.

\subsection{Mantle Models and the Structure of the Hawaiian Plume}

[48] One plausible explanation for the high ${ }^{3} \mathrm{He} /{ }^{4} \mathrm{He}$ magmatic pulses is that they reflect the length scale heterogeneities in the upwelling mantle. Assuming that high ${ }^{3} \mathrm{He} /{ }^{4} \mathrm{He}$ ratios are associated with the plume center, the different helium isotopic evolution of Mauna Loa and Mauna Kea require a lateral difference in the scale of heterogeneity within the upwelling mantle. One possible asymmetrically zoned mantle model is shown in Figure 12, where the spikes are assumed to be produced by melting of heterogeneities in the upwelling plume. The duration of the magma pulses would be directly related to heterogeneity size as they upwell through the melting zone, assuming that they have distinct composition and are not homogenized in a magma chamber. If the upwelling rates are known, the spike duration can then be used to constrain the size of the heterogeneities. Estimates of upwelling rates vary widely, and include variability across the upwelling zone, with the upwelling presumed to be fastest in the 


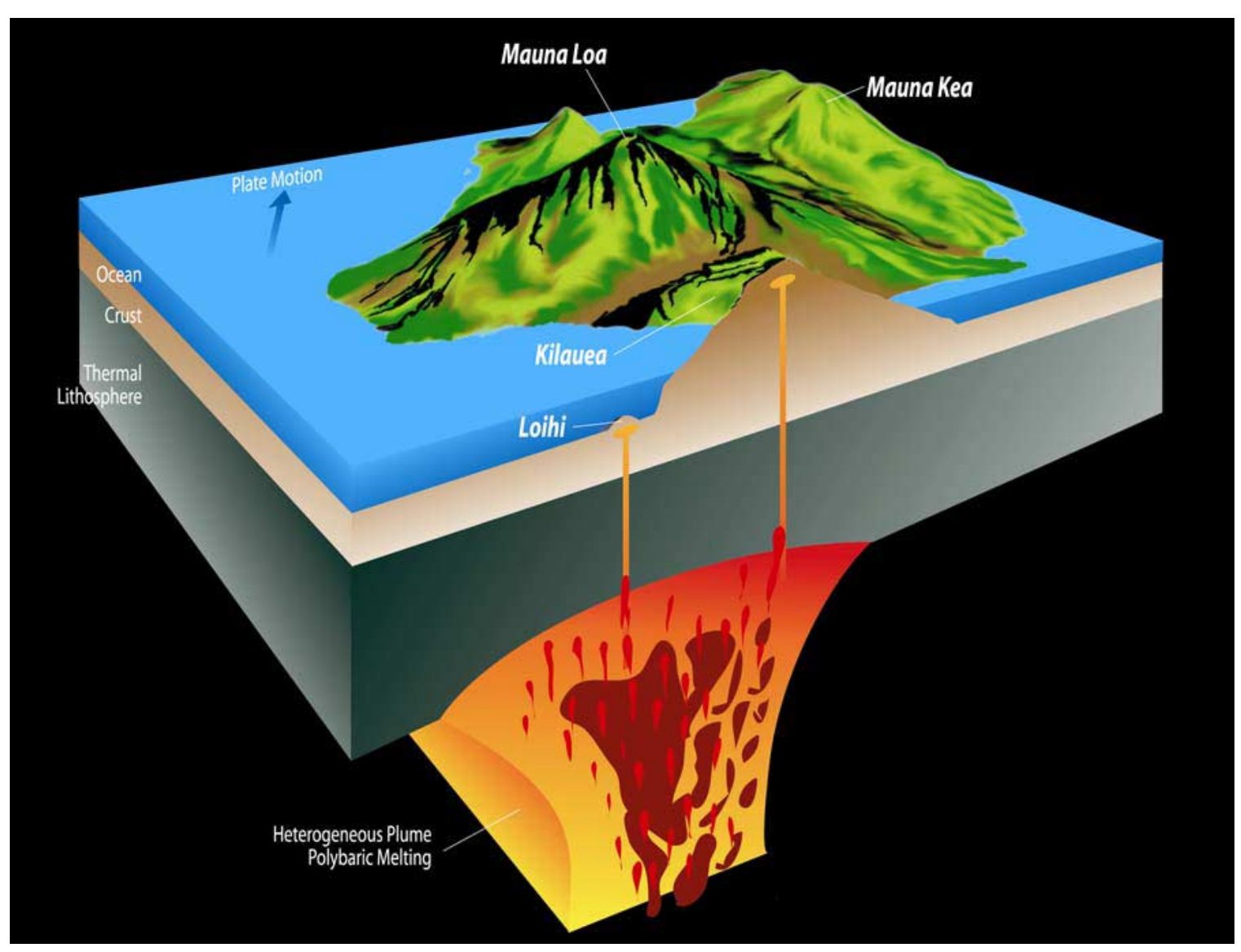

Figure 12. A cartoon showing a variation on the concentrically zoned plume model for Hawaii, where the heterogeneities are asymmetric (based on the different temporal evolution of Mauna Kea and Mauna Loa). The darker zones within the upwelling region designate high ${ }^{3} \mathrm{He} /{ }^{4} \mathrm{He}$ material. The outer material has lower ${ }^{3} \mathrm{He} /{ }^{4} \mathrm{He}$ ratios, but is more enriched than ambient mantle (as represented by MORB) with respect radiogenic isotopes. Although this model is oversimplified, it highlights the key features of the helium data: the Loa volcanoes (Loihi and Mauna Loa) have consistently higher ${ }^{3} \mathrm{He} /{ }^{4} \mathrm{He}$ than Kea volcanoes (Kilauea and Mauna Kea), and are presumed to overlie the plume center. Mauna Kea is characterized by short pulses of high ${ }^{3} \mathrm{He} /{ }^{4} \mathrm{He}$ ratio material early in its evolution.

hottest, low viscosity, center. The Hawaiian plume model of Watson and McKenzie [1991] used upwelling rates that vary between 2 and $40 \mathrm{~cm} / \mathrm{yr}$ from plume edge to plume center. These rates would imply heterogeneities between $60 \mathrm{~m}$ and $12 \mathrm{~km}$ (using $3.0 \mathrm{Ka}$ and $30 \mathrm{Ka}$ as the minimum and maximum duration). Estimates based on Th and $\mathrm{U}$ disequilibrium of Sims et al. [1999] provide mantle upwelling rates between 10 and $100 \mathrm{~cm} / \mathrm{yr}$ which are similar. The Hawaiian plume model of Hauri et al. [1994] included upwelling rates of 10 to $1000 \mathrm{~cm} / \mathrm{yr}$ from edge to center, which would imply length scales of $300 \mathrm{~m}$ and $300 \mathrm{~km}$. The use of spike duration to infer the scale of source heterogeneities has also been suggested by Blichert-Toft et al.
[2003] and Eisele et al. [2003]. Eisele et al. [2003] discuss the importance of shear induced by differential plume velocity, which would cause the heterogeneities to elongate, which is potentially important for inferring the geometry. The heterogeneities observed in the HSDP2 temporal record could be caused by other more complex geometries, including the possible "filter" of melt migration and aggregation (see for example, the fractal tree melt transport model of Hart [1994]).

[49] It is well known that more than three distinct geochemical components are required to explain the complex isotope geochemistry of Hawaiian basalts [e.g., Tatsumoto, 1978; Stille et al., 1984; 
Kurz and Kammer, 1991; Lassiter and Hauri, 1998; Mukhopadhyay et al., 2003]. The possible components include recycled materials (such as lithosphere, oceanic crust, and altered oceanic crust, and sediments), depleted ambient mantle, and a possible undegassed mantle reservoir. As mentioned above, the undegassed component is not required to explain most of the isotopic variability (e.g., Sr-Nd-Hf-Pb-Os) but remains a plausible explanation for very high ${ }^{3} \mathrm{He} /{ }^{4} \mathrm{He}$ ratios. Although most of the lavas from the Mauna Kea HSDP2 section have higher ${ }^{3} \mathrm{He} /{ }^{4} \mathrm{He}$ ratios than MORB (i.e., 8-14 Ra) the other isotopic characteristics are not consistent with a primitive undepleted reservoir. In particular, the isotopic, major, and trace element data have been used to argue that Kea (and Koolau) components of Hawaiian volcanism are derived from recycled materials [Lassiter et al., 1998; Hauri, 1996]. In the cartoon, the outer (lighter colored) upwelling material is distinct from the plume center and is assumed to represent recycled material entrained into the plume.

[50] There are other plausible models for the plume geometry [e.g., Frey and Rhodes, 1993; BlichertToft et al., 2003; Eisele et al., 2003] and as mentioned above, Figure 12 is an oversimplification. Ihinger [1995] has suggested that the geochemical differences between adjacent volcanoes, as well as the existence of the Loa and Kea chains of volcanos, can be explained by the motion of discrete plumelets in a convecting mantle, coupled with the trajectory of each plumelet as it impinges on the moving lithosphere. This model would require that Mauna Kea and Mauna Loa are derived from distinct plumelets, each with distinct geochemistry. The model in Figure 12 is preferred because it allows convergence of geochemical signatures (e.g., as implied by Figures 5 and 6), and explicitly includes a small and episodic contribution from the plume center as required by the older Mauna Kea lavas. It is clear that the plume flux is not uniform in space or time, and the model is intended to highlight and illustrate the key observations and hypotheses derived from the helium data. Most importantly, Mauna Loa is assumed to be closer to the plume center, and the
Mauna Kea helium spikes are of limited duration but are assumed to derive from the plume center.

\section{Conclusions}

[51] The principal conclusions can be summarized as follows:

[52] 1. The lowest ${ }^{3} \mathrm{He} /{ }^{4} \mathrm{He}$ ratios, found near the top of the core, are close to MORB values, and the results from the top $1000 \mathrm{~m}$ of the HSDP2 core agree with HSDP1 data, with the important exception of the high ${ }^{3} \mathrm{He} /{ }^{4} \mathrm{He}$ values near $840 \mathrm{~m}$ depth.

[53] 2. The ${ }^{3} \mathrm{He} /{ }^{4} \mathrm{He}$ values in Mauna Kea lavas increase with age. There is a gradual increase with depth from $\sim 8 \mathrm{Ra}$ near the top of the Mauna Kea section to $\sim 12-14$ Ra near the base of the core.

[54] 3. The helium isotope variability in HSDP2 Mauna Kea lavas is dominated by short duration "spikes" of high ${ }^{3} \mathrm{He} /{ }^{4} \mathrm{He}$, up to $25 \mathrm{Ra}$, mainly in the submarine section of the core, at depths greater than $1000 \mathrm{~m}$. There are 12 excursions in the core; all but one are in the submarine section, and most (7) are in the deepest section (1950 to $3070 \mathrm{~m}$ ). The baseline ${ }^{3} \mathrm{He} /{ }^{4} \mathrm{He}$ value rises from $10-12 \mathrm{Ra}$ near $1000 \mathrm{~m}$ depth to $12-14 \mathrm{Ra}$ at $3000 \mathrm{~m}$.

[55] 4. The helium spikes are found only in lavas older than $380 \mathrm{Ka}$ in age, and most are older than $430 \mathrm{Ka}$, based on an age model derived from Ar-Ar data (W. D. Sharp et al., manuscript in preparation, 2003). This behavior contrasts markedly with Mauna Loa, which erupted high ${ }^{3} \mathrm{He} /{ }^{4} \mathrm{He}$ ratio lavas continuously for roughly $200 \mathrm{Ka}$. The Mauna Kea spike duration varies between 3.0 and $30 \mathrm{Ka}$. Excluding excursions defined by single intrusive units (3) and single lava flows (3), the average spike duration is $15( \pm 9) \mathrm{Ka}$.

[56] 5. The high ${ }^{3} \mathrm{He} /{ }^{4} \mathrm{He}$ spikes are interpreted as pulses of magma from the actively upwelling Hawaiian hot spot. The rapid return to baseline ${ }^{3} \mathrm{He} /{ }^{4} \mathrm{He}$ values, and that spikes are only found in lavas older than $380 \mathrm{Ka}$, suggests that Mauna Kea was never directly over the high ${ }^{3} \mathrm{He} /{ }^{4} \mathrm{He}$ component of the Hawaiian plume, which is postulated to be the plume center. Assuming that the mantle is upwelling at 2 to $40 \mathrm{~cm} /$ year, the duration of the 
magmatic pulses imply plume-heterogeneities that are $\sim 60 \mathrm{~m}$ to $12 \mathrm{Km}$ in size.

[57] 6. Within the HSDP2 lavas having the highest ${ }^{3} \mathrm{He} /{ }^{4} \mathrm{He}$ ratios there is a relationship between olivine grain size and helium isotopic compositions, with the largest olivines having slightly higher ${ }^{3} \mathrm{He} /{ }^{4} \mathrm{He}$ ratios. This is interpreted as the trapping of different melt generations during the growth of the olivine crystals.

[58] 7. The helium isotopic variations are correlated with major elements, trace elements and isotopes. The high ${ }^{3} \mathrm{He} /{ }^{4} \mathrm{He}$ are associated with high ${ }^{208} \mathrm{~Pb} /{ }^{204} \mathrm{~Pb}$, slightly higher ${ }^{87} \mathrm{Sr} /{ }^{86} \mathrm{Sr}$ (at depths of 2200 to $2500 \mathrm{~m}$ ), and relatively low ${ }^{143} \mathrm{Nd} /{ }^{144} \mathrm{Nd}$, $\mathrm{Zr} / \mathrm{Nb}$, and $\mathrm{SiO}_{2}$. These correlations show that the geochemical variations are caused by mixing of mantle melts, and that helium is strongly coupled to the magmatic variability. The high ${ }^{3} \mathrm{He} /{ }^{4} \mathrm{He}$ ratio samples are isotopically similar to those from Loihi seamount, and the isotopic data are generally consistent with a Loihi-like plume center.

[59] 8. The geochemical correlations argue against the hypothesis that helium is more compatible than Th and $U$ on silicate melting. The most reasonable explanation for high ${ }^{3} \mathrm{He} /{ }^{4} \mathrm{He}$ values in Hawaiian volcanos is derivation from an undegassed mantle source.

\section{Appendix A: Grain Size Dependence of Helium in Olivine}

[60] Duplicate measurements show that there are significant variations within a single olivine population within a single sample, as illustrated in Tables 1 and 3. As mentioned above, this is not due to experimental uncertainties, but must relate to natural variability within the olivine phenocryst populations. There are some important systematics to the grain size experiments, most notably that the larger olivines tend to have higher ${ }^{3} \mathrm{He} /{ }^{4} \mathrm{He}$ ratios. Several of the samples do have higher ${ }^{3} \mathrm{He} /{ }^{4} \mathrm{He}$ ratios in the smaller grain sizes (SR668 and SR531), and several are close to equilibrium (i.e., isotopic composition is identical for different grain sizes), but most have higher ${ }^{3} \mathrm{He} /{ }^{4} \mathrm{He}$ ratios in the larger olivines. The lavas with higher ${ }^{3} \mathrm{He} /{ }^{4} \mathrm{He}$ ratios, deeper in the core, appear to have larger helium isotopic variations between different grain sizes. This latter point is illustrated by Figure A1, which shows the total ${ }^{3} \mathrm{He} /{ }^{4} \mathrm{He}$ range between different grain sizes (in a single olivine population) as a function of the maximum ${ }^{3} \mathrm{He} /{ }^{4} \mathrm{He}$ for that sample. The high ${ }^{3} \mathrm{He} /{ }^{4} \mathrm{He}$ ratio samples have a range of 1.5 to $2.5 \mathrm{R}_{\mathrm{a}}$ (5 to 8 times the measurement standard deviations) between different grain sizes, while the lower ${ }^{3} \mathrm{He} /{ }^{4} \mathrm{He}$ ratio samples have a range of 0.2 to $0.9 \mathrm{R}_{\mathrm{a}}$ (between 0.7 and 3 times the measurement standard deviation).

[61] The helium concentrations in the olivine phenocrysts do not appear to have any simple grain size dependence. In several cases (SR741-7.90, SR212-8.20) the larger size fraction (greater than $2 \mathrm{~mm}$ ) has more than ten times higher helium content of the smaller size fractions. However, it is more common for the smaller grain sizes to have higher helium concentrations, or that concentrations are similar between different grain sizes.

[62] It is well documented that helium resides within melt inclusions; it is also well known that olivine hosted melt inclusions form at many different depths, and can have different major element, trace element, and isotopic compositions [e.g., Saal et al., 1998; Shimizu, 1998; Sobolev and Shimizu, 1993]. One plausible explanation for the relationship between ${ }^{3} \mathrm{He} /{ }^{4} \mathrm{He}$ ratios and olivine grain size is that phenocrysts form at different stages of the magmatic system and trap different generations of melts, particularly if the magmatic chemistry is changing rapidly. There are no systematic differences in major element compositions with olivine grain size, nor is there evidence of different zoning patterns (Table 4). This is not a conclusive test for different phenocryst populations because wide differences in olivine compositions are not expected, and $\mathrm{Fe} / \mathrm{Mg}$ diffusivities are high enough in olivine that magmatic equilibration takes only days to months [Gaetani and Watson, 2000].

[63] Another possible explanation is that the olivine grain size-dependent helium data are influenced by crystal-melt diffusive equilibration and that the different olivine populations have equilibrated with different magmas. For example, smaller olivines 


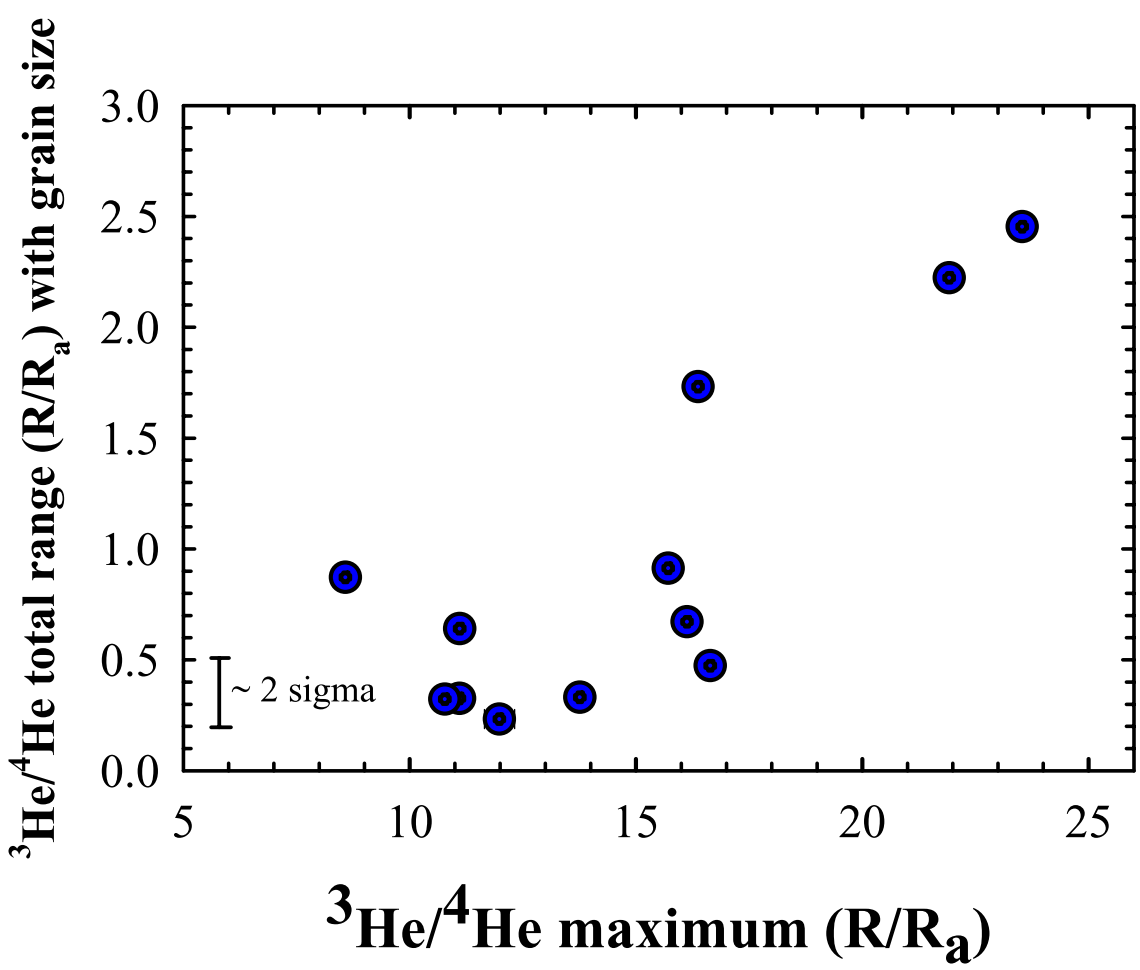

Figure A1. Maximum ${ }^{3} \mathrm{He} /{ }^{4} \mathrm{He}$ ratio for a particular sample (x axis) versus range in ${ }^{3} \mathrm{He} /{ }^{4} \mathrm{He}(\mathrm{R} / \mathrm{Ra})$ observed for olivine grain size fractions of the same sample. The ${ }^{3} \mathrm{He} /{ }^{4} \mathrm{He}$ "total range" is defined as the absolute value of the largest difference between the grain size measurements from the same olivine population, for grain sizes of 0.5 $1 \mathrm{~mm}, 1-2 \mathrm{~mm}$, and $>2 \mathrm{~mm}$. The olivines from deep in the core with the greatest total range in ${ }^{3} \mathrm{He} /{ }^{4} \mathrm{He}$ between grain sizes are also the ones with the highest ${ }^{3} \mathrm{He} /{ }^{4} \mathrm{He}$ ratios. Note that the largest total range in ${ }^{3} \mathrm{He} /{ }^{4} \mathrm{He}$, of roughly $2.5 \mathrm{Ra}$ is well outside experimental uncertainty $(2 \sigma \sim 0.3 \mathrm{Ra})$ but is significantly lower than the range observed in the core (see text and Figure 2).

could have equilibrated with late stage lower ${ }^{3} \mathrm{He} /{ }^{4} \mathrm{He}$ melts, whereas the larger olivines grew from earlier melts having higher ${ }^{3} \mathrm{He} /{ }^{4} \mathrm{He}$, but are large enough to preserve the original isotopic composition. Using a helium diffusion coefficient of $\sim 4 \times 10^{-10} \mathrm{~cm}^{2} / \mathrm{sec}$ (olivine at $1200 \mathrm{C}$ [Trull and Kurz, 1993; Hart, 1984a]), and the approximate diffusive equilibration length scale of $\mathrm{x}=$ sqrt [Dt], different phenocryst sizes would have significantly different timescales for equilibration. The equilibration time for the three grain sizes would be 47,188 , and 522 days (for 0.5 to $1.0 \mathrm{~mm}, 1.0$ to $2.0 \mathrm{~mm}$, and $\sim 2.5 \mathrm{~mm}$ grains, respectively, using $1 / 2$ the mean grain size). These equilibration times are relatively short for active magmatic systems, making diffusive equilibrium a plausible explanation for the grain size differences. If the olivines reside in a magma reservoir, and the magmatic ${ }^{3} \mathrm{He} /{ }^{4} \mathrm{He}$ ratio changes due to influx of new magma to the system (after the olivines are formed), the smaller grains would equilibrate more rapidly with the new magma than the large grains. This explanation would require that ${ }^{3} \mathrm{He} /{ }^{4} \mathrm{He}$ ratios were generally dropping immediately after an excursion, and that smaller crystals were formed later than the large crystals.

[64] It is not possible to distinguish between diffusive olivine re-equilibration and trapping of different melt inclusion populations as the explanation for the grain size dependant helium isotopic variability. Either scenario would imply that the Mauna Kea magmatic system was changing rapidly, which is consistent with the rapid ${ }^{3} \mathrm{He} /{ }^{4} \mathrm{He}$ variability found in the down-core record. However, as discussed in the text, many other geochemical parameters, derived from whole rock measurements (i.e., trace elements, major elements, and isotopes), display significant variability. The strong correlations between helium and other elements demon- 
strate that helium is coupled to the magmatic geochemistry (e.g., Figures 3-8); this precludes any purely diffusive mechanism for the major helium isotopic variations, such as Rayleigh fractionation. Additionally, there is no relationship between helium concentration and isotopic composition, which argues strongly against any Rayleigh fractionation process. Although we emphasize that the olivine grain size helium isotopic variations are small relative to the overall variations, grain size is clearly an important variable in helium isotopic studies and should be documented.

\section{Acknowledgments}

[65] The authors wish to acknowledge the dedication of Don DePaolo, Ed Stolper and Don Thomas in bringing the project this far, and the cooperative spirit of the entire scientific team. We also wish to thank Caroline Seaman, Fred Frey, Glenn Gaetani and Mike Rhodes for many discussions, and Neel Chatterjee for assistance with the electron microprobe. This manuscript benefited from thorough and insiteful reviews by Fred Frey, Al Hofmann, Don Thomas, and Warren Sharp. MK wishes to thank Institut de Physique du Globe for their hospitality while this manuscript was finalized, and particularly C. Allègre, M. Moreira, and B. Bourdon for helpful discussions. This work was supported by EAR/NSF through the Continental Dynamics and Instrumentation and Facilities programs, by internal WHOI funds, and is WHOI contribution 11086.

\section{References}

Albarède, F. (1993), Residence time analysis of geochemical fluctuations in volcanic series, Geochim. Cosmochim. Acta, 57, 615-621.

Albarède, F. (1998), Time-dependent models of U-Th-He and $\mathrm{K}-\mathrm{Ar}$ evolution and the layering of mantle convection, Chem. Geol., 145, 413-429.

Allegre, C. J., T. Staudacher, P. Sarda, and M. Kurz (1983), Constraints on evolution of Earth's mantle from rare gas systematics, Nature, 303, 762-766.

Althaus, T., S. Niedermann, and J. Erzinger (2003), Noble gases in olivine phenocrysts from drill core samples of the Hawaii Scientific Drilling Project (HSDP) pilot and main holes (Mauna Loa and Mauna Kea, Hawaii), Geochem. Geophys. Geosyst., 4(1), 8701, doi:10.1029/2001GC000275.

Anderson, D. L. (1998a), The Helium Paradoxes, Proc. Natl. Acad. Sci. U. S. A., 95, 4822-4827.

Anderson, D. L. (1998b), A model to explain the various paradoxes associated with mantle noble gas geochemistry, Proc. Natl. Acad. Sci. U. S. A., 95, 9087-9092.

Blichert-Toft, J., D. Weis, C. Maerschalk, and F. Albarède (2003), Hawaiian hotspot dynamics as inferred from the Hf and $\mathrm{Pb}$ isotope evolution of Mauna Kea volcano, Geoch. Geophys. Geosyst., 4(2), 8704, doi:10.1029/2002GC000340.

Blundy, J., and B. Wood (2003), Mineral-melt partitioning of uranium, thorium and their daughters, in Uranium Series Geochemistry, Rev. in Mineral. and Geochem., vol. 52, edited by B. Bourdon et al., pp. 59-124, Mineral. Soc. of Am., Washington, D.C.

Breddam, K., M. D. Kurz, and M. Storey (2000), Mapping the conduit of the Iceland mantle plume with helium isotopes, Earth Planet. Sci. Lett., 176, 45-55.

Chan, N. H., J. B. Kadane, and T. Jiang (1998), Time series analysis of diurnal cycles in small-scale turbulence, Environmetrics, 9, 235-244.

Clague, D. A., and G. B. Dalrymple (1989), Tectonics, geochronology, and origin of the Hawaiian-Emperor chain, in The Geology of North America: The Eastern Pacific Ocean and Hawaii, edited by E. L. Winterer, D. M. Hussong, and R. W. Decker, pp. 188-217, Geol. Soc. Am., Boulder, Colo.

DePaolo, D. J., and E. M. Stolper (1996), Models of Hawaiian volcano growth and plume structure; implications of results from the Hawaii Scientific Drilling Project, J. Geophys. Res., 101, 11,643-11,654.

DePaolo, D. J., E. M. Stolper, D. M. Thomas, and M. O. Garcia (1999), Hawaiian Scientific Drilling Project: Core logs and summarizing data report, rep., Calif. Inst. of Technol., Pasadena.

DePaolo, D. J., J. G. Bryce, A. Dodson, D. L. Shuster, and B. M. Kennedy (2001), Isotopic evolution of Mauna Loa and the chemical structure of the Hawaiian plume, Geochem. Geophys. Geosyst., 2, Paper number $2000 \mathrm{GC} 000139$.

Eiler, J. M., K. A. Farley, and E. M. Stolper (1998), Correlated helium and lead isotope variations in Hawaiian lavas, Geochim. Cosmochim. Acta, 62, 977-984.

Eisele, J., W. Abouchami, S. J. G. Galer, and A. W. Hofmann (2003), The long-term $\mathrm{Pb}$ isotope evolution of Mauna Kea lavas from the HSDP-2 drill core, Geochem. Geophys. Geosyst., 4(5), 8710, doi:10.1029/2002GC000339.

Farley, K. A., and E. Neroda (1998), Noble gases in the Earth's mantle, Annu. Rev. Earth Planet. Sci., 26, 189-218.

Farley, K. A., J. H. Natland, and H. Craig (1992), Binary mixing of enriched and undegassed (primitive?) mantle components $(\mathrm{He}, \mathrm{Sr}, \mathrm{Nd}, \mathrm{Pb})$ in Samoan lavas, Earth Planet. Sci. Lett., 111, 183-199.

Feigenson, M. D., L. L. Bolge, M. J. Carr, and C. T. Herzberg (2003), REE inverse modeling of HSDP2 basalts: Evidence for multiple sources in the Hawaiian plume, Geochem. Geophys. Geosyst., 4(2), 8706, doi:10.1029/2001GC000271.

Frey, F. A., and J. M. Rhodes (1993), Intershield geochemical differences among Hawaiian volcanoes: Implications for source compositions, melting process and magma ascent paths, Philos. Trans. R. Soc. London, Ser. A, A342, 121-136.

Gaetani, G. A., and E. B. Watson (2000), Open system behavior of olivine-hosted melt inclusions, Earth Planet. Sci. Lett., 183, 27-41.

Graham, D., J. Lupton, and M. Garcia (1990), He isotopes in olivine phenocrysts from submarine basalts of Mauna Kea and Kohala, Island of Hawaii, Eos Trans. AGU, 71, 657. 
Hart, S. R. (1984a), He diffusion in olivine, Earth Planet. Sci. Lett., 70, 297-302.

Hart, S. R. (1984b), A large scale isotope anomaly in the Southern Hemisphere mantle, Nature, 309, 753-757.

Hart, S. R. (1994), Equilibration during mantle melting: A fractal tree model, Proc. National Acad. Sci. U.S.A., 90, $11,914-11,918$.

Hauri, E. K. (1996), Major-element variability in the Hawaiian mantle plume, Nature, 382, 415-419.

Hauri, E. H., J. A. Whitehead, and S. R. Hart (1994), Fluid dynamic and geochemical aspects of entrainment in mantle plumes, J. Geophys. Res., 99, 24,275-24,300.

Hieronymus, C. F., and D. Bercovici (2000), Non-hotspot formation of volcanic chains; control of tectonic and flexural stresses on magma transport, Earth Planet. Sci. Lett., 181, $539-554$.

Hilton, D. R., K. Gronvold, C. G. Macpherson, and P. R. Castillo (1999), Extreme ${ }^{3} \mathrm{He} /{ }^{4} \mathrm{He}$ ratios in northwest Iceland: Constraining the common component in mantle plumes, Earth Planet. Sci. Lett., 173, 53-60.

Hofmann, A. W. (1997), Mantle geochemistry: The message from oceanic volcanism, Nature, 385, 219-229.

Huang, S., and F. A. Frey (2003), Trace element abundances of Mauna Kea basalt from phase 2 of the Hawaii Scientific Drilling Project: Petrogenetic implications of correlations with major element content and isotopic ratios, Geochem. Geophys. Geosyst., 4(6), 8711, doi:10.1029/2002GC000322.

Ihinger, P. D. (1995), Mantle flow beneath the Pacific Plate: Evidence from seamount segments in the Hawaiian-Emperor chain, Am. J. Sci., 295, 1035-1057.

Kinzler, R. J., and T. L. Grove (1992), Primary magmas of Mid-Ocean Ridge Basalts: 2. Applications, J. Geophys. Res., 97, 6907-6926.

Kurz, M. D. (1993), Mantle heterogeneity beneath oceanic islands: Some inferences from isotopes, Proc. R. Soc. London, Ser. A, A342, 91-103.

Kurz, M. D., and D. Geist (1999), Dynamics and evolution of the Galapagos hotspot from helium isotope geochemistry, Geochim. Cosmochim. Acta, 63, 4139-4156.

Kurz, M. D., and W. J. Jenkins (1981), The distribution of helium in oceanic basalt glasses, Earth Planet. Sci. Lett., $53,41-54$.

Kurz, M. D., and D. P. Kammer (1991), Isotopic evolution of Mauna Loa Volcano, Earth Planet. Sci. Lett., 103, 257269.

Kurz, M. D., W. J. Jenkins, and S. R. Hart (1982), Helium isotopic systematics of oceanic islands: Implications for mantle heterogeneity, Nature, 297, 43-47.

Kurz, M. D., W. J. Jenkins, S. Hart, and D. Clague (1983), Helium isotopic variations in Loihi Seamount and the island of Hawaii, Earth Planet. Sci. Lett., 66, 388-406.

Kurz, M. D., M. O. Garcia, F. A. Frey, and P. A. O'Brien (1987), Temporal helium isotopic variations within Hawaiian volcanoes: Basalts from Mauna Loa and Haleakala, Geochim. Cosmochim. Acta, 51, 2905-2914.

Kurz, M. D., T. Kenna, D. Kammer, J. M. Rhodes, and M. O. Garcia (1995), Isotopic evolution of Mauna Loa volcano: A view from the submarine south west rift, in Mauna Loa
Revealed: Structure, Composition, History, and Hazards, Geophys. Monogr. Ser, vol. 92, edited by J. P. Lockwood and J. M. Rhodes, pp. 289-306, AGU, Washington, D.C.

Kurz, M. D., T. C. Kenna, J. C. Lassiter, and D. J. DePaolo (1996), Helium isotopic evolution of Mauna Kea Volcano: First results from the $1 \mathrm{~km}$ drill core, J. Geophys. Res., 101, $11,781-11,791$.

Lassiter, J. C., and E. H. Hauri (1998), Osmium-isotope variations in Hawaiian lavas: Evidence for recycled oceanic lithosphere in the Hawaiian plume, Earth Planet. Sci. Lett., 164, 483-496.

Lassiter, J. C., D. J. DePaolo, and M. Tatsumoto (1996), Isotopic evolution of Mauna Kea Volcano: Results from the initial phase of the Hawaii Scientific Drilling Project, J. Geophys. Res., 101, 1769-1780.

Moore, J. G., and D. A. Clague (1992), Volcano growth and evolution of the island of Hawaii, Bull. Geol. Soc. Am., 104, $1471-1484$.

Moreira, M., and M. D. Kurz (2001), Subducted oceanic lithosphere and the origin of "high $\mu$ " basalt helium isotopic signature, Earth Planet. Sci. Lett., 189, 49-57.

Morgan, W. J. (1971), Convection plumes in the lower mantle, Nature, 230, 42-43.

Mukhopadhyay, S., J. C. Lassiter, K. A. Farley, and S. W. Bogue (2003), Geochemistry of Kauai shield-stage lavas: Implications for the chemical evolution of the Hawaiian plume, Geochem. Geophys. Geosyst., 4(1), 1009, doi:10.1029/2002GC000342.

Pietruszka, A. J., and M. O. Garcia (1999a), A rapid fluctuation in the mantle source and melting history of Kilauea Volcano inferred from the geochemistry of its historical summit lavas (1790-1982), J. Petrol., 40, 1321-1342.

Pietruszka, A. J., and M. O. Garcia (1999b), The size and shape of Kilauea Volcano's summit magma storage reservoir: A geochemical probe, Earth Planet. Sci. Lett., 167, $311-320$.

Priestley, M. B. (1981), Spectral Analysis and Time Series, Academic, San Diego, Calif.

Rhodes, J. M., and M. J. Vollinger (2004), Composition of basaltic lavas sampled by phase-2 of the Hawaii Scientific Drilling Project: Geochemical stratigraphy and magma types, Geochem. Geophys. Geosyst., 5, Q03G13, doi:10.1029/ 2002GC000434.

Saal, A. E., S. R. Hart, N. Shimizu, E. H. Hauri, and G. D. Layne (1998), $\mathrm{Pb}$ isotopic variability in melt inclusions from oceanic island basalts, Polynesia, Science, 282, $1481-1484$.

Shimizu, N. (1998), The geochemistry of olivine-hosted inclusions in a FAMOUS basalt ALV519-4-1, Phys. Earth Planet. Inter, 107, 183-201.

Sims, K. W. W., D. J. DePaolo, M. T. Murrell, W. S. Baldridge, S. Goldstein, D. Clague, and M. Jull (1999), Porosity of the melting zone and variations in the solid mantle upwelling rate beneath Hawaii; inferences from ${ }^{238} \mathrm{U}-{ }^{230} \mathrm{Th}-{ }^{226} \mathrm{Ra}$ and ${ }^{235} \mathrm{U}-{ }^{231} \mathrm{~Pa}$ disequilibria, Geochim. Cosmochim. Acta, 63, 4119-4138.

Sleep, N. H. (1990), Hotspots and mantle plumes: Some phenomenology, J. Geophys. Res., 95, 6715-6736. 
Sobolev, A. V., and N. Shimizu (1993), Ultra-depleted primary melt included in an olivine from the Mid-Atlantic Ridge, Nature, 363, 151-154.

Staudigel, H., A. Zindler, S. R. Hart, T. Leslie, C. Y. Chen, and D. Clague (1984), The isotope systematics of a juvenile volcano: $\mathrm{Pb}, \mathrm{Nd}$, and $\mathrm{Sr}$ isotope ratios of basalts from Loihi Seamount, Earth Planet. Sci. Lett., 69, 13-29.

Stille, P., D. M. Unruh, and M. Tatsumoto (1984), Pb, Sr, Nd, and Hf isotopic constraints on the origin Hawaiian basalts and evidence for a unique mantle source, Geochim. Cosmochim. Acta, 50, 2303-2319.

Tatsumoto, M. (1978), Isotopic composition of lead in oceanic basalt and its implication to mantle evolution, Earth Planet. Sci. Lett., 38, 63-87.

ten Brink, U. (1991), Volcano spacing and plate rigidity, Geology, 19, 397-400.

Trull, T. W., and M. D. Kurz (1993), Diffusivity of ${ }^{3} \mathrm{He}$ and ${ }^{4} \mathrm{He}$ in olivine and clinopyroxene at magmatic and mantle temperatures, Geochim. Cosmochim. Acta, 57, $1313-1324$.
Valbracht, P. J., H. Staudigel, M. Honda, I. McDougall, and G. R. Davies (1996), Isotopic tracing of volcanic source regions from Hawaii: Decoupling of gaseous from lithophile magma components, Earth Planet. Sci. Lett., 144, $185-198$

van der Hilst, R. D., and H. Karason (1999), Compositional heterogeneity in the bottom 1000 kilometers of Earth's mantle: Toward a hybrid convection model, Science, 283, 18851888.

Walter, M. J. (1998), Melting of garnet peridotite and the origin of komatiite and depleted lithosphere, J. Petrol., 39, 29-60.

Wang, Z., N. E. Kitchen, and J. M. Eiler (2003), Oxygen isotope geochemistry of the second HSDP core, Geochem. Geophys. Geosyst., 4(8), 8712, doi:10.1029/2002GC000406.

Watson, S., and D. McKenzie (1991), Melt generation by plumes: A study of Hawaiian volcanism, J. Petrol., 32(3), $501-537$.

Wilson, J. T. (1963), A possible origin of the Hawaiian Islands, Can. J. Phys., 41, 863-870. 